\title{
Patient Preferences for Benefits and Risks Associated with Disease Modifying Drugs in Multiple Sclerosis
}

\author{
Abhijeet J. Bhanegaonkar \\ West Virginia University
}

Follow this and additional works at: https://researchrepository.wvu.edu/etd

\section{Recommended Citation}

Bhanegaonkar, Abhijeet J., "Patient Preferences for Benefits and Risks Associated with Disease Modifying Drugs in Multiple Sclerosis" (2012). Graduate Theses, Dissertations, and Problem Reports. 4833.

https://researchrepository.wvu.edu/etd/4833

This Dissertation is protected by copyright and/or related rights. It has been brought to you by the The Research Repository @ WVU with permission from the rights-holder(s). You are free to use this Dissertation in any way that is permitted by the copyright and related rights legislation that applies to your use. For other uses you must obtain permission from the rights-holder(s) directly, unless additional rights are indicated by a Creative Commons license in the record and/ or on the work itself. This Dissertation has been accepted for inclusion in WVU Graduate Theses, Dissertations, and Problem Reports collection by an authorized administrator of The Research Repository @ WVU.

For more information, please contact researchrepository@mail.wvu.edu. 


\title{
Patient Preferences for Benefits and Risks Associated with Disease Modifying
} Drugs in Multiple Sclerosis

\author{
Abhijeet J. Bhanegaonkar \\ Dissertation Submitted to the \\ School of Pharmacy \\ at West Virginia University \\ in Partial Fulfillment of the requirements for the degree of
}

Doctor of Philosophy

In

Pharmaceutical \& Pharmacological Sciences

S. Suresh Madhavan, MBA, Ph.D., Chair

John F.P. Bridges, Ph.D.

Virginia (Ginger) Scott, Ph.D.

Cindy Tworek, MPH, Ph.D.

Gauri Pawar, MD

Kitty Rajagopalan, Ph.D.

Department of Pharmaceutical Systems and Policy

Morgantown, West Virginia

2012

Keywords: Multiple sclerosis, disease modifying drugs, conjoint analysis, treatment satisfaction, benefit-risk preferences

Copyright 2012 Abhijeet J. Bhanegaonkar 


\begin{abstract}
Patient Preferences for Benefits and Risks Associated with Disease Modifying Drugs in Multiple Sclerosis
\end{abstract}

\title{
Abhijeet J. Bhanegaonkar
}

Multiple sclerosis (MS) is a chronic inflammatory demyelinating neurological disorder with no known cure. Disease modifying drugs (DMDs) used in the treatment of MS reduce the frequency relapses and delay the progression of the disease. Although DMD therapy is the mainstay of treatment of MS, it is associated with variety of side effects and severe adverse events. A majority of currently available DMDs are injectable, except one which is available in the pill form. Therapeutic decisions in MS are challenging due to the inconvenience of administration, frequency of administration, longer duration of therapy, side effects, and risk of adverse events associated with DMDs. The purpose of this series of studies was to better understand different aspects of DMDs from patients' point of view. A total of three studies were conducted using qualitative and quantitative research methods. Data for the first study were collected using focus group interviews among eighteen MS patients attending neurology clinic affiliated to a teaching hospital. Study two and study three were performed using a webbased survey questionnaire in a sample of MS patients residing in the United States using a cross-sectional study design. The specific objectives are the three studies were: 1) To explore patients' experiences, opinions, and expectations related to DMDs used in MS, 2) to estimate preference weights and relative importance of attributes for DMDs used in MS treatment using conjoint analysis, and 3) to assess disease and treatment related factors associated satisfaction with treatment among MS patients. Participants in the first study had an understanding of importance of DMDs in the therapeutic management of MS. MS patients reported to adapt themselves to available DMD choices, but had greater expectations from emerging DMDs. Participants reported that the convenience of DMD administration, occurrence of relapses, delay of disability progression were important factors related to DMD; however, most were concerned about the side-effects that affected day-to-day functioning and the adverse events associated with DMDs. The results of the second study revealed that attributes indicating risks associated with DMDs (progressive multifocal leukoencephalopathy and severe liver dysfunction) were the most important attributes followed flu-like symptoms, delaying disability progression, frequency of relapses, and mode of DMD administration. Strength of evidence on treatment outcomes expressed in number of years was the least important attribute to patients. The results of the third study indicated that factors such as type of current DMD used, relapses experienced, disability status, total number of MS symptoms experienced, and past experiences with DMDS were associated with lower treatment satisfaction scores. 


\section{DEDICATION}

This research is dedicated to

\section{My Parents}

Shailaja and Jagannath Bhanegaonkar

I am indebted to my parents for their love, patience, and faith in me 


\section{ACKNOWLEDGEMENTS}

First and foremost, I would like to thank my advisor and Ph.D. committee chair, Dr. S. Suresh Madhavan for his unwavering support, thoughtful advices, and patience throughout the course of this research study. I would like to thank Dr. John F.P. Bridges for providing his intellectual input and sharing his wealth of knowledge on conjoint analysis. I want to express my gratitude to Dr. Kitty Rajagopalan for working with me in the early stages of this study to conceptualize this project. I also wish to thank Dr. Gauri Pawar for providing clinical inputs and allowing me access to MS patients at the WVU neurology clinic. I would like to extend my thanks to Dr. Cindy Tworek for her valuable feedback on the project and writing. I am thankful to Dr. Virginia (Ginger) Scott for her involvement and support throughout my graduate school at WVU. This research study wouldn't have been possible without the financial support provided by Biogen Idec Inc.

Special thanks go out to Dr. Joan Langlois for reviewing focus group transcripts. I really appreciate analytical guidance provided by Dr. Sambamoorthi. I would also like to thank Angie Frame from the school of pharmacy for her assistance from time to time during this research study. I would also like to thank Ajay, Rini, Tricia Lee, Vinodh, Parag, Amit, Srilekha, and Prashanti for having been more like a family away from home.

No words can adequately express my gratitude for all the support provided by my brother, Amit. My dream of pursuing higher education in the United States would not be a reality without you. Thank you for believing in me!! Amit, Purva, and Anusha: Thank you!

Finally, I would like to thank God for providing me strength to accomplish my goal. 


\section{TABLE OF CONTENTS}

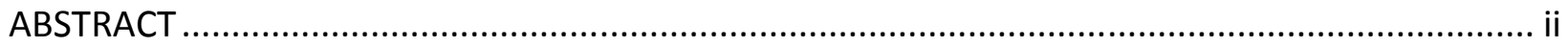

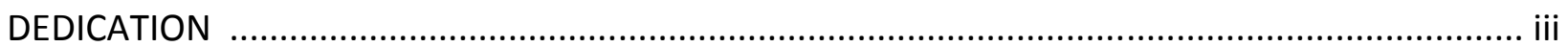

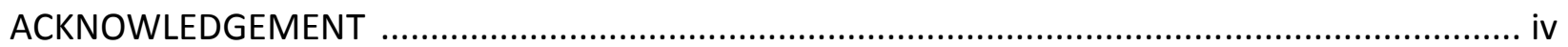

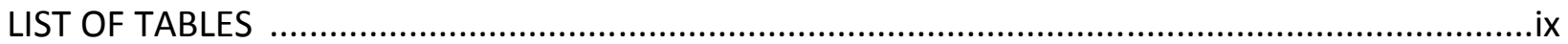

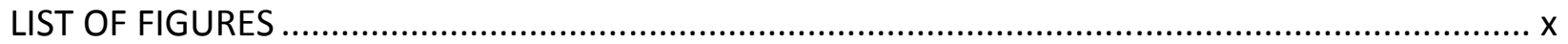

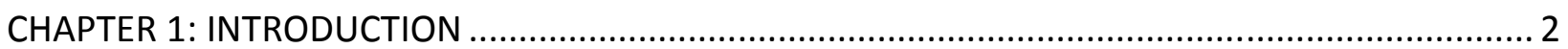

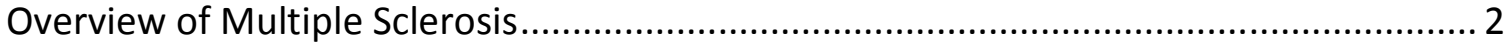

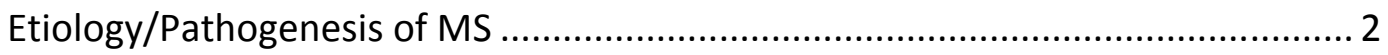

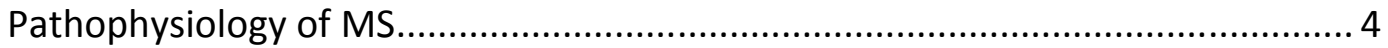

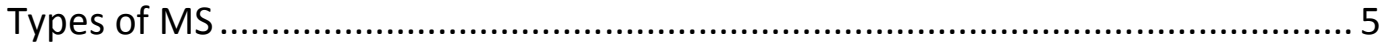

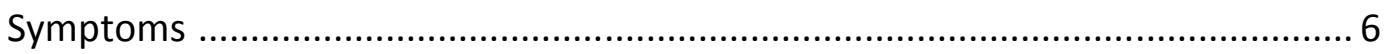

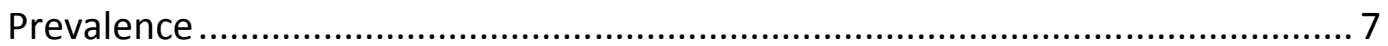

Economic, Clinical, and Humanistic Burden of MS ...................................... 8

Disease Modifying Drugs............................................................................... 9

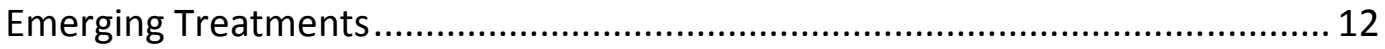

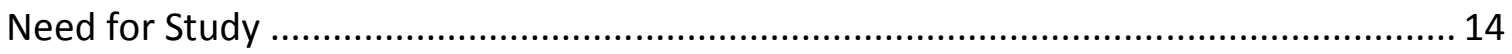

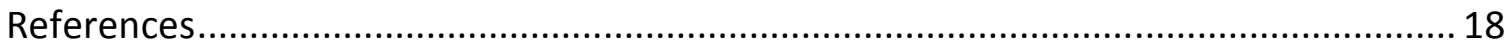

CHAPTER 2: UNDERSTANDING PATIENTS' PERSPECTIVES ON DISEASE MODIFYING DRUGS USED

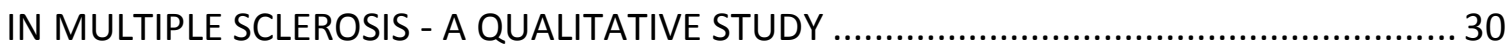

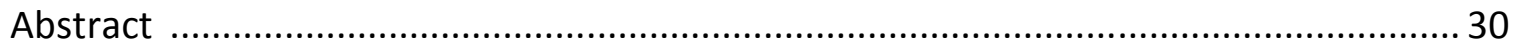

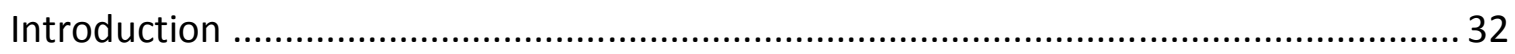

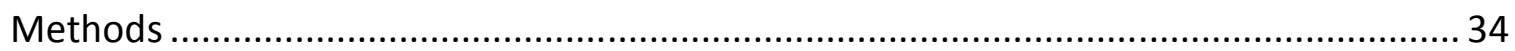

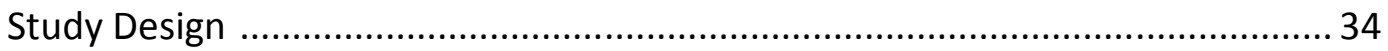

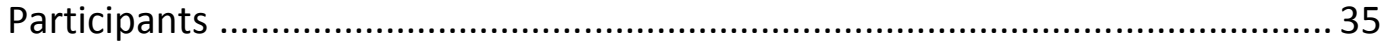

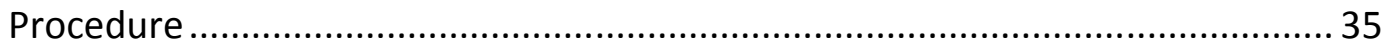

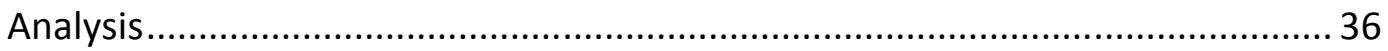

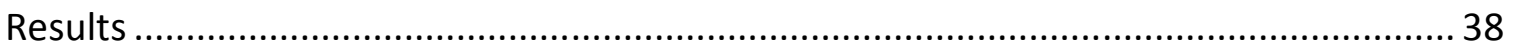

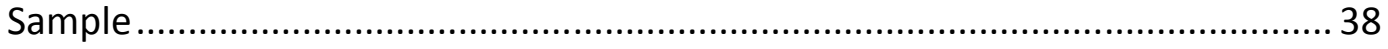




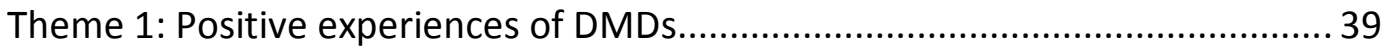

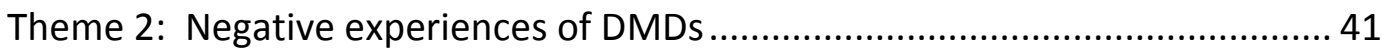

Theme 3: DMD adherence .............................................................................. 44

Theme 4: Perceived or actual value of DMD.................................................... 48

Theme 5: Expectations from future DMD .......................................................... 52

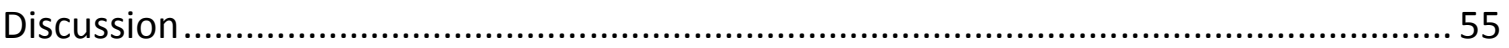

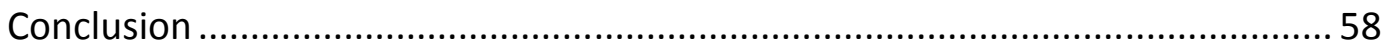

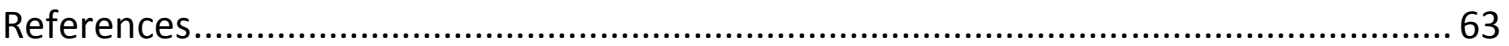

CHAPTER 3: BENEFIT-RISK PREFERENCES FOR DISEASE MODIFYING TREATMENT AMONG

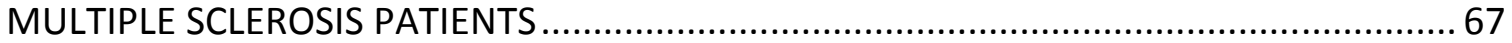

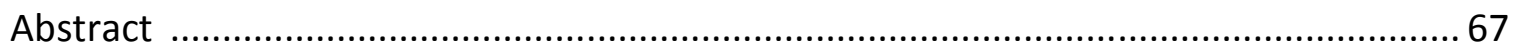

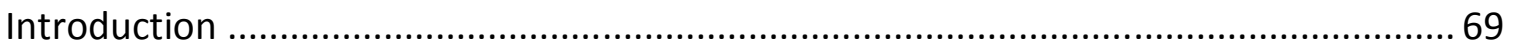

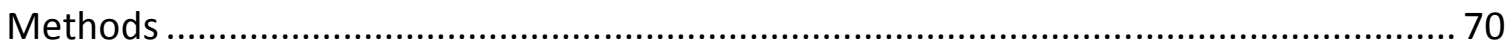

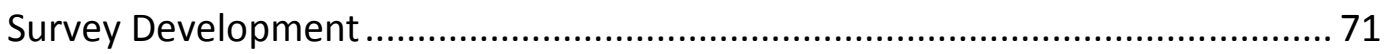

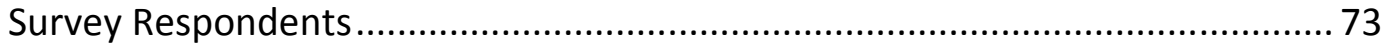

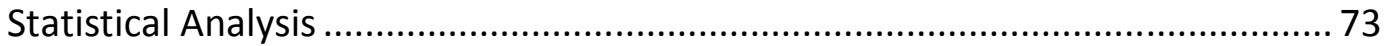

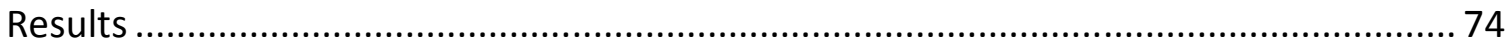

Survey Population Characteristics............................................................ 74

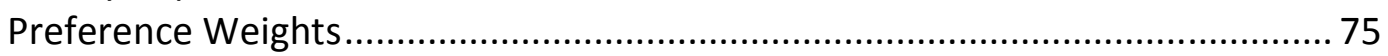

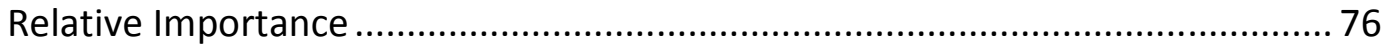

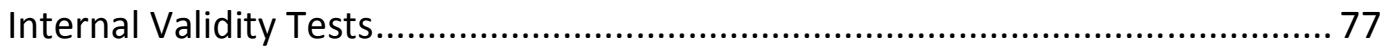

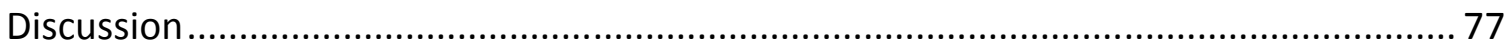

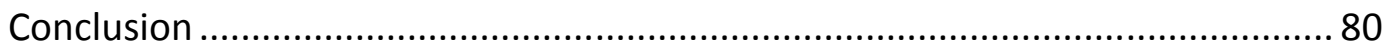

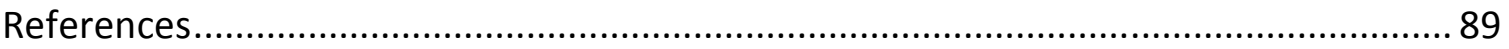

CHAPTER 4: ASSOCIATION OF DISEASE AND TREATMENT RELATED CHARACTERISTIC WITH TREATMENT SATISFACTION AMONG INDIVIDUALS WITH MULTIPLE SCLEROSIS ............93

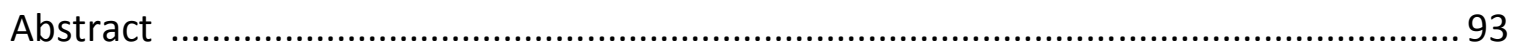

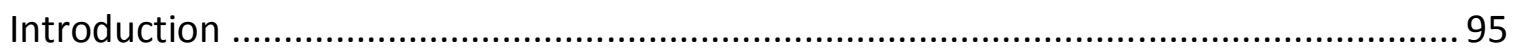

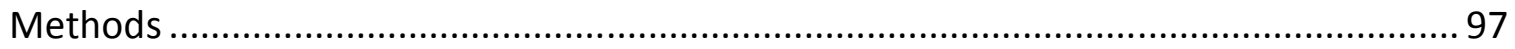

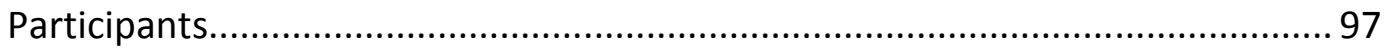

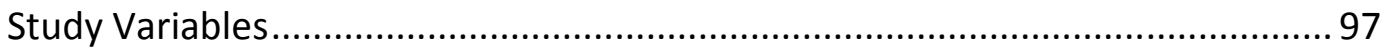




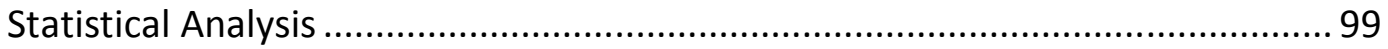

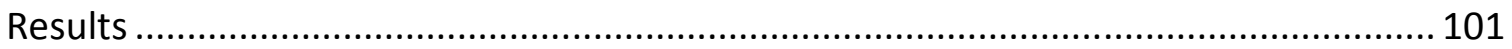

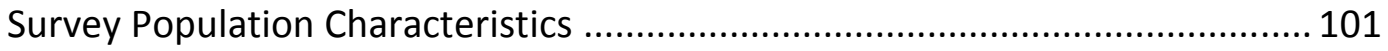

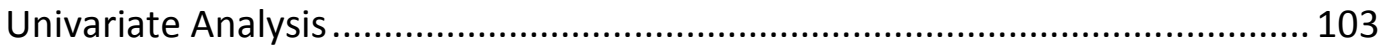

Linear Regression Analyses ....................................................................... 103

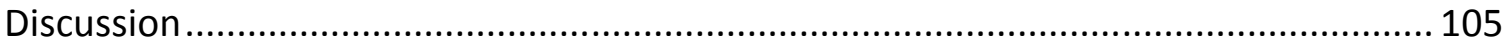

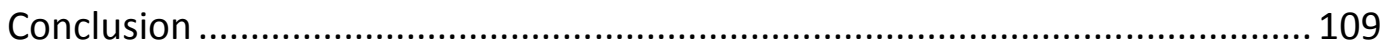

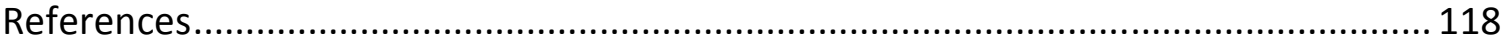

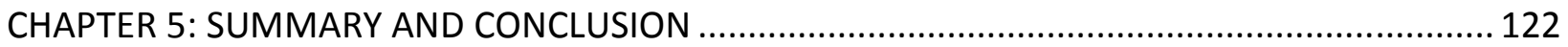

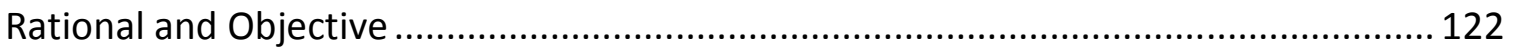

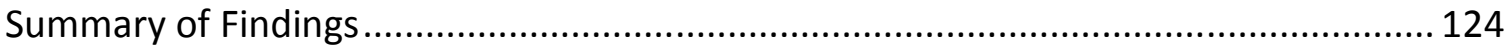

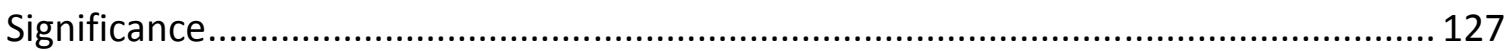

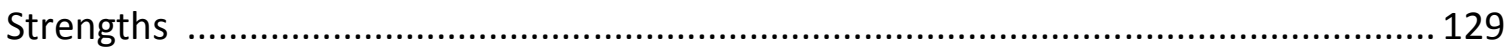

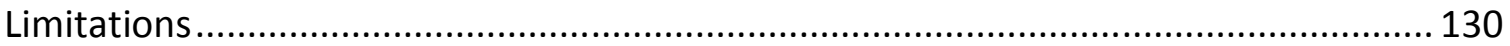

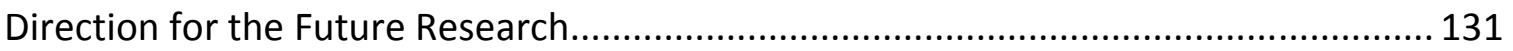

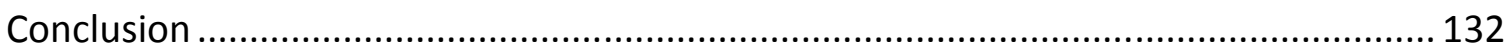

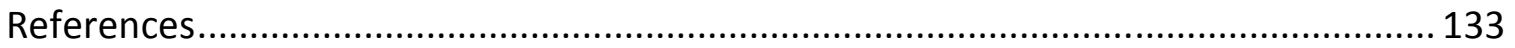

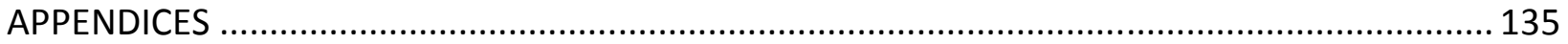

Appendix A. Focus Group - Script for Telephonic Invitation ..................................... 136

Appendix B. Focus Group - Invitation Letter............................................................. 140

Appendix C. Focus Group - Moderator Script ......................................................... 142

Appendix D. Focus Group - Sociodemographic Questionnaire ................................. 145

Appendix E. Focus Group - Acknowledgement ..................................................... 148

Appendix F. Focus Group - Important Resources for Emotional Discomfort ................ 149

Appendix G. Web-Based Survey- Invitation E-mail .............................................. 150 
Appendix H. Web-Based Survey - Survey Questionnaire......................................... 151

Appendix I. Web-Based Survey - First Reminder ............................................... 185

Appendix J. Web-Based Survey - Thank You Letter ............................................... 187

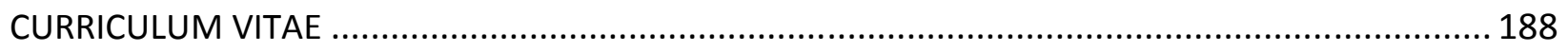




\section{LIST OF TABLES}

Table 2.1: Currently Available DMDs for Treatment of Multiple Sclerosis. 60

Table 2.2: Demographic Information of Focus Group Participants

Table 2.3: Multiple Sclerosis History and Treatment Information of Focus Group Participants

Table 3.1: Treatment Attributes and Levels 81

Table 3.2: Summary of Participants' Sociodemographic Characteristics 82

Table 3.3: Summary of Participants' Multiple Sclerosis Related Characteristics. 83

Table 3.4: Parameter Estimates for Disease Modifying Drug Attributes.

Table 4.1: Summary of Participants' Sociodemographic Characteristics

Table 4.2: Summary of Participants' Multiple Sclerosis and Treatment Related Characteristics

Table 4.3: TSQM Scores by Participants' Sociodemographic, Disease, and Treatment Related Characteristics

Table 4.4: Results of Linear Regression Analysis 115

Table 4.5: Summary of the Block-wise Entry of Covariates in the Linear Regression Models ... 116 


\section{LIST OF FIGURES}

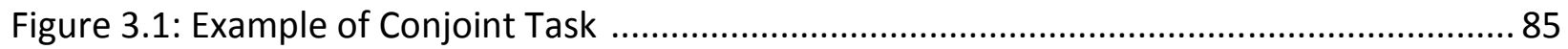

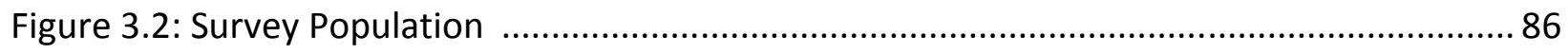

Figure 3.3: Disease Modifying Drug Preference Weights for Multiple Sclerosis Patients ...........87

Figure 3.4: Relative Importance of Disease Modifying Drug Attributes .................................. 88

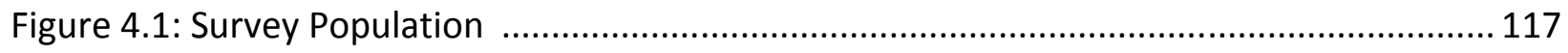


CHAPTER 1 


\section{CHAPTER 1}

\section{INTRODUCTION}

\section{Overview of Multiple Sclerosis}

Multiple sclerosis (MS) is a chronic demyelinating inflammatory neurological disorder which affects the white matter of the brain, spinal cord, and optic nerves. MS is characterized by neurological episodes followed by remission with unpredictable relapses. Varying degrees of functional impairments and disabilities are observed in MS patients depending on the site and magnitude of lesions/damage in the brain, spinal cord, and optic nerve.

\section{Etiology/Pathogenesis of MS}

The cause and the exact pathogenesis of MS is not yet completely understood.

However, epidemiological studies indicate several environmental and genetic factors to be associated with development, as well as outcomes of MS. It is hypothesized that development of MS takes place in genetically susceptible individuals after being exposed to certain environmental factors (Ramagopalan, 2010).

a. Genetic risk factors:

Genetic epidemiological studies have revealed importance of role played by genetic factors in susceptibility to MS (Dyment, 2004). Although MS is not considered to be a genetic disorder, several specific genes are linked to an increase in the risk of developing MS. Although not directly associated, certain Human Leukocyte Antigen (HLA) types are found to have strong genetic effect in MS (Ramagopalan, 2010). These haplotypes may solely be associated with MS or may affect susceptibility to MS in combination with other haplotypes 
(Dyment, 2005; Masterman, 2000; Barcellos, 2006; Ramagopalan, 2007). Studies looking at genetic factors associated with MS indicated moderate effects of genes such as interleukin7 receptors $\alpha$ (IL7RA), interleukin-2 receptor $\alpha$ (IL2RA), C-type lectin-domain family 16 member A (CLEC16A), CD58 (Formerly lymphocyte function-associated antigen 3; CD58), tumor-necrosis-factor receptor superfamily member 1A (TNFRSF1A), interferon regulatory factor 8 (IRF8), and CD6 (CD6) on increased susceptibility as well as disease outcomes (De Jager, 2009). Various genes, not limited to above mentioned list, may act independently or interactively with other environmental factors to develop MS. As MS is commonly seen among women, sex hormones are considered to play a crucial role in developing MS (Coo, 2004). Caucasians with their origins in Scandinavia and Scotland have very high susceptibility to MS compared to individuals with other racial origins (Milo, 2010). Such observations in various studies have led researchers to dig deeper into genetic etiology of MS. In families with a history of MS, it is more likely for the first, second, and third degree relatives to develop MS as compared to the general population (Dyment, 2004). Also, the risk of developing MS is higher in blood relatives such as siblings, parents, and children. Monozygotic twins (identical) have higher risk of developing MS as compared to dizygotic twins (Fraternal) (Hansen, 2005).

b. Environmental risk factors:

Causation studies have indicated several environmental risk factors that can have a potential role in the development of MS in a susceptible population. However, these factors can neither be a necessary nor a sufficient cause in the development of MS (Raine, 2008). Occupational exposure to toxins mainly organic solvents has been found to increase 
the chances of developing MS although the evidence on this is weak (Marrie, 2004).

Decreased exposure to sun is considered to increase the risk of MS (Marrie, 2004). MS is much less common in people living near the equator (Alonso, 2008; Compston, 2008). Emotional stress is also considered to be a risk factor although the evidence is weak (Marrie, 2004). Some of the other factors which are thought to be the causal factors for MS are vaccination (Marrie, 2004), diet (Ghadirian, 1998), smoking (Ascherio, 2007), and being born in the spring (Willer, 2005). Various infectious agents are also proposed to be the risk factors for MS. Higher levels of human herpes virus (HHV) antibodies (Caselli, 2002; Soldan, 1997) and HHV-6 DNA (Álvarez-Lafuente, 2002; Tejada-Simon, 2002) were found in the blood serum of patients with MS as compared to the control subjects. Epstein-Barr virus (EBV) is also considered to be relevant to MS as antibodies to this virus have been found are at higher levels than expected among the MS patients (Levin, 2003). Past infections such as measles, mumps, and rubella are also linked to MS (Compston, 2008).

\section{Pathophysiology of MS}

Current understanding of the underlying pathophysiology of MS suggests that the myelin sheath protecting the axon is targeted by the autoimmune inflammatory system in the body for destruction leading to a demyelination process. The myelin sheath is composed of lipid and has the important function of insulating the axon and helping in nerve signal conduction. It is hypothesized that the demyelination process takes place when inflammatory mediators from the circulating blood enter through a damaged blood brain barrier (BBB) and disrupt the myelin sheath present on neurons. This destruction is carried out by an overproduction of cytokines like tumor necrosis factor alpha and lymphotoxin alpha that trigger 
specific reactions within the myelin sheath and contribute to myelin damage by the immune system (Ledeen, 1998). The demyelination process results in axonal damage and death by hampering the efficiency of electrical conduction through the neural network within parts of the central nervous system (Trapp, 1998). Demyelination is characterized by scars and hardened areas on parts of the central nervous system (CNS) and these areas are known as lesions. The magnitude of demyelination, resolution of the attack, and remyelination determines the impact, duration of symptoms, and the time required to heal following an attack (Trapp, 1998). The myelin sheath rebuilt by the process of remyelination is not as effective as the original myelin sheath. The inability of nerves to conduct electrical signals as a result of demyelination and inflammation leads to various CNS related symptoms.

\section{Types of MS}

Predicting the course of MS is a challenge due to the variability in symptoms and progression of the disease. However, following four major clinical subtypes are used to describe prognosis of MS and are frequently used for making clinical decisions.

a. Relapsing remitting multiple sclerosis (RRMS) - RRMS is the most common subtype of MS with approximately $80-85 \%$ patients diagnosed with this subtype at the initial diagnosis of the disease. The rest of the MS diagnoses at onset are of primary progressive multiple sclerosis (PPMS) (Bell, 2007; Kidd, 2001). RRMS is characterized by periodic and clearly defined attacks followed by full or partial recovery. The period between two attacks are characterized by a lack of new symptoms, although the underlying disease process may be continuing. 
b. Primary progressive multiple sclerosis (PPMS) - Patients with PPMS experience gradual worsening after the onset of the disease. PPMS is characterized by indistinct relapses and remissions after the onset of MS.

c. Secondary progressive multiple sclerosis (SPMS) - This is a major progressive subtype of MS. Approximately $80 \%$ of the RRMS patients experience a progression of their disease within 7-15 years to secondary progressive multiple sclerosis (SPMS) characterized by a sudden decline in neurological function without any remission (Willer, 2000). According to a National Institute for Health and Clinical Excellence (NICE) 2003 report, almost 50\% of patients who experience RRMS develop SPMS 10 years after onset, and $90 \%$ after 25 years from initial diagnosis (NICE, 2003; Weinshenker, 1989).

d. Progressive relapsing multiple sclerosis (PRMS) - In this subtype, the patient experiences worsening progression of MS from the initial diagnosis marked by superimposed relapses and remissions. The progressive phase of multiple sclerosis is dominated by disability that accumulates over the course of disease.

\section{Symptoms}

A patient with MS or possible MS may present with the following clinical symptoms:

a. Primary symptoms are fatigue, weakness, numbness, gait disturbances, visual disturbances, dizziness, ataxia, bladder and bowel problems, changes in sexual function, cognitive problems, pain and muscle weakness, spasm, and spasticity (Gulick, 1998; Rao, 2004; Schapiro, 1997).

b. Secondary symptoms occur as an implication of primary symptoms. These symptoms may include obesity, contractures, and urinary tract infections (Schapiro, 1997). 
c. Tertiary symptoms stem from psychological (depression due to MS), vocational (inability to perform job related functions) and social (relationship problems) effects of MS (Schapiro, 1997).

The magnitude of demyelination and damage to the axon determines the clinical symptoms. Studies have shown that approximately one half of MS patients will require some type of walking aid within 15 years of the onset of MS. Approximately $10 \%$ will require wheelchair assistance. Approximately $90 \%$ will have significant disability and functional limitations within 25 years of onset of MS (Kieseier, 2003; Weinshenker, 1989).

\section{Prevalence}

According to the National Multiple Sclerosis Society, prevalence of MS in the United States (US) is 400,000 or approximately 135 per 100,000 population. Epidemiological studies from different geographical areas have provided a wide range of prevalence estimates for MS in the US. The accuracy of these estimates is limited by the fact that incidence rates are higher in the north as compared to the south. Regional variation in the occurrence of MS is explained by higher incidence of MS in regions with temperate climate compared to the tropical regions. Prevalence of MS is often higher in the regions north of 40 degrees latitude and away from equator (Kurtzke, 1977). Based on various studies, the incidence rate ranges from 85-177 adults per 100,000 population in the US (Bell, 2007). Prevalence of MS in women is observed to be twice as much as that of men, with the recent data suggesting a continuous increase in the prevalence of MS in women recently (Noonan, 2002). 


\section{Economic, Clinical, and Humanistic Burden of MS}

Early onset of disabilities (between 20-40 years of age) and lifelong nature of MS impose considerable burden on patients, their families, and the society (Prescott, 2007). Despite being an incurable disease and a cause for chronic disability, life expectancy of patients is not affected by MS. Costs associated with medical care (drug treatment, hospitalizations, hospital visits for routine check-up, and physical therapy), care provided by non-professionals (family and friends), loss of work productivity (long and short term sick leave and early retirement), and other non-medical care contribute greatly to the direct cost of care of MS patients (Kobelt, 2006). Total annual medical and lost productivity costs associated with MS was estimated to be approximately $\$ 28$ billion in the US (Society for Neuroscience, 2011). The lifetime (direct and indirect) cost for an individual with MS was estimated to be \$2.2 millon (Goldstein, 1998). Treatment costs represent a significant portion of the total cost of MS. In 2007, the cost associated with disease modifying drug (DMD) treatment was reported to be approximately $\$ 2,000$ per month (Kunze, 2007). Impaired physical functioning, health-related quality of life (HRQoL), social and emotional well being, and family relationships account for the intangible costs of MS.

Patients with MS experience lower quality of life $(\mathrm{Q} o \mathrm{~L})$ compared to the patients with other chronic illnesses, such as, diabetes, arthritis, and epilepsy (Hermann, 1996). The lower HRQoL in MS is mainly due to the decrementing effects on patients' physical, neurological, psychiatric, and psychological functioning on a daily basis. Multiple sclerosis substantially influences family, work, and social aspects of life of an individual (Solari, 2001). With a progressive disease course, patients with MS face challenges in accomplishing tasks associated 
with daily living on their own and often require structural changes in the house and nonprofessional/professional care (Stenager, 1994). The attacks and remission periods in MS are unpredictable, which makes coping with MS difficult. Disease management in MS is highly demanding and inflicts substantial burden on patients and their families. The well-being of MS patients is severely affected due to risk of losing independence, personal autonomy, dignity, and future plans over time (Boeije, 2002). Apart from physical disability and distress, MS patients also suffer from considerable neuropsychiatric burden (Mitchell, 2005). Individuals with MS are highly susceptible to developing psychiatric symptoms and disorders especially, depression and anxiety (Chwastiak, 2007). Psychological, social, and psychiatric domains of HRQoL are increasingly utilized along with physical disability assessment to model the global impact of disease.

\section{Disease Modifying Drugs}

Over the last two decades, a significant increase in the understanding of molecular and cellular mechanisms of immune cell activation and passage through the blood brain barrier into the central nervous system has resulted in an evolution of disease modifying treatment options in MS. The last three decades have seen the growth of anti-inflammatory treatment strategies aimed at treating the inflammatory nature of acute lesions in MS. Immunological treatments have gained prominence in recent years due to the increasing understanding of disease pathogenesis and the need to provide selective therapeutic interventions for MS.

Currently, the following six disease modifying drugs (DMDs) are approved by the U.S. Food and Drug Administration (FDA) for the treatment of multiple sclerosis.

- Interferon- $\beta-1 \mathrm{a}$ (Avonex ${ }^{\bullet}$, Biogen; Rebif ${ }^{\circledR}$, Pfizer-Serono) 
- Interferon- $\beta-1 b$ (Betaseron ${ }^{\oplus}$, Berlex; Extavia ${ }^{\circledR}$, Novartis)

- Glatirimer acetate (Copaxone , Teva)

- Natalizumab (Tysabri ${ }^{\oplus}$, Biogen)

- Fingolimod (Gilenya ${ }^{\circledR}$, Novartis)

- Mitoxantrone (Novantrone ${ }^{\circledR}$, Novartis)

Two major goals of pharmacotherapy of MS are to:

a. Reduce the frequency and severity of relapses, and

b. Delay the onset of the progressive stage and resultant disability due to multiple sclerosis (Thompson, 2001).

Interferon- $\beta$ and glatiramer acetate are immunomodulatory agents that are considered to be the primary treatment of choice among patients with relapsing remitting multiple sclerosis. These agents are known to shift the pro-inflammatory autoimmune responses to a more favorable anti-inflammatory response, often without affecting the immune status of the patient (Neuhaus, 2007).

Several mechanisms of action are hypothesized for Interferon- $\beta$ in multiple sclerosis. Interferons affect disease activity by preventing T-lymphocytes from crossing the blood brain barrier (Leppert, 1996; Stuve, 1996; Yong, 1998) by limiting T-cell activation within the central nervous system (CNS) (Frohman, 2005) and production of pro-inflammatory cytokine tissue necrosis factor $\alpha$ associated with T-cells (Chabot, 1997). Treatment efficacy of interferons is supported by positive findings on magnetic resonance imaging (MRI) indicating a significant drop in total active lesions and total lesion load (Li, 1999; Paty, 1993). Interferons are found to reduce the relapse frequency by one third and attenuate the gravity of exacerbations (Polman, 
2000). Interferon- $\beta$ - 1a (Avonex ${ }^{\oplus}$ ) (US FDA 2008 Avonex ${ }^{\oplus}$ package insert) is administered intramuscularly once a week whereas Interferon- $\beta$ - 1a (Rebif ${ }^{\oplus}$ ) is administered subcutaneously three times per week (US FDA 2008 Rebif $^{\oplus}$ package insert). Interferon- $\beta$ - 1 b (Betaseron ${ }^{\oplus}$ ) is injected subcutaneously every other day (US FDA 2008 Betaseron package insert).

Glatiramer acetate acts by binding with the major histocompatibility complex (MHC) and blocks the presentation of various myelin antigens to the T-cells (Arnon, 2004). It also produces glatiramer specific T-cells, which specifically suppress T-helper 2 (Th2) cells that enter the brain and suppress the autoimmune response against myelin (Gonsette, 2004). In a two year, multicenter, randomized control trial, glatiramer acetate showed a $29 \%$ annual decrease in the frequency of relapses. Glatiramer acetate is administered subcutaneously once each day (US FDA 2008 Copaxone package insert).

Natalizumab, a humanized monoclonal antibody, is the first drug from the selective adhesion molecule inhibitor class used in the treatment of relapsing forms of MS (Polman, 2006; Giovannoni, 2007). Natalizumab inhibits the interaction of $\alpha 4$-integrin present on the white blood cells (mononuclear leukocytes) with the vascular cell adhesion molecule-1(VCAM1) expressed on the surface of cerebral endothelial cells, thereby preventing leukocytes from entering into the CNS (Yednock, 1992). In a phase III trial, natalizumab monotherapy resulted in significant reduction (68\%) in annual relapse rates and delayed accumulation of physical disability by $42 \%$ over a two year time period (Polman, 2006). Natalizumab is administered by intravenous infusion every month (US FDA 2008 Tysabri package insert).

Fingolimod is the first oral DMD available for MS patients. It is a sphingosine 1phosphate receptor modulator which is structurally similar to naturally occurring sphingosine 
molecule (Chun, 2010). It is thought to activate lymphocytes $\mathrm{S}_{1} \mathrm{P}_{1}$ resulting in preventing exit of the lymphocytes from the lymph nodes (Chun, 2010). This reduces penetration of lymphocytes through the blood brain barrier into the central nervous system.

Mitoxantrone is an antineoplastic immunosuppressive agent and is the first approved treatment for worsening forms of multiple sclerosis, especially among younger patients with relapsing remitting multiple sclerosis or those who present with early secondary progressive multiple sclerosis (Cohen, 2004). It is the preferred treatment among patients not responding to first line of therapy and who continue to experience declining neurological function and progressive disability. A distinct immunological effect makes it the preferred treatment among patients who do not respond to other immunomodulatory treatments. The mechanism of action for mitoxantrone involves disruption of DNA synthesis leading to extended cell-cycle progression (Smith, 1983). It is known to exert its immunosuppressive effects in MS by hampering production of immune cells, such as T-lymphocytes, B-lymphocytes, and macrophages (Mauch, 1992; Fidler, 1986). Mitoxantrone also initiates programmed cell death of antigen presenting cells (Neuhaus, 2005) and B-lymphocytes (Bellosillo, 1998). In a large two year multicenter, randomized, placebo-control, investigator blinded trial, mitoxantrone demonstrated a significant reduction in relapse rate, disease progression (Hartung, 2002), and lesion load (Krapf, 2005). Mitoxantrone is injected intravenously and the drug is administered once every three months for two to three years (US FDA 2008 Novantrone package insert).

\section{Emerging Treatments}

In spite of the above mentioned treatment choices, difficulties in decision making related to selection of DMD treatment in MS continue to persist for both, neurologists and 
patients. Although the primary treatment choices (IFN- $\beta$ s and glatiramer acetate) are safe to administer, their long term efficacy remains unknown. Mitoxantrone, Natalizumab, and the more recently approved DMD Fingolimod, exhibit significant efficacy in active MS, but are limited in their use due to adverse drug events associated with them. Neurodegeneration and lack of regeneration of injured CNS tissue is recognized as the crucial factor in predicting the course of disability among MS patients. With an increasing understanding and knowledge of the mechanisms of immune cell migration and activation, targeting specific immunological responses is now emerging as the primary focus of newer therapeutic strategies under investigation (Frohman, 2005). Therefore, future pharmacotherapy will be largely focused on neuro-protection and neuro-repair.

Another approach proposed for treatment of MS is the use of two or more drugs with independent mechanisms of action targeting different steps in the MS pathway (Costello, 2007). Synergistic or additive therapeutic effect of combination therapies has been observed to improve clinical outcomes in other chronic autoimmune diseases like rheumatoid arthritis (Wingerchuk, 2008). Preliminary outcomes and safety profile of few combination therapies including IFN- $\beta$ s and/or glatiramer acetate with other drugs in short term studies in MS patients have been promising (Gonsette, 2004).

Various alternative therapies with an oral route of administration and novel modes of action have shown a significant and consistent effect on both clinical relapses and MRI measures (Cohen, 2007). Future DMDs are expected to provide novel mechanism of actions resulting in improved clinical effectiveness, and better safety profiles, along with convenient routes of administration and improved administration devices. Treatments with a less invasive 
route of administration are expected to improve patient satisfaction, treatment adherence, and resultant therapeutic efficacy.

\section{Need for Study}

Study 1 - Need for understanding opinions, experiences, and expectations of MS patients regarding DMDs and MS (Focus Group Method)

Current research in MS is targeted toward improving pathophysiological understanding of the underlying disease and development of new, efficacious, safe, and tolerable treatment strategies capable of altering the disease course and address the symptoms. Despite several advances in the field of MS, patients still continue to live with various needs and concerns as they experience increasing physical, psychological, and socio-economic burden associated with the disease. The requirements and expectations of MS patients are diverse due to the heterogeneity of the disease, symptoms, treatment, and several other MS related factors. Multiple sclerosis is a chronic disease without a known cure that requires long term treatment. Adherence to prescribed pharmacotherapy is an important predictor of treatment success (Cramer, 1998). Low adherence hinders optimal clinical efficacy of treatment (Dunbar-Jacob, 2000). All of the DMDs currently used for treating MS are administered parenterally except for one DMD which is administered orally. Factors like needle phobia (Cox, 2006), difficulty in self injecting (Cox, 2006), injection site reactions (Panitch, 2002; Samuel, 2006), and discomfort in self injecting (Rio, 2005; Cramer, 2006) are commonly reported by MS patients. All these factors are also known to reduce treatment adherence significantly among MS patients. Challenges associated with DMD medications not only affect patients' satisfaction with the 
treatment but also influence behaviors pertaining to stopping and switching treatments, and most importantly lower treatment adherence. Studies evaluating adherence and factors influencing adherence to DMDs in multiple sclerosis patients have indicated that a significant number of patients discontinue therapy within the first six months after initiation of therapy (Mohr, 1996; Tremlett, 2003). Similar trends were observed up to the first two years after starting the DMD treatment in a study done by Rio et al. (Rio, 2005). None of the previously published studies have attempted to understand qualitative experiences of MS patients with respect to DMDs, thus qualitative approach of focus group discussions is an effective way to obtain a deeper understanding of different dimensions associated with DMDs that MS patients often experience.

Study 2 - Need for evaluating MS patient preferences for DMDs (Stated Preference Method Conjoint Analysis)

Disease modifying agents approved by the US FDA during the last decade were perceived as a hope for better treatment outcomes in MS. These agents provided physicians and patients a wider treatment choice, often necessitating them to make a series of trade-offs on the important attributes of therapeutic management. Although clinical efficacy characteristics, such as time to next relapse and slowed disability progression are the key elements of preferred treatment, patients' valuation for a treatment choice may also be influenced by other characteristics such as nature, frequency, administration convenience, cost of the treatment, adverse drug events, and other side effects. Previous studies have reported general dissatisfaction with treatment and care in MS patients. This dissatisfaction with treatment may reflect a failure to understand patient preferences while selecting a DMD. 
Therefore it is important to evaluate patient preferences for DMDs in the treatment of MS.

This study will provide an opportunity to quantify the value that MS patients put on the benefits and risks of DMDs. This information will also help clinicians and patients in making decisions with respect to MS treatment.

\section{Study 3 - Need for evaluating factors associated with treatment satisfaction in MS patients}

The individual and societal burden of MS is significant, especially due to the prevalence of early onset of disabilities, usually between the ages of 20 to 40 years (Prescott, 2007). These are the years which are considered to be the most productive working years in people's lives. The chronic and incurable nature of MS also adds substantially to this burden. Patients with MS are affected in several ways based on the magnitude of neurological impairment and resultant changes in associated aspects of life. Approximately $50 \%$ of the MS patients become unable to fulfill job and household related responsibilities, one half of MS patients require some type of walking aid within 15 years of onset of MS, and 50\% require wheelchair assistance within 25 years of onset of MS (Confavreux, 2000). Costs associated with productivity loss contribute significantly towards the total costs of MS (Kobelt, 2006). DMDs used in the therapeutic management of MS are the mainstay therapies known to reduce frequency of relapses thereby stopping or delaying the worsening of MS and the resultant accumulation of the disability. Adherence to DMDs is a major challenge in the therapeutic management of MS. Nonadherence to DMDs among MS patients is associated with DMD related factors such as perceived or experienced lack of efficacy, injection site reactions, pain at injection sites, side effects associated with DMDs, difficulty in self-injecting, and not being able find someone to give injection (Treadaway, 2009). Although studies have been done to assess patient 
satisfaction with specific injection devices (Cramer, 2006), information on factors affecting treatment satisfaction in a large sample of MS patients using different DMDs is still lacking.

Given the potential for DMDs to influence different aspects MS patients' lives, it is essential to fill the current knowledge gaps with respect to treatment satisfaction in MS patients. 


\section{References}

1. Alonso A, Hernán MA. Temporal trends in the incidence of multiple sclerosis: a systematic review. Neurology. 2008 July; 71 (2): 129-35.

2. Alvarez-Lafuente R, Martín-Estefanía C, de las Heras V, Castrillo C, Cour I, Picazo JJ, Varela De Seijas E, Arroyo R. Prevalence of herpesvirus DNA in MS patients and healthy blood donors. Acta Neurol Scand. 2002 Feb;105(2):95-9.

3. Arnon R, Aharoni R. Mechanism of action of glatiramer acetate in multiple sclerosis and its potential for the development of new applications. Proc Natl Acad Sci U S A. 2004;101 Suppl 2:14593-98.

4. Ascherio A, Munger KL. "Environmental risk factors for multiple sclerosis. Part II: Noninfectious factors". Ann. Neurol. 2007 June; 61 (6): 504-13.

5. Barcellos LF, Sawcer S, Ramsay PP, et al. Heterogeneity at the HLA-DRB1 locus and risk for multiple sclerosis. Hum Mol Genet. 2006; 15: 2813-24.

6. Bell C, Graham J, Earnshaw S, Oleen-Burkey M, Castelli-Haley J, Johnson K. Costeffectiveness of four immunomodulatory therapies for relapsing-remitting multiple sclerosis: a Markov model based on long-term clinical data. J Manag Care Pharm. $2007 ; 13: 245-61$

7. Bellosillo B, Colomer D, Pons G, Gil J. Mitoxantrone, a topoisomerase II inhibitor, induces apoptosis of B-chronic lymphocytic leukaemia cells. Br J Haematol. 1998;100:142-46.

8. Boeije HR, Duijnstee MS, Grypdonck MH, Pool A. Encountering the downward phase: biographical work in people with multiple sclerosis living at home. Soc Sci Med. 2002;55:881-93. 
9. Caselli E, Boni M, Bracci A, Rotola A, Cermelli C, Castellazzi M, Di Luca D, Cassai E. Detection of antibodies directed against human herpesvirus 6 U94/REP in sera of patients affected by multiple sclerosis. J Clin Microbiol. 2002 Nov;40(11):4131-7.

10. Chabot S, Williams G, Yong VW. Microglial production of TNF-alpha is induced by activated T lymphocytes. Involvement of VLA-4 and inhibition by interferonbeta-1b. J Clin Invest. 1997;100:604-12.

11. Chun J, Hartung HP. Mechanism of action of oral fingolimod (FTY720) in multiple sclerosis. Clin Neuropharmacol. 2010 Mar-Apr;33(2):91-101.

12. Chwastiak LA, Ehde DM. Psychiatric issues in multiple sclerosis. Psychiatr Clin North Am. 2007;30:803-17.

13. Cohen BA, Mikol DD. Mitoxantrone treatment of multiple sclerosis: safety considerations. Neurology. 2004;63:S28-S32.

14. Cohen BA, Rieckmann P. Emerging oral therapies for multiple sclerosis. Int J Clin Pract. 2007;61:1922-30.

15. Compston A, Coles A. "Multiple sclerosis". Lancet. 2008 October; 372 (9648): 1502-17.

16. Confavreux C, Vukusic S, Moreau T, Adeleine P. Relapses and progression of disability in multiple sclerosis. N Engl J Med. 2000;343:1430-1438.

17. Coo H, Aronson KJ. A systematic review of several potential non-genetic risk factors for multiple sclerosis. Neuroepidemiology. 2004 Jan-Apr;23(1-2):1-12.

18. Costello F, Stuve O, Weber MS, Zamvil SS, Frohman E. Combination therapies for multiple sclerosis: scientific rationale, clinical trials, and clinical practice. Curr Opin Neurol. 2007;20:281-85 
19. Cox D, Stone J. Managing self-injection difficulties in patients with relapsing-remitting multiple sclerosis. J Neurosci Nurs. 2006;38:167-71.

20. Cramer JA. Consequences of intermittent treatment for hypertension: the case for medication compliance and persistence. Am J Manag Care. 1998;4:1563-68.

21. Cramer JA, Cuffel BJ, Divan V, Al-Sabbagh A, Glassman M. Patient satisfaction with an injection device for multiple sclerosis treatment. Acta Neurol Scand. 2006 Mar;113(3):15662.

22. De Jager PL, Jia X, Wang J, et al. Meta-analysis of genome scans and replication identify CD6, IRF8 and TNFRSF1A as new multiple sclerosis susceptibility loci. Nat Genet 2009; 41: 77682.

23. Dunbar-Jacob J, Erlen JA, Schlenk EA, Ryan CM, Sereika SM, Doswell WM. Adherence in chronic disease. Annu Rev Nurs Res. 2000;18:48-90.

24. Dyment DA, Ebers GC, Sadovnick AD. Genetics of multiple sclerosis. Lancet Neurol. 2004 Feb;3(2):104-10.

25. Dyment DA, Herrera BM, Cader MZ, et al. Complex interactions among MHC haplotypes in multiple sclerosis: susceptibility and resistance. Hum Mol Genet. 2005; 14: 2019-26.

26. Fidler JM, DeJoy SQ, Gibbons JJ, Jr. Selective immunomodulation by the antineoplastic agent mitoxantrone. I. Suppression of B lymphocyte function. J Immunol. 1986;137:727-32.

27. Frohman EM, Stuve O, Havrdova E, Corboy J, Achiron A, Zivadinov R et al. Therapeutic considerations for disease progression in multiple sclerosis: evidence, experience, and future expectations. Arch Neurol. 2005;62:1519-30. 
28. Ghadirian P, Jain M, Ducic S, Shatenstein B, Morisset R. Nutritional factors in the aetiology of multiple sclerosis: a case-control study in Montreal, Canada. Int J Epidemiol. 1998;27(5): 845-52.

29. Giovannoni G, Kinkel P, Vartanian T. Treating multiple sclerosis in the natalizumab era: risks, benefits, clinical decision making, and a comparison between North American and European Union practices. Rev Neurol Dis. 2007;4:184-93.

30. Gonsette RE. Combination therapy for multiple sclerosis. Int MS J. 2004;11:10-21.

31. Gulick EE. Symptom and activities of daily living trajectory in multiple sclerosis: a 10-year study. Nurs Res. 1998;47:137-46.

32. Hansen T, Skytthe A, Stenager E, Petersen HC, Kyvik KO, Brønnum-Hansen H. Risk for multiple sclerosis in dizygotic and monozygotic twins. Mult Scler. 2005 Oct;11(5):500-3.

33. Hartung HP, Gonsette R, Konig N, Kwiecinski H, Guseo A, Morrissey SP et al. Mitoxantrone in progressive multiple sclerosis: a placebo-controlled, double-blind, randomised, multicentre trial. Lancet. 2002;360:2018-25.

34. Hermann BP, Vickrey B, Hays RD, Cramer J, Devinsky O, Meador K et al. A comparison of health-related quality of life in patients with epilepsy, diabetes and multiple sclerosis. Epilepsy Res. 1996;25:113-18.

35. Kidd PM. Multiple sclerosis, an autoimmune inflammatory disease: prospects for its integrative management. Altern Med Rev. 2001;6:540-566.

36. Kieseier BC, Hartung HP. Multiple paradigm shifts in multiple sclerosis. Curr Opin Neurol. 2003;16:247-52. 
37. Kobelt G, Berg J, Atherly D, Hadjimichael O. Costs and quality of life in multiple sclerosis: a cross-sectional study in the United States. Neurology. 2006;66:1696-702.

38. Krapf H, Morrissey SP, Zenker O, Zwingers T, Gonsette R, Hartung HP. Effect of mitoxantrone on MRI in progressive MS: results of the MIMS trial. Neurology. 2005;65:690695.

39. Kunze AM, Gunderson BW, Gleason PP, Heaton AH, Johnson SV. Utilization, cost trends, and member cost-share for self-injectable multiple sclerosis drugs--pharmacy and medical benefit spending from 2004 through 2007. J Manag Care Pharm. 2007;13:799-806.

40. Kurtzke JF. Geography in multiple sclerosis. J Neurol. 1977;215:1-26.

41. Leppert D, Waubant E, Burk MR, Oksenberg JR, Hauser SL. Interferon beta-1b inhibits gelatinase secretion and in vitro migration of human T cells: a possible mechanism for treatment efficacy in multiple sclerosis. Ann Neurol. 1996;40:846-52.

42. Ledeen RW, Chakraborty G. Cytokines, signal transduction, and inflammatory demyelination: review and hypothesis. Neurochem Res. 1998 Mar;23(3):277-89.

43. Levin LI, Munger KL, Rubertone MV, Peck CA, Lennette ET, Spiegelman D, Ascherio A. Multiple sclerosis and Epstein-Barr virus. JAMA. 2003 Mar;289(12):1533-6.

44. Li DK, Paty DW. Magnetic resonance imaging results of the PRISMS trial: a randomized, double-blind, placebo-controlled study of interferon-beta1a in relapsing-remitting multiple sclerosis. Prevention of Relapses and Disability by Interferon-beta1a Subcutaneously in Multiple Sclerosis. Ann Neurol. 1999;46:197-206.

45. Marrie RA. Environmental risk factors in multiple sclerosis aetiology. Lancet Neurol. December 2004; 3 (12): 709-18. 
46. Masterman T, Ligers $\mathrm{A}$, Olsson $\mathrm{T}$, Andersson $\mathrm{M}$, Olerup $\mathrm{O}$, Hillert J. HLA-DR15 is associated with lower age at onset in multiple sclerosis. Ann Neurol. 2000; 48: 211-19.

47. Mauch E, Kornhuber HH, Krapf H, Fetzer U, Laufen H. Treatment of multiple sclerosis with mitoxantrone. Eur Arch Psychiatry Clin Neurosci. 1992;242:96-102.

48. Milo R, Kahana E. Multiple sclerosis: geoepidemiology, genetics and the environment. Autoimmun Rev. 2010 Mar;9(5):A387-94.

49. Mitchell AJ, Benito-Leon J, Gonzalez JM, Rivera-Navarro J. Quality of life and its assessment in multiple sclerosis: integrating physical and psychological components of wellbeing. Lancet Neurol. 2005;4:556-66.

50. Mohr DC, Goodkin DE, Likosky W, Gatto N, Neilley LK, Griffin C et al. Therapeutic expectations of patients with multiple sclerosis upon initiating interferon beta-1b: relationship to adherence to treatment. Mult Scler. 1996;2:222-26.

51. National Institute for Clinical Excellence (2003a). Multiple sclerosis: UnderstandingNICE guidance - information for people with MS, their families and carers, and the public.NICE [On-line]. Accessed from: http://www.nice.org.uk/page.aspx?o=94081 Retrieved on November 23, 2007.

52. Neuhaus O, Wiendl H, Kieseier BC, Archelos JJ, Hemmer B, Stuve O et al. Multiple sclerosis: Mitoxantrone promotes differential effects on immunocompetent cells in vitro. $J$ Neuroimmunol. 2005;168:128-37.

53. Neuhaus O, Kieseier BC, Hartung HP. Immunosuppressive agents in multiple sclerosis. Neurotherapeutics. 2007;4:654-60. 
54. Noonan CW, Kathman SJ, White MC. Prevalence estimates for MS in the United States and evidence of an increasing trend for women. Neurology. 2002;58:136-38.

55. Panitch H, Goodin DS, Francis G, Chang P, Coyle PK, O'Connor P et al. Randomized, comparative study of interferon beta-1a treatment regimens in MS: The EVIDENCE Trial. Neurology. 2002;59:1496-506.

56. Paty DW, Li DK. Interferon beta-1b is effective in relapsing-remitting multiple sclerosis. II. MRI analysis results of a multicenter, randomized, double-blind, placebo-controlled trial. UBC MS/MRI Study Group and the IFNB Multiple Sclerosis Study Group. Neurology. 1993;43:662-67.

57. Polman CH, Uitdehaag BM. Drug treatment of multiple sclerosis. BMJ. 2000;321:490-494.

58. Polman $\mathrm{CH}, \mathrm{O}$ 'Connor PW, Havrdova E, Hutchinson $\mathrm{M}$, Kappos L, Miller DH et al. A randomized, placebo-controlled trial of natalizumab for relapsing multiple sclerosis. $N$ Engl J Med. 2006;354:899-910.

59. Prescott JD, Factor S, Pill M, Levi GW. Descriptive analysis of the direct medical costs of multiple sclerosis in 2004 using administrative claims in a large nationwide database. J Manag Care Pharm. 2007;13:44-52.

60. Raine CS, McFarland HF, Hohlfeld R. Multiple Sclerosis: A Comprehensive Text. 2008, Saunders/Elsevier.

61. Ramagopalan SV, Morris AP, Dyment DA, Herrera BM, DeLuca GC, Lincoln MR, Orton SM, Chao MJ, Sadovnick AD, Ebers GC. The inheritance of resistance alleles in multiple sclerosis. PLoS Genet. 2007 Sep;3(9):1607-13. 
62. Ramagopalan SV, Dobson R, Meier UC, Giovannoni G. Multiple sclerosis: risk factors, prodromes, and potential causal pathways. Lancet Neurol. 2010 Jul;9(7):727-39.

63. Rao SM. Cognitive function in patients with multiple sclerosis: impairment and treatment. Int J MS Care. 2004; 1: 9-22.

64. Rio J, Porcel J, Tellez N, Sanchez-Betancourt A, Tintore M, Arevalo MJ et al. Factors related with treatment adherence to interferon beta and glatiramer acetate therapy in multiple sclerosis. Mult Scler. 2005;11:306-9.

65. Samuel L, Lowenstein EJ. Recurrent injection site reactions from interferon beta 1-b. J Drugs Dermatol. 2006;5:366-67.

66. Schapiro RT, Baumhefner RW, \& Tourtellotte WW (1997). Multiple Sclerosis: A Clinical Viewpoint to Management. In Raine CS, McFarland HF, \& Tourtellotte WW (Eds.), Multiple Sclerosis: Clinical and Pathogenetic Basis (1st ed., pp. 391-420). London. Chapman \& Hall

67. Smith IE. Mitoxantrone (novantrone): a review of experimental and early clinical studies. Cancer Treat Rev. 1983;10:103-15.

68. Society for Neuroscience, (2011) V.5.1.11. Available at: http://www.sfn.org/skins/main/pdf/brss/BRSS Multiple Sclerosis.pdf. Accessed April19, 2012.

69. Solari A, Radice D. Health status of people with multiple sclerosis: a community mail survey. Neurol Sci. 2001;22:307-15.

70. Soldan SS, Berti R, Salem N, Secchiero P, Flamand L, Calabresi PA, Brennan MB, Maloni HW, McFarland HF, Lin HC, Patnaik M, Jacobson S. Association of human herpes virus 6 (HHV-6) 
with multiple sclerosis: increased IgM response to HHV-6 early antigen and detection of serum HHV-6 DNA. Nat Med. 1997 Dec;3(12):1394-7.

71. Stenager E, Stenager EN, Knudsen L, Jensen K. Multiple sclerosis: the impact on family and social life. Acta Psychiatr Belg. 1994;94:165-74.

72. Stuve O, Dooley NP, Uhm JH, Antel JP, Francis GS, Williams G et al. Interferon beta-1b decreases the migration of T lymphocytes in vitro: effects on matrix metalloproteinase-9. Ann Neurol. 1996;40:853-63.

73. Tejada-Simon MV, Zang YC, Hong J, Rivera VM, Killian JM, Zhang JZ.Detection of viral DNA and immune responses to the human herpesvirus 6101 -kilodalton virion protein in patients with multiple sclerosis and in controls. J Virol. 2002 Jun;76(12):6147-54.

74. Thompson AJ. Symptomatic management and rehabilitation in multiple sclerosis. J Neurol Neurosurg Psychiatry. 2001;71 Suppl 2:ii22-ii27.

75. Trapp BD, Peterson J, Ransohoff RM, Rudick R, Mörk S, Bö L. Axonal transaction in the lesions of multiple sclerosis. N Engl J Med. 1998 Jan;338(5):278-85.

76. Treadaway K, Cutter G, Salter A, et al. Factors that influence adherence with diseasemodifying therapy in MS. J Neurol. 2009;256(4):568-576.

77. Tremlett HL, Oger J. Interrupted therapy: stopping and switching of the beta-interferons prescribed for MS. Neurology. 2003;61:551-54.

78. U.S. Food and Drug Administration. Avonex ${ }^{\circledast}$ - Package Insert. Available at: http://www.fda.gov/CDER/foi/label/2003/ifnbbio013103LB.pdf Accessed January 14, 2008. 
79. U.S. Food and Drug Administration. Rebif ${ }^{\oplus}$ - Package Insert. Available at: http://www.fda.gov/cder/foi/label/2003/ifnbser050203LB.pdf Accessed January 14, 2008.

80. U.S. Food and Drug Administration. Betaseron ${ }^{\circledR}$ - Package Insert. Available at:: http://www.fda.gov/MEDWATCH/safety/2005/Betaseron_PI.pdf Accessed January 14, 2008.

81. U.S. Food and Drug Administration. Copaxone - Package Insert. Available at: http://www.fda.gov/cder/foi/label/2001/20622s15lbl.pdf Accessed January 14, 2008.

82. U.S. Food and Drug Administration. Novantrone - Package Insert. Available at:: http://www.fda.gov/cder/foi/label/2005/019297s028lbl.pdf Accessed January 14, 2008.

83. U.S. Food and Drug Administration. Tysabri - Package Insert. Available at:: http://www.fda.gov/cder/foi/label/2006/125104s015lbl.pdf Accessed January 14, 2008.

84. Weinshenker BG, Bass B, Rice GP, Noseworthy J, Carriere W, Baskerville J et al. The natural history of multiple sclerosis: a geographically based study. I. Clinical course and disability. Brain. 1989;112 (Pt 1):133-46.

85. Whetten-Goldstein K, Sloan FA, Goldstein LB, Kulas ED. A comprehensive assessment of the cost of multiple sclerosis in the United States. Mult Scler. 1998;4:419-25.

86. Willer CJ, Ebers GC. Susceptibility to multiple sclerosis: interplay between genes and environment. Curr Opin Neurol. 2000;13:241-47.

87. Willer CJ, Dyment DA, Sadovnick AD, Rothwell PM, Murray TJ, Ebers GC; Canadian Collaborative Study Group. Timing of birth and risk of multiple sclerosis: population based study. BMJ. 2005 Jan;330(7483):120. 
88. Wingerchuk DM. Current evidence and therapeutic strategies for multiple sclerosis. Semin Neurol. 2008;28:56-68.

89. Yednock TA, Cannon C, Fritz LC, Sanchez-Madrid F, Steinman L, Karin N. Prevention of experimental autoimmune encephalomyelitis by antibodies against alpha 4 beta 1 integrin. Nature. 1992;356:63-66.

90. Yong VW, Chabot S, Stuve O, Williams G. Interferon beta in the treatment of multiple sclerosis: mechanisms of action. Neurology. 1998 Sep;51(3):682-9. 
CHAPTER 2 


\title{
CHAPTER 2
}

\section{UNDERSTANDING PATIENTS' PERSPECTIVES ON DISEASE MODIFYING DRUGS USED IN MULTIPLE SCLEROSIS - A QUALITATIVE STUDY}

\begin{abstract}
Objective: The purpose of this qualitative study was to explore patients' experiences, opinions, and expectations related to disease modifying drugs (DMDs) used in multiple sclerosis (MS). Methods: A sample of 18 individuals with confirmed diagnosis of MS was recruited through a university hospital-based neurology clinic. Four focus group (FG) sessions involving semistructured interviews were conducted. The FG discussions were audio-recorded and were later transcribed for coding purposes. Qualitative content analysis of transcribed data was performed by two blinded reviewers using QSR NVivo 8 software. The data were coded into specific themes as per the research questions.

Results: Qualitative analysis indicated five major themes related to experiences with existing DMDs and expectations from the future DMDs: positive experiences of DMDs, negative experiences of DMDs, adherence, perceived/actual value of DMD, and expectations from future DMD. Although a majority of the participants had experienced side effects associated with injectable DMDs, they were generally content with clinical benefits associated with DMDs they were currently taking. Future DMDs were expected to be safer and easier to administer. Conclusions: This study provides an in-depth understanding of various factors associated with DMDs that are important to MS patients. With increasing number of treatment choices, MS
\end{abstract}


patients' involvement in complex treatment decisions will become even more crucial. In order to select the best possible treatment for MS patients, it is imperative to choose a treatment that is clinically effective, while keeping their preferences and needs in mind. Improving patients' knowledge about benefits and risks of DMDs and allowing them to actively participate in making informed treatment decisions will be increasingly important and challenging with respect to future treatment. 


\section{Introduction}

Multiple sclerosis (MS) is a progressive demyelinating inflammatory disorder affecting the central nervous system involving the white matter of the brain, spinal cord, and optic nerves. Approximately 400,000 individuals in the United States (US) are currently affected by this chronic debilitating neurological condition (NMSS, 2011). It mainly affects young adults between the ages of 20 and 40 (Confavreux, 1980). It is the major cause of non-traumatic disability among young adults in the US (Dutta, 2007).

MS is characterized by worsening of physical and cognitive abilities in an affected individual over the long course of the disease. At the initial diagnosis, approximately $85 \%$ of MS patients are diagnosed with the relapsing remitting multiple sclerosis (RRMS) subtype which is characterized by periodic and clearly defined attacks, also known as relapse, followed by full or partial recovery (Rudick, 2008). With the passage of time, recovery from each relapse remains incomplete resulting in a gradual accumulation of physical and cognitive deficits (Weinshenker, 1989; Lublin, 1996; Coles, 2009). A majority of the RRMS patients experience progression of their MS within 7-15 years following RRMS onset to the secondary progressive multiple sclerosis (SPMS), which is characterized by a gradual and continuous decline in neurological functions without any relapse (Weinshenker, 1989; Lublin, 1996; Coles, 2009). Approximately $15 \%$ of MS patients experience the progressive form of MS from the initial diagnosis, without any preceding relapses (Rudick, 2008). Patients with primary progressive multiple sclerosis (PPMS) never experience relapses, whereas those with progressive relapsing multiple sclerosis (PRMS) do not experience any relapse after a gradual worsening at the onset but eventually may experience relapses at a very low rate (Weinshenker, 1989; Lublin, 1996; Coles, 2009). 
Despite these different subtypes of MS, all MS patients experience declining quality of life over the course of the disease as a result of decline in neurological functioning and the resultant symptoms.

Currently, there is no known cure available for MS. However, over the last two decades, a significant increase in the understanding of molecular and cellular mechanisms of immune cell activation and passage through the blood brain barrier into the central nervous system has resulted in an evolution of drugs for MS commonly known as disease modifying drugs (DMDs). With the influx of various DMDs in the market, patients' and clinicians' perceptions have shifted towards MS being a modifiable disease, and since then DMDs have become a vital part of the therapeutic management of MS. DMDs help patients in maintaining neurological functions by: a) reducing the frequency and severity of relapses, and b) delaying the onset of the progressive stage and resultant disability due to MS (Thompson, 2001). There are currently seven DMDs (6 injectable and 1 oral) that are approved by the U.S. Food and Drug Administration (FDA) for the treatment of MS. These DMDs are perceived as a hope for better treatment outcomes in MS. Interferon beta-1a, Interferon beta-1b, and glatiramer acetate are considered to be the first line of treatments that are relatively safer, but modestly efficacious. Other promising DMDs like natalizumab, fingolimod, and, less used mitoxantrone, are usually considered as the second line of treatments (Rudick, 2011). These DMDs are known to exhibit significant efficacy in active MS, but are limited in their use due to adverse events associated with them. Several other drugs have shown promising results in the late phases of drug development. Currently available DMDs are shown in table 2.1. These DMDs provide physicians and patients with a 
wider treatment choice for therapeutic management of MS. However, the difficulty in selection of a DMD still persists for neurologists and patients.

MS patients have reported needle phobia (Cox, 2006), difficulty in self-injecting (Cox, 2006), injection site reactions (Panitch, 2002; Samuel, 2006), and discomfort in self-injecting (Rio, 2005; Cramer, 2006) as the common issues associated with injectable DMDs. Challenges associated with DMD medications not only affect patients' satisfaction with the treatment, but also influence behavior pertaining to stopping and switching treatments, and most importantly lower treatment adherence. Adherence to prescribed pharmacotherapy is an important predictor of treatment success (Cramer, 1998). Low treatment adherence hinders optimal clinical efficacy of treatment (Dunbar-Jacob, 2000).

Therefore, it is important to explore MS patients' perspectives on DMDs. None of the previously published studies have attempted to examine and understand subjective DMD experiences among the MS patient population. The qualitative method is a valid approach to identify aspects important among patients and to explore relevant meanings and beliefs associated with those aspects (Sim, 1998). The objective of this study was to better understand experiences, perceptions, and expectations among MS patients related to treatments with DMDs.

\section{Methods}

\section{Study Design}

Data were collected using focus group interviews among individuals with multiple sclerosis in a semi-structured interview format. 


\section{Participants}

A purposive sample of 18 individuals was recruited for in-depth focus group discussion sessions through the neurology clinic at the West Virginia University School of Medicine (WVUSOM). Eligible individuals had to meet the following inclusion criteria: 1 ) at least 18 years of age; 2) confirmed diagnosis of MS; 3 ) at least one visit to the outpatient neurology clinic at WVUSOM within the last one year; 4) relapse-free at the time of participation; and 5) current use of a DMD to treat MS. A list of probable candidates for focus group discussion was prepared by the research nurse working in the neurology clinic using clinic records. Individuals from this list were contacted via telephone by the neurology research nurse or the lead researcher $(A B)$ and a brief explanation of the study was provided. Eligible individuals interested in focus group participation were sent an invitation letter with details of the study including, date, time, and directions to the venue.

\section{Procedure}

The procedures for this research study were reviewed for human subject ethics compliance and approved by the Institutional Review Board of West Virginia University. Semistructured focus group interviews were conducted. All discussion sessions were conducted and moderated by the lead researcher $(A B)$, which helped in controlling for interviewer bias. Each discussion session was audio-recorded and data were transcribed verbatim. The study purpose was explained to all participants and a consent form was administered to each individual.

Focus group discussions involved two parts. In the first part, participants were given a brief questionnaire to complete. This questionnaire included questions related to sociodemographic information and individual disease and treatment history. All participants 
completed this questionnaire before beginning the discussions. In the second part, participants were asked about their experiences with disease modifying drugs used in the treatment of MS, in addition to other aspects such as health related quality of life, treatment satisfaction, health concerns, and expectations from future disease modifying treatments for MS. Neurologists, research nurses, and other members of the research team thoroughly reviewed the questions in the interview guide prior to each focus group discussion session.

Each session was audio-recorded and individuals were asked to use an assigned number to identify themselves each time before they spoke. During the focus group discussion, whenever required, clarification on answers was sought from the participants in order to correctly understand their treatment experiences. At the end of the focus group discussion, each participant was provided a \$25 Wal-Mart gift card as a token of appreciation for their study participation. All focus group discussion sessions were moderated by the lead researcher (AB) to control for interviewer effects (Blackwell, 2006). The moderator was not involved in the clinical care of focus group participants, which allowed them to speak freely about their experiences, opinions, and concerns with respect to their condition and treatments.

\section{Analysis}

Analysis involved a dynamic process of data collection and coding, where each of the process helped to inform the next one. Audio-recorded data from each focus group were immediately transcribed following the discussion session. The content was reviewed by the lead researcher $(A B)$ after each interview, which helped in reflecting upon the tentative categories. Data collection ended after completion of the fourth focus group due to data saturation. There was a significant amount and range of information to conduct formal analyses of all the 
transcripts collectively. Qualitative content analysis and coding of transcribed data were performed by two blinded coders on the research team who analyzed the transcripts. Coding and analysis were performed using Qualitative Solutions and Research (QSR) NVivo Version 8.0 software.

Coding procedures involved identification of meaningful phrases or quotes with respect to the research questions. Terms describing the characteristics associated with each phrase or quote were generated and identified as 'codes'. Different categories were created to encompass all the codes that were related to each other. These categories were modified and broadened in scope to include different relevant aspects discussed by participants. Categories which had similar or overlapping codes were merged wherever appropriate, or dropped when found to be repetitious or redundant. Both coders compared respective codes and categories after analyzing each transcript. This procedure was performed for the analysis of all four transcripts. There was high concordance between codes and categories created by both the coders after initial analysis. Wherever there were inconsistencies with respect to coding and categorization, a resolution was reached by discussion and consensus with members of research team. Opposing views of participants were used to determine the strength of results.

The next step in the analysis was to organize similarly coded phrases or quotes from all transcripts. Once such pooling was done, all similarly coded content was carefully studied and a brief description capturing extent and essence of that data was written using verbatim phrases and quotes. Each category was refined using an iterative process. Analysis involved finding and evaluating differing perspectives in the information shared by participants once a category was developed. A total of five specific categories (key themes) emerged. Finally the entire research 
team was consulted in order to get their feedback on interpretation of the data and conclusions. This process helped to avoid researcher bias and validate conclusions.

\section{Results}

Sample

Socio-demographic information is provided in table2.2. A total of 18 individuals with confirmed diagnosis of MS participated in this study. Eleven participants were female and seven participants were male. All participants were White and a majority of the participants were married or were living with partners. The age of participants ranged from 26 years to 70 years with a mean age of $\sim 49$ years $(S D=14.4)$. Almost all the participants had at least high school level education. A majority of the participants were enrolled in publicly funded insurance programs, such as Medicaid or Medicare. Nearly one half of the participants were unable to work due their condition at the time of the study. Two thirds of the study participants had a household income above $\$ 25,000$.

Table 2.3 provides disease and treatment information for focus group participants. On average, the disease duration was 11 years. Thirteen participants had been living with MS for more than 5 years. A majority of the participants (66\%) had relapsing remitting MS. Ten participants reported being on a DMD for more than five years. A majority of the participants were on Interferon- $\beta 1 \mathrm{a}$ and rest of the participants were on other types of DMDs. More than half of the participants had experience with Interferon- $\beta$ 1a and Glatiramer acetate during their course of MS treatment. All participants who had some type of health insurance reported that their insurance covered the DMD they were taking in part or fully. The three participants who 
were uninsured reported receiving their DMD through a drug support program from the pharmaceutical companies making their respective DMDs.

Apart from DMDs, a majority of patients were also taking other medicines for symptoms associated with MS. These symptoms included fatigue, headache, vision problems, neuropathy, pain, sleep issues, overactive bladder, bowel problems, depression, cognitive problems, muscle stiffness, muscle spasms etc. Participants indicated that they adopted non-pharmacologic methods in order to better manage their MS and associated symptoms. Such methods included physical therapy, prayers, water therapy, meditation, and relaxation activities such as fishing and sitting with pets. Participants also reported to make dietary changes by cutting out on foods containing gluten, dairy products, eggs, products containing yeast, etc or by drinking Noni juice. A few participants also reported using herbals (St. John's Wort) and supplements (Vitamin D, Vitamin B12, etc).

The following five themes were identified from analysis of the transcripts: 1) positive experiences of DMDs, 2) negative experiences of DMDs, 3) DMD adherence, 4) perceived or actual value of DMD, and 5) expectations from future DMD.

\section{Theme 1: Positive experiences of DMDs}

Positive experiences were related to patients' perceived improvements in their quality of life, mainly related to energy levels, cognition, and a general feeling of well being. QOL/General wellbeing

P1N1 "I had no problems on my drug. You know it's just worked out well for me. So my quality of life is good." 
P1N2 "Starting on it (DMD) I was able to gain my weight back and a little bit extra and my quality of life is fantastic. I mean for what it was and what it is I really can't complain."

P2N4 "I think it helps me to keep from feeling worse."

P3N6 "I don't want to move back in hospital and so that's why I do take them."

Energy Levels

P3N3 "I take it regularly. I still got my energy levels the same I was."

Cognition

P3N1 "Even my cognitive skills, I think clear my, brain's not fuzzy."

Relapse Reduction

Patients highlighted the fact that they were experiencing less relapses which added significantly to their positive experiences with DMDs.

P1N1 "I have had fewer relapse so I feel that it (the drug) is doing its job then."

P3N2 "I believe mine is (working) because I have not had a relapse but only once, and my hope is that it continues to work."

P3N4 "I take my treatments knowing that is not a cure but hopefully it will prolong the time between the relapses because I know I can speak from my experiences you know, laying in bed helpless, you know, you can look at your legs and your hands, want them to move, and they won't, they won't listen to you. So if I can prolong that extra episode, I will still take the treatments. The three years I am on it, I have not had a relapse."

P4n2 "To have (relapses) just twice a year I would say that I feel that the medication I am on is doing a pretty good job... If I have an injection site reaction, big deal. The overall results are good, you know as long as I am upright and talking...." 


\section{Theme 2: Negative experiences of DMDs}

Negative experiences reported by patients with their current DMD or the ones that they used in the past were associated with lack of treatment benefit, side effects, or concerns over adverse events that were bothersome.

Lack of benefit

Some patients mentioned lack of benefits from their DMDs as they experienced increased relapses leading to frequent hospitalizations, increase in the number of lesions on MRI, or continued progression of their MS.

P2n2 "I don't think it (DMD) helped me. My MRIs showed that I was getting worse."

P2N3 "they (DMDs) were not working.. I was relapsing, relapsing, one after another, one after another. I think when every time I was on the other drugs, I was in a hospital, getting pumped with cortisone."

P4N1 "I am not actually very happy with my drug, because I am just seeing steady decline. I don't really feel like that its helping me."

Injection site reactions

Injection site reactions were commonly reported by the participants. Some injection site reactions led to feelings of embarrassment and frustration.

P1n2 "When I take my shot, a lot of the time I will just get the redness but sometimes it will swell up, it's not as thick, it's just a round cute lump. Being young you get vain and think someone is looking at you because you have this huge tumor thing looking growing out from wherever you took that shot."

P2N2 "I had just local site reactions, the knots and the redness." 
Side effects

Patients reported that side effects due to injection affected their day to day activities and also affected their productivity for next few days. Patients also experienced other side effects such as loss of weight, vomiting, flu-like symptoms, fatigue, chills etc. that made them feel sick which they attributed directly to the injection they were on.

P1N2 "It made me really sick. And for some reason the day after I would take the shot it would cause me to vomit. So, you just kind of knew the day after to be prepared. I lost a lot of weight, I would say at least 15 lbs ..... got the flu like symptoms from it afterwards."

P2N2 "if I take it the morning, I get puky sick so I take it at night and go to bed."

P2N4 "It was almost close to horrible, I would get chills, I would get fever... I do remember couple of times just sitting with tons of blankets on me you know and every corner and just shaking having so many chills"

P3N2 "zaps all the energy that you have.... It basically just sucks the life out of you for a day or 2/3 days"

P3N3 anything more or less that is inconvenient for me is the headache"

P3N5 "I seem to have little less energy compared to other ones"

P3N6 "the night I take my injections, next day I will do nothing. I usually get real sick and cold chills. I will get hot. I will get up and sit in bath tub all night running under the hot water. The day after (I take my DMD) I am braindead"

P4n1 "I make sure to take it later in the day so if I do have any flu like symptoms or any like feeling just bad from it, I sleep through it" 
Certain side effects related to the DMDs that did not subside with the passage of time or made patients feel worse about their condition were more concerning. Those were some of the main reasons behind switching DMDs. While choosing a DMD one patient said that he traded off between frequency and the perceived level of side effects keeping benefits as constant thinking all DMDs deliver same level of effectiveness.

P1N4 "When I was trying to decide what treatment to go on, I chose it because it was the least symptoms and they don't have to do the blood work or check your liver function. Even though its once day but it was really convenient I just felt that it might be the safer one for me to try since all I mean that outcome of all them is about the same."

P3n5 (About Past DMD1) "the reason I switched with it was I would have adverse reaction, every time almost, I would get the shot, it felt that if you took a pin and prick my face, it would just explode. I just felt like all the blood, my body was pushing into my head, and like I said the last time I took it, I passed out. Just to give the story I was sicker than a dog" (About Past DMD2) "I felt like I had full blown flu and then next 3-4 days I am slowly recovering from that and then I have to take my shot again. So it's just the same thing over and over again, and it just started to get really repetitious" Patients voiced their concern that DMDs might affect their organ like, kidney, liver, heart, etc. Side effects of DMDs which made patients feel worse about their condition made patients think whether it is because DMDs are affecting the organs. Despite getting routinely tested for enzyme levels and finding it to be normal, patients had a constant fear at the back of their mind. 
P1N1 "After I was on it like 3 months where my chest tightened up real bad and I was like I felt like I was going to fall right over and I felt I was having heart attack."

P1n2 "since I was getting sick so much, I was much concerned about it damaging the liver or kidney it would affect but as long as I was having the blood work done and it came up fine I was okay with that, but there still always that thought at the back of your mind thinking well, is it damaging a little at a time by the time they catch it its going be too late"

P2N2 "I know it lowers my white blood count, so I can't be around sick people. I am a nurse that makes it hard. I have two kids so that makes it hard."

P3n2 "Is it going kill my liver, you know, or is it going to affect any other organs in my body, my kidneys.... am I going to develop congestive heart failure from this modifying drug later on in my life as I get older."

P4N1 "I am somewhat concerned about what it's doing to the liver"

P4N2 "I will have real rapid heart rate and I will get red, just red as in cherry red. I feel like I never had a heart attack before but it sure do feel pretty close."

\section{Theme 3: DMD adherence}

Positive aspects affecting adherence

Adherence with DMD among MS patients was found to be the function of, mainly, convenience aspects of a DMD and the belief that it helps them maintain day to day activities. Although some DMDs may cause a feeling of weakness, patients were willing to tolerate it as a trade off for being able to stay mobile. Being able to enjoy life with family and kids and maintain independence of physical functioning is what made patients take their DMDs as 
prescribed. Patients displayed an understanding that there is no cure for their MS and taking the DMD is the only hope that is going to keep the disease progression at bay and keep them to remain healthier and mobile for a longer period.

P2N2 "I take mine as prescribed because my goal is to stay mobile as long as I can, to stay out of the wheelchair"

P3N2 "My thought process was, take it once a week for one day, for one day harpooned for one day and get through it, and you got six days to do what you can."

P3N3 "I don't want to progress and get worse...I don't want the thought of someone happen to dress me, feed me.... one (another reason) is my children, I want to be able to get out and walk and do simple things... course and my wife, she is really adamant but that's why I take my medicine and I take it as I am supposed to."

P3N4 "My energy levels might be low now, but at least I am not laid up in bed". So I haven't missed any of my therapy treatments at all"

P4N2 "I want to stay as healthy as I can, and if I take my DMD, it is helping me, so I am not going to mess that up. I can't beat the MS, but I can control it. So if taking this medicine helps me I am on that bus. I am not going to miss it."

Some patients understood that injection site reaction is part of DMDs and were willing to bear with the injection site reactions as long as the treatment was working for them.

P4n3 "I have accepted it. I mean you know I go with it. I just figured as long as its working I will tolerate some red spots and knots."

Convenience, frequency, and flexibility of administration of DMDs were associated with adherence. There appeared to be a higher preference for not having to self-inject the DMDs 
and having to take the DMD less frequently. It was more convenient for some patients to take their DMDs in their own home.

P2N2 "I would take my shots on my own, not though that it was convenient to take everyday, and my pills are very convenient to take everyday"

P3N2 "It is convenient to take it in my own home."

P3N5 "since I have been on it (DMD), I love it, because you know, the ease of it, not having to self administer, you know, you just go to the doctor once a month and then it's done for the next month before you have to go back to have another infusion"

P3N6 "It's pretty convenient only having to take just once a week"

Negative aspects affecting adherence

Whereas, one patient mentioned that the major inconvenience for her was to travel long distance to get her monthly infusion. It was an important issue for her due to her inability to drive as a result of MS related disability and that she needed to find someone to accompany her to the clinic. However, this inconvenience was balanced off by the convenience of monthly frequency of DMD.

P4N1 "I had to go to Pittsburgh to get the shot so that was like 55 miles away and it was, it would have been more convenient if I could have gotten the infusion somewhere in the Uniontown, but it's nice that you can go one time and get it done with it" Some talked about their inability to self-inject and the need to seek help from others to get injections. In such situations, it was hard to find a person who would inject appropriately. Other issues that were brought up were simply forgetting to take their DMD, running out of medicine while being away from home, and being in a place where it's not convenient to take 
it. Self injecting can be inconvenient to the patients who have disability or aggravated symptoms of MS. It is recommended that the injection site should be rotated periodically in order to allow for a recovery at the injection site and to help to decrease the chances of injection site reactions. However help is required in order to take the shot where patient cannot reach. Patients reported having somebody to give them the injection was very convenient.

P1N2 "I do take it a lot in my stomach. I have a hard time in the back side area because you can reach only so far. I have tried to have my fiancé to try help me and he is deathly afraid so it's all by myself"

P1N5 "If you can get somebody to help yourself, (but) it's hard. If you can find somebody to give you a shot, right there is one (pointing towards his Fiancé'). She got scared to death, you could ask (her)"

P2N3 "I can't reach my shots; my sister gives it to me."

P3N2 "if wasn't for my wife then, you know, be there to help me because I can't do that myself"

P3N3 "I have been a bad girl and run out of medicine, or forgot to take or been away at camp and didn't take enough medicine with me"

P3n4 "I am not needle shy, I am not stick shy. Now after couple of years of poking myself, yeah I got a nurse to do it for me made it easier."

P4N1 "I was self injecting myself. Now my hands I have tremors, so people say you should try it. So I actually have somebody coming in and doing it for me."

P4N2 "I rotate the injection sites. My husband does all of them but my stomach, and I do my 
stomach"

P4n3 "Yeah I pretty much take it, there may be a time or two that I miss because of appointment or something or I am not in place where I can do it but other than that I take it. Three times a week, every time same time all of that."

Those who reported that they do not take their DMDs as prescribed reported following reasons for their non-adherence. Some patients reported needle phobia while some patients simply didn't like the ritual of getting stuck with the needle every now and then.

P1N1 "that took little more courage to jab that needle down in my leg"

P1N2 "It's a hassle to have to take it every day. I know that I should, but I guess since I am young I have the mind frame that I am invincible... I believe if you try to think positively it's going to help you... it's such a low dose that it's ... I kind of rationalize thinking if I skip a day, it will be okay."

P3N2 "I don't look forward to you know getting stuck with the needle, I mean I am not a chicken but you know if I can't get away from it, then I will take it."

P3n5 "I never missed it (DMD), but I wish I would have some time, because I dreaded the shots so much that, you know, I wish I should have missed some days."

P3N6 "I don't like needles. I am a big baby I don't like shots, but I have been taking them."

Theme 4: Perceived or actual value of DMD

Patients provided valuation of DMDs using monetary value and effectiveness of the treatment.

Monetary Valuation 
For one patient cost was a factor that prompted him to split his doses for out-of-pocket costs reasons. Splitting doses can affect treatment outcomes. One patient didn't have any type of insurance and found it hard to pay for the DMDs and had to go without any treatment until he had the insurance that covered his DMD costs. A majority of the patients were aware of the reported cost of DMDs without insurance. Many were concerned about affordability of DMDs in case they lose their health insurance in the future or the Insurance stopped covering their DMD for any reason.

P1n1 "I pay copay, if the insurance didn't pay for it I wouldn't be on it, because there is no way to pay for all this."

P1N4 "For a period of time where I only took one shot every other day because of my insurance, and I had to pay for the whole amount one month's supply myself so I took it every other day instead of every day... to spread it out for two months. Then beginning of next year my insurance picked back-up...."

P1n2 "It doesn't matter how much money you make, there is no way you could physically pay that much money a month that's just not possible but my insurance pays a lot so I am not concerned about paying for it but it's always a scary though at back of your mind that for some reason you lost it then there it's just not possible to continue taking it."

P3N1 "without the insurance there is no way I could afford that"

P3N2 "I don't pay it for personally but if I didn't have insurance, I couldn't afford it. My copay is $\$ 50$ a month my insurance pays the rest of it. And of course that being said one day the insurance company may call and say look we will pay this but you are going to pay more for that." 
P3N4 "without my insurance I would be dead fast, so that to me is a major concern"

P3n5 "I couldn't get the medicines, I didn't have the money"

P3N6 "I had no trouble other than paying to take it"

P4N3 "if they (insurance) stopped covering it, yeah I couldn't take it because it is just too expensive"

High premium for the DMDs was also a concern for patients who were on private plans.

P1N4 "I have to keep paying high premium, so, my concern is the premiums you have to pay"

P1N5 "I had a big issue with how I am going to pay for and everything"

Patients who did not have any insurance or those whose insurance did not cover DMDs sought to receive DMDs through support programs of Pharmaceutical companies. Those patients expressed their gratitude for receiving DMDs.

P3n5 "I am on the support program, thank the lord, they provide the medicine to me, for the month and the only thing that I am required to pay for is the administration itself"

P4N1 "I mean if they (Pharmaceutical company) wouldn't have helped me I wouldn't be taking the medication because I couldn't afford."

Benefit Valuation

Patients valued perceived effectiveness of DMDs in general and believed that taking DMD help them in preventing relapses, maintaining their mobility and vision, and have a better quality of life.

P1N2 "I believe that taking the shots will prevent relapses which will keep me mobile so as long as I take my shots like I am supposed to. Continuing to receive treatment will keep me walking, being able to see, etc" 
P2N3 "I think if I stop taking it, I think maybe I would run into problem. I thought about not taking my drugs just to see what I would be like, but I don't think I can do it, because I think I will be worse"

$\mathrm{P} 3 \mathrm{n} 2$ "there is no cure, but there are treatments, they are better now and you can live a wonderful life enjoying"

P3n3 "the reason more or less I stay with the medicine. I don't want to be dependant yet."

P4N3 "I think the medication keeps me doing the things. I can't do everything like I did before but what I think is that it (DMD) helps me do that, because without it I don't think I will be able to do anything"

Side Effect Valuation

Some patients selected their DMDs with more frequent injections administration over DMDs with less frequent administrations because they didn't want worry about periodic tests to test if there was any issue with liver due to the DMD. Few patients were interested in trying monthly DMD, however, their concern was the chances of adverse event associated with it. However, patients mentioned that they would like to see more data and saw more value in the monthly frequency of administration.

P3n2 "such severe side effects (PML)is a little bit scary so I would like for them to do little more research about that, or what could do about it but cause that was the once a month infusion that would be incredible that you don't have to take shots."

$\mathrm{P} 4 \mathrm{n} 2$ "The reason that I picked my DMD because I didn't want to have to go and have my liver checked, and I wanted the best thing that I thought. And the worst thing about it (DMD) is I have to take it every day. That's a big deal. That versus going to get my labs done all 
the time."

Perceived Cost of Lost Opportunity

One patient who chose not to start using DMDs soon after getting a diagnosis of MS expressed her regret that she should have started taking a DMD soon after diagnosis in order to avoid disability.

P3n1 "I also didn't start the treatment right away. That might have been a bad thing too" Diminishing Utility

There was a false impression with respect to DMDs which revealed that a patient thought that it was okay to stop treatment with DMD after a certain age as it does not help after a certain point.

P3n1 "In the beginning I went to support groups and I had a networking of friends and acquaintances on different drugs and therapies and everyone of them told me, that when you hit 50 you don't have to take the stuff anymore, you can stop."

\section{Theme 5: Expectations from future DMD}

Pills

Although a majority patients reported overall satisfaction with DMDs they were currently taking, many hoped that the future DMDs would be available in easy to administer formulation such as an oral dosage form.

P1n1 "I would like us to have as a pill instead of a shot. Even though I take my shots with no problems."

P1n3 "I would just love to take a pill."

P1n4 "It would be better I think if they could just give you an IV and (it will) last (for) an year. 
Take an IV one day and you are good for an year."

Some felt that having DMD in pill form would improve adherence.

P1n5 "I agree too, because it would be easier to take, and if you take a pill you will not skip it. You will take it."

Repair myelin

Some patients had high expectations from DMDs such as to providing a cure by repairing damaged myelin.

P1N2 "It would be nice if for some reason you having multiple relapses, its causing so much damage so I mean I will have to agree if there was a pill, shot, a liquid, anything that you could take to help repair the damage that will be phenomenal."

P1N4 "I wish they could find the way to repair the myelin that's damaged and causing the nerve not to work right."

P4n1 "I am actually not really concerned about the DMDs as much as I am looking for something that will repair myelin."

Improvement in health

Some patients expect their current DMDs to work in the long term by allowing patients to remain in a stable condition without progressing to a worse condition. They also expected that DMDs would help in regaining strength and mobility.

P2n3 "I am hoping that this treatment that I am taking will last for a long time. In other words, I hope down the road, 10 years from now, I feel like I do now. I am hoping the legs will get stronger, and I won't need a cane or I don't need a walker" 
Cure

Patients were well aware of the fact that currently available DMDs can only reduce the relapse rate and delay the worsening of MS. They expected future MS treatments should cure the condition instead of slowing the course of disease.

P3n2 "Unless that serves a complete cure for this disease, my expectations are not high."

P3N5 "Until you call me and say I got a cure for it I don't really care."

Better than current DMD

One patient expected that the newer DMDs worked better than her existing DMD.

Newer DMDs were not an option for her until they were in the market for a while and used in larger population to make sure there are no concerns associated with it.

P4n3 "But I am kind of the theory and the position now that if it's not broken so don't fix it. If I would stop taking it (current DMD) and take something else, would I do as well? So that's... it (current DMD) works, so stay put. I bet new drugs come out. They have got to be around and I got to see the results and know, because I am asthmatic and I have other problems that I have, so I don't want to create other problems with what I already have. So I need to make sure it works."

Despair

Some patients did not have high expectations from the future DMDs.

P3n4 "I have no expectations. There is no need to get your hopes up"

P4n2 "I know in the real world it will be wonderful if they could come up with the cure and no one would have to go through what we go through. But I know that will never be a possibility." 


\section{Discussion}

To the authors' knowledge, this is the first study to utilize qualitative methods to understand DMD experiences and expectations among MS patients. Using qualitative methods allowed the researchers to understand the broad range of perspectives among patients who had the experience of using one or more DMDs to treat their MS. There was an overall understanding among patients that currently available DMDs used to treat MS are capable of preventing relapse rates more or less to the same extent, and there is no cure available for MS. A majority of patients believed that the DMDs to be effective in preventing their relapses and progression of the disease. Reduction in frequency of relapse was the most important perceived benefit that patients experienced with their DMDs. Other perceived benefits experienced by patients were related to their general sense of well being, ability to stay mobile, be physically active, maintain cognitive health, and experience high energy levels. Relapse rate reduction is one of the most important clinical outcome measures used to determine efficacy of DMDs in clinical trials and clinical practice. Health related quality of life (Using Multiple Sclerosis Impact Scale-29), ability to stay mobile (Expanded Disability Status Scale/Patient Determined Disability Steps), physical activity (Short Form-36/Short Form-12), cognitive health (several cognitive function batteries), and energy levels (Modified Fatigue Impact Scale) are also used routinely in clinical trials, health outcomes studies, and clinical practice. MS affects different aspects of patients' life; hence, the impact of MS on patients is often multidimensional.

Negative experiences with DMDs were related to perceived or experienced lack of efficacy, injection site reactions, and side effects. Patients thought that DMDs just provide a 
security blanket as chances of relapse rate reduction is more or less the same with all the DMDs. Injection site reactions are quite common among patients taking parenteral DMDs. Many patients in our study experienced injection site reactions with their DMDs.

Discontinuation or switching of DMDs among patients in this study was mainly due to injection site reactions and side effects of DMDs. Although the study participants had not experienced any major adverse event due to their DMDs, they shared their concerns about chances of adverse events associated with DMDs in general.

Adherence with DMDs among MS patients is a major issue. A recent systematic review by Giovannoni (2012) indicated that the average rate for DMD discontinuation ranged between $16 \%$ and $27 \%$. Previous studies evaluating adherence and factors influencing adherence to DMDs among MS patients have indicated that a significant number of patients stop taking their DMDs within the first six months after starting therapy (Mohr, 1996; Tremlett, 2003). Higher discontinuation rates for first line DMDs were observed in other long term follow up studies (Rio, 2005; Portaccio, 2008). In this study, the following factors appeared to be associated with adherence: perceived/actual benefit of delaying disability, convenience of administration, frequency of administration, flexibility of administration, perceived quality of life, ability to selfinject, finding help to give injections, forgetting to take it, insurance coverage, not having enough medicine, etc. These findings were consistent with previously published studies (Treadaway, 2009).

A majority of patients in our study had health insurance which covered their DMD and the patients were only responsible for the co-pay amount. Those who did not have any health insurance were receiving their DMDs through support programs. Almost all patients were of 
the opinion that it would be impossible for them to take their DMDs if their insurance did not cover the drug. Prescription coverage for the DMD and adherence were also found to be related. The out-of-pocket costs were of minimal concern for the patients in this study. Other studies have found that with the increasing out-of-pocket costs, the abandonment rates go up (Gleason, 2009). The data also suggests that apart from the monetary valuation, patients constructed value of DMD from the perceived clinical benefit, quality of life, and severe adverse events. It was interesting to know patient valuation of DMDs based on perceived cost of missed opportunity to initiate treatment with DMD after initial diagnosis. Another interesting valuation of DMDs was a perceived diminishing benefit from DMDs.

Although there are different DMD options available for MS patients, the chances of relapse reductions are fairly similar 30\% (Goodin, 2002) and the effectiveness of these DMDs also depend on patient and disease related factors. Currently available DMDs are all injections except one, which is an oral formulation. Acceptability and adherence are always concerns with these treatments. The safety profile of some of newer injectable and oral DMDs is not as favorable as their effectiveness. In our study, patients hoped to see newer DMDs with better mechanisms of action (myelin repair), routes of administration (oral), quality of life, and something that could potentially cure them.

The following limitations should be noted. First, the patients participating in this study were associated with a single clinic affiliated with a teaching hospital. Patients who participated were identified by self-selection, and may not represent other MS patients attending the same clinic. Moreover patients were residents of the Appalachian region. The MS Patient populations from other clinics or geographical areas may have had different 
experiences, opinions, and expectations. A multicenter study involving a larger sample of MS patients could overcome this limitation and provide richer data on patients' experiences, opinions, and expectations. Another limitation is that it is possible that some patients might not have shared negative thoughts about their treatments due to inhibitions although the moderator addressed confidentiality before starting the focus group process. In addition, the moderator disclosed to participants prior to starting focus group discussion that he was not involved in their clinical care which may have affected their responses. Including only those patients who were taking DMDs at the time of participation may have contributed to selection bias. Patients who have discontinued their treatment with DMDs, patients who are newly diagnosed, or those who never took DMDs to treat their MS may have different treatment experiences and expectations.

\section{Conclusion}

Several DMDs for the treatment of MS have shown promising results in phase 3or late stages of drug development. Treatment options for MS patients are expected to increase significantly in the near future. The toxicity profiles of all the new treatments may not be completely known. A possibility of higher risk with treatments with high efficacy and easier routes of administration cannot be ruled out as these drugs would be relatively new and would lack long term safety-efficacy data. This study shows qualitative evaluation of experiences with existing DMDs and expectations of future DMDs from MS patients' perspectives. With continuous improvement in the diagnosis criteria, it is now possible to have early diagnosis of MS. The current outlook on therapeutic management of MS supports early initiation of DMDs in order to achieve optimal clinical outcomes in the long-term. It is possible that patients' 
preferences for benefit risk might differ from that of clinicians. Hence, with the increasing number of treatment choices, MS patients' involvement in complex treatment decisions will become even more crucial. In order to select the best possible treatment for an individual MS patient, it is imperative to choose a treatment that is clinically effective, while keeping their preferences and needs in mind. Improving patients' knowledge about benefits and risks of DMDs and allowing them to actively participate and make informed treatment decisions will be increasingly important and challenging with respect to future treatment. 
Table 2.1: Currently available DMDs for treatment of multiple sclerosis

\begin{tabular}{|c|c|c|c|}
\hline Drug & Brand Name & Route & Frequency \\
\hline Interferon- $\beta-1 a$ & Avonex Biogen & IM & Once a week \\
\hline Interferon- $\beta-1 a$ & Rebif $^{\oplus}$ EMD Serono \& Pfizer & SC & Thrice a week \\
\hline Interferon- $\beta-1 b$ & Extavia ${ }^{\oplus}$ Novartis & $\mathrm{SC}$ & Every other day \\
\hline Interferon- $\beta-1 b$ & Betaseron Bayer & $\mathrm{SC}$ & Once a day \\
\hline Fingolimod & Gilenya ${ }^{\circledast}$ Novartis & Oral & Once a day \\
\hline Glatirimer acetate & Copaxone ${ }^{\oplus}$ Teva & SC & Once a day \\
\hline Mitoxantrone & Novantrone EMD Serono & IV & Once every three months \\
\hline Natalizumab & Tysabri Biogen & IV & Once every 4 weeks \\
\hline
\end{tabular}

IM - Intramuscular Injection
SC - Subcutaneous Injection
IV - Intravenous Infusion 
Table 2.2: Sociodemographic information of focus group participants $(N=18)$

\begin{tabular}{|c|c|c|}
\hline \multicolumn{2}{|c|}{ Sociodemographic Variable } & Subjects, n (\%) \\
\hline \multicolumn{3}{|l|}{ Sex } \\
\hline & Male & 7 (39) \\
\hline & Female & $11(61)$ \\
\hline \multicolumn{3}{|c|}{ Marital status } \\
\hline & Single & $4(22)$ \\
\hline & Married & $12(67)$ \\
\hline & Divorced or Separated & $2(11)$ \\
\hline \multirow[t]{2}{*}{ Age } & Years (Mean \pm SD) & $48.50( \pm 14.43)$ \\
\hline & (Range in years) & $26-70$ \\
\hline \multicolumn{3}{|l|}{ Race } \\
\hline & White/Caucasian & $18(100)$ \\
\hline \multicolumn{3}{|c|}{ Education } \\
\hline & Some high school or less & $1(6)$ \\
\hline & High school graduate or GED & $5(28)$ \\
\hline & Vocational College or some college & $6(33)$ \\
\hline & College degree & $4(22)$ \\
\hline & Graduate/ professional degree & $2(11)$ \\
\hline \multicolumn{3}{|c|}{ Insurance } \\
\hline & Private health insurance & $5(28)$ \\
\hline & $\begin{array}{l}\text { Government health insurance } \\
\text { (Medicare/Medicaid) }\end{array}$ & $10(55)$ \\
\hline & Uninsured & $3(17)$ \\
\hline \multicolumn{3}{|c|}{ Employment status } \\
\hline & Employed/self-employed full time & $4(22)$ \\
\hline & Retired & $4(22)$ \\
\hline & Homemaker & $1(6)$ \\
\hline & Unable to work due to MS & $9(50)$ \\
\hline \multicolumn{3}{|c|}{ Household income } \\
\hline & $<\$ 25,000$ & $5(28)$ \\
\hline & $\$ 25,000-\$ 49,999$ & $7(38)$ \\
\hline & $\$ 50,000-\$ 99,999$ & $5(28)$ \\
\hline & Refuse to answer & $1(6)$ \\
\hline
\end{tabular}


Table 2.3: Multiple sclerosis history and treatment information of focus group participants $(\mathrm{N}=18)$

\begin{tabular}{|c|c|}
\hline MS related Variable & Subjects, n (\%) \\
\hline \multicolumn{2}{|l|}{ Time since diagnosis of $\mathrm{MS}$} \\
\hline$<5$ years & $5(28)$ \\
\hline $5-10$ years & $5(28)$ \\
\hline$>10$ years & $8(44)$ \\
\hline \multicolumn{2}{|l|}{ Primary diagnosis } \\
\hline Primary progressive & $2(11)$ \\
\hline Secondary progressive & $1(6)$ \\
\hline Relapsing remitting & $12(67)$ \\
\hline Progressive relapsing & $1(6)$ \\
\hline Don't know & $2(11)$ \\
\hline \multicolumn{2}{|l|}{ Time since initiation of DMD } \\
\hline$\leq 5$ years & $8(44)$ \\
\hline$>5$ years & $10(55)$ \\
\hline \multicolumn{2}{|l|}{ Current DMD } \\
\hline Avonex & $5(28)$ \\
\hline Rebif & $4(22)$ \\
\hline Betaserone & $1(6)$ \\
\hline Copaxone & $5(28)$ \\
\hline Tysabri & $2(11)$ \\
\hline Drug in a clinical trial & $1(6)$ \\
\hline \multicolumn{2}{|l|}{ Past use of the following DMD* } \\
\hline Avonex & $9(50)$ \\
\hline Rebif & $6(33)$ \\
\hline Betaserone & $2(11)$ \\
\hline Copaxone & $10(55)$ \\
\hline Novantrone & $1(6)$ \\
\hline Tysabri & $3(17)$ \\
\hline Drug in a clinical trial & $1(6)$ \\
\hline \multicolumn{2}{|l|}{ Prescription drug coverage } \\
\hline Yes & $15(83)$ \\
\hline No & $3(17)$ \\
\hline
\end{tabular}

*- Responses not exclusively limited to one DMD hence the percentage will not add to $100 \%$ 


\section{References}

1. Blackwell GM. Interviewing methods. In BlackwellG, Hammond S, Fife-Schaw C, Smith J, eds. Research Methods in Psychology. ${ }^{3 r d}$ edition. Los Angeles, CA: Sage Publications, 2006:232-253.

2. Coles A. Multiple sclerosis. Pract Neurol. 2009 Apr;9(2):118-26.

3. Confavreux C, Aimard G, Devic M. Course and prognosis of multiple sclerosis assessed by the computerized data Processing of 349 patients. Brain. 1980;103: 281-300.

4. Cox D, Stone J. Managing self-injection difficulties in patients with relapsing-remitting multiple sclerosis. J Neurosci Nurs. 2006;38:167-71.

5. Cramer JA. Consequences of intermittent treatment for hypertension: the case for medication compliance and persistence. Am J Manag Care. 1998;4:1563-68.

6. Cramer JA, Cuffel BJ, Divan V, Al-Sabbagh A, Glassman M. Patient satisfaction with an injection device for multiple sclerosis treatment. Acta Neurol Scand. 2006 Mar;113(3):156-62.

7. Dunbar-Jacob J, Erlen JA, Schlenk EA, Ryan CM, Sereika SM, Doswell WM. Adherence in chronic disease. Annu Rev Nurs Res. 2000;18:48-90.

8. Dutta R, Trapp BD. Pathogenesis of axonal and neuronal damage in multiple sclerosis. Neurology. 2007 May 29;68(22 Suppl 3):S22-31; discussion S43-54.

9. Giovannoni G, Southam E, Waubant E. Systematic review of disease-modifying-therapies to assess unmet needs in multiple sclerosis: tolerability and adherence. Mult Scler. 2012 Jan 16. [Epub ahead of print] PubMed PMID22249762. 
10. Gleason PP, Starner Cl, Gunderson BW, Schafer JA, Sarran HS. Association of prescription abandonment with cost share for high-cost specialty pharmacy medications. J Manag Care Pharm. 2009;15(8):648-658.

11. Goodin DS, Frohman EM, Garmany GP Jr, Halper J, et al. Disease modifying therapies in multiple sclerosis: report of the Therapeutics and Technology Assessment Subcommittee of the American Academy of Neurology and the MS Council for Clinical Practice Guidelines. Neurology. 2002 Jan 22;58(2):169-78.

12. Lublin FD, Reingold SC. Defining the clinical course of multiple sclerosis: results of an international survey. National Multiple Sclerosis Society (USA) Advisory Committee on Clinical Trials of New Agents in Multiple Sclerosis. Neurology. 1996 Apr;46(4):907-11.

13. Mohr DC, Goodkin DE, Likosky W, Gatto N, Neilley LK, Griffin C et al . Therapeutic expectations of patients with multiple sclerosis upon initiating interferon beta $1 \mathrm{~b}$ : relationships to adherence to treatment. Mult Scler. 1996; 2: 222-26.

14. National Multiple Sclerosis Society 2011. Available at:

http://www.nationalmssociety.org/about-multiple-sclerosis/what-we-know-aboutms/who-gets-ms/index.aspx Accessed on February 10, 2012.

15. Panitch H, Goodin DS, Francis G, Chang P, Coyle PK, O'Connor P et al. Randomized, comparative study of interferon beta-1a treatment regimens in MS: The EVIDENCE Trial. Neurology. 2002;59:1496-506.

16. Portaccio E, Zipoli V, Siracusa G, Sorbi S, Amato MP. Long-term adherence to interferon beta therapy in relapsing-remitting multiple sclerosis. Eur Neurol. 2008;59:131-135. 
17. Río J, Porcel J, Téllez N, Sánchez-Betancourt A, Tintoré M, Arévalo MJ, Nos C, Montalban X. Factors related with treatment adherence to interferon beta and glatiramer acetate therapy in multiple sclerosis. Mult Scler. 2005 Jun;11(3):306-9.

18. Rudick RA, Miller DM. Health-related quality of life in multiple sclerosis: current evidence, measurement and effects of disease severity and treatment. CNS Drugs. 2008;22(10):827-39.

19. Rudick RA. Multiple sclerosis, natalizumab, and PML: Helping patients decide. Cleve Clin J Med. 2011 Nov;78 Suppl 2:S18-23.

20. Samuel L, Lowenstein EJ. Recurrent injection site reactions from interferon beta 1-b. J Drugs Dermatol. 2006;5:366-67.

21. Sim J. Collecting and analysing qualitative data: issues raised by the focus group. J Adv Nurs. 1998 Aug;28(2):345-52.

22. Thompson AJ. Symptomatic management and rehabilitation in multiple sclerosis. $J$ Neurol Neurosurg Psychiatry. 2001;71 Suppl 2:ii22-ii27.

23. Treadaway K, Cutter G, Salter A, et al. Factors that influence adherence with diseasemodifying therapy in MS. J Neurol. 2009;256(4):568-576.

24. Tremlett HL, Oger J. Interrupted therapy. Stopping and switching of the b-interferons prescribed for MS. Neurology. 2003; 61: 551-/54.

25. Weinshenker BG, Bass B, Rice GP, Noseworthy J, Carriere W, Baskerville J et al. The natural history of multiple sclerosis: a geographically based study. I. Clinical course and disability. Brain. 1989;112 ( Pt 1):133-46. 
CHAPTER 3 


\title{
CHAPTER 3
}

\section{BENEFIT-RISK PREFERENCES FOR DISEASE MODIFYING TREATMENT AMONG MULTIPLE SCLEROSIS PATIENTS}

\begin{abstract}
Objective: To use choice based, stated preference method to estimate preference weights and relative importance of attributes for disease modifying drugs (DMDs) used in the treatment of multiple sclerosis (MS).

Methods: A total of 3,743 individuals with MS who resided in the US were invited to participate in an online survey. These individuals were part of an MS registry and an online medication monitoring service provider in the United States (US). The survey questionnaire included nine choice-based conjoint tasks. Each task involved two hypothetical DMD alternatives described using seven attributes: treatment administration (mode), evidence on treatment outcomes in years (evidence on outcomes), number of relapses within 5 years (relapses), delaying disability progression by ' $n$ ' years (delaying disability progression), severe disability or death from progressive multifocal leukoencephalopathy (PML) within 5 years, severe liver dysfunction within 5 years (liver dysfunction), and experiencing flu-like symptoms following DMD administration (flu-like symptoms). Each attribute had 3 levels. Relative importance of DMD attributes and attribute levels were estimated using c-logit regression model. Parameter estimates of all attribute levels were rescaled in the range of 0 to 10 and grouped by attribute.
\end{abstract}


Results: A total of 897 individuals completed the survey ( $24 \%$ Response rate). PML was the most important attribute followed by liver dysfunction, flu-like symptoms, delaying disability progression, relapses, and mode of DMD administration. Evidence on treatment outcomes in years was the least important attribute to patients. The results of this study indicate a preference for DMDs that have lower chances of severe adverse events (SAE) like PML and Liver Dysfunction, and side effects affecting day to day functioning such as flu-like symptoms. Participants also indicated a preference for lower relapse rate, delayed worsening of MS, treatment in pill form, and stronger evidence on DMD outcomes in terms of number of years. Conclusions: The results of this study indicate that efficacy and convenience of administration are important factors in a DMD; however adverse events and side effects associated with DMDs still continue to be the cause of concern for MS patients. The results show a need to address patients' concerns surrounding the adverse events to optimize selection of DMDs for MS patients. 


\section{Introduction}

MS is a neurological condition that typically affects young adults between $20-40$ years of age (Confavreux, 1980), precisely during the most active and productive period in their lives, making it the leading cause of non traumatic disability in young adults (Dutta, 2007). Although there is no cure for MS, advances in pathophysiological understanding of MS over the past two decades have led to several therapeutic alternatives, commonly known as disease modifying drugs (DMD). National Multiple Sclerosis Society recommends initiation of DMDs in patients soon after they are diagnosed with MS. Seven DMDs are currently approved by the United States Food and Drug Administration (US FDA) for the treatment of MS. Six of these DMDs are available as injection and only one DMD is available in oral form. Primary goal of available DMDs is to reduce relapse rate and to delay progression of MS (Montalban, 2007). Several promising therapies are currently being studied in late phase clinical trials. In future, DMDs with different mechanisms of action, formulations, modes of administration, and frequencies of administration are expected to foray in the market resulting in an increase in the choice of DMDs for patients and clinicians.

Therapeutic decisions in MS can be challenging due to the inconvenience of administration, frequency of administration, longer duration of therapy, and side effects associated with DMDs. These factors can also contribute to reducing patients' adherence with DMDs. In order to make optimal therapeutic decisions with respect to DMDs, a better understanding of DMD preferences among individuals with MS is required. A stated preference method, such as conjoint analysis has been increasingly utilized to elicit patients' preferences for health care interventions and treatment outcomes (Bridges, 2003; Bridges, 2012). As the 
DMD options are increasing, involvement of MS patients will be ever more vital in therapeutic decision making and the success of it thereof. With the growth of evidence based health care, understanding what patients prefer in their treatments would not only improve patient care but also aid in achieving the best possible treatment outcomes. Although patient preferences have been studied for a range of therapies for various health conditions, only one published study evaluated benefit-risk preferences for DMDs in patients diagnosed with MS (Johnson, 2009). This study utilized attributes associated with DMD efficacy and mortality risk. However, patients may define DMDs using attributes additional to those used in a previous study. The attributes of DMD used in the treatment of MS included in this study were developed using rigorous qualitative interviews with MS patients reflecting attributes used by them to evaluate DMDs.

The purpose of this study was to use a choice based, stated preference method to estimate preference weights and relative importance of attributes for DMDs used in the treatment of MS.

\section{Methods}

Conjoint analysis is a method based on the assumption that any product, service, or intervention can be defined by its attributes and the value of such product, service, or intervention for an individual depends on the level of its attributes (Ryan, 2000). Conjoint analysis is a valid, reliable, and commonly used technique in evaluating attributes that are preferred by patients in their treatments along with the magnitude of each attribute that influenced their preferences (Ryan, 1997; Johnson, 2007). In conjoint analysis, preference by 
patients assigned weights to different treatment attributes are quantified by asking patients to choose between 2 or more treatment choices where treatment options are varied by the levels of predefined treatment attributes (Bridges, 2007; Bridges, 2003; Johnson, 2010). Conjoint analysis has its roots in mathematical psychology and economics (McFadden, 1973; Anderson, 1977), and is commonly used in market research (Green, 1978; Green, 1990), transport economics (Louviere, 1988), environmental economics (Ch.Gan, 1993), healthcare services (Ryan, 2000), and medicine (Bridges, 2008). Our study was guided by good research practices laid out by the ISPOR Conjoint Analysis Task Force (Bridges, 2010).

\section{Survey Development}

Salient features of DMDs used in the treatment of MS were identified using focus group discussion with MS patients, literature review, and consulting with neurologists and neurology research nurses treating MS patients. Four focus group discussion sessions involving a total of 18 individuals with self-reported clinician confirmed diagnosed of MS were conducted. All patients had experience of using DMDs to treat their MS. Focus group discussions were audio recorded and transcribed. Transcripts were analyzed by 2 blinded reviewers to identify DMD attributes and respective levels. The neurologist and neurology research nurse treating MS patients were consulted prior to the final selection of attributes and their levels. Seven DMD attributes with three levels each were used in the survey (Table 3.1). Two attributes were related to DMD benefit (reduction in the number of relapses in the next 5 years and delay in the progression of MS), three attributes were related to risks associated with DMDs (severe disability or death from PML, severe liver dysfunction, and flu-like symptoms), mode of DMD administration, and evidence on outcomes in terms number of years of research. 
A brief description of measures of outcomes (attributes) and objective of choice questions were provided to all patients for them to better improve comprehension of choice tasks. The initial version of the web based survey was pretested using in-person, open ended interviews. The objective of pretesting the survey questionnaire was to determine cognitive and time burden. Seven patients with MS between 24-60 years of age participated. All participants had a clinician diagnosed MS, current use of DMD, and relapse-free at the time of pretesting. Patients in the pretesting phase reported that they understood the explanation tasks completely and accepted trade-off among DMD attributes. Understanding of meaning of attributes (benefit/risks) with respect to DMDs, time taken to complete the survey, ease/difficulty in understanding meaning of terms, font, colors, etc were also evaluated. Information gathered during the pretest was utilized to make small changes related to number of words, ordering of questions, font size, and questions per screen in the web based survey. In the final web-based survey, each task had 2 treatment choices with varying levels of attributes. An example of a choice task is shown in Figure 3.1. Using seven attributes mentioned above with three levels each, 2,187 unique treatment profiles were generated. Using 2,187 profiles one could create approximately 2.4 million different pairs. A D-optimal experimental design which consisted of 81 choice pairs was generated. Minimal overlap in the levels of attributes was allowed in order to avoid lexicographic responses by patients. The design met the criteria for level balance, orthogonality, and utility balance (Ryan, 2008). In order to reduce cognitive and response burden, these pairs were divided into 9 blocks comprising of 9 choice tasks per block. Each patient randomly received 1 out of 9 blocks. One 
choice task from any given block was repeated at the end of $9^{\text {th }}$ choice task which was used for the purpose of response validation (Johnson, 2009).

\section{Survey Respondents}

The web-based survey was developed using Qualtrics survey software. Patients diagnosed with MS were recruited using two separate panels of MS patients in the US. Details of survey participants are provided in Figure 3.2. The first panel comprised of MS patients who are subscribers of www.MediGuard.org, which is a free medication monitoring service that provides patients with safety alerts, recalls, a check for drug interactions, and other drug related updates. The second panel was comprised of MS patients from the Biogen Idec Mailing list. Participants were required to be 18 years of age or older, have a self reported clinician confirmed diagnosis of MS, and have current residence in the United States. Web-based survey was administered from August 2011 through November 2011. All participants completing the survey received a $\$ 25$ gift card as an incentive for their participation. Apart from conjoint analysis choice tasks, all patients were asked to provide information on sociodemographic characteristics, patients' experiences with multiple sclerosis, treatment history, health status, health related quality of life, and satisfaction with current treatment. This study was approved by the West Virginia University Institutional Review Board. Out of 971 patients who completed the survey, 897 passed the data validity checks.

\section{Statistical Analysis}

We estimated preference weights for each level of attribute using c-logit regression. Dependant variable in the regression model was the preferred treatment profile from the choice tasks whereas the Independent variables in the c-logit regression model included 
attribute levels given in table 3.1. Each attribute had three levels, and rather than dummy coding attribute levels where one level would be used as reference category, attribute levels were effect coded in order to allow parameter estimation for all attribute levels. Effect coding was done by excluding one attribute level and coding the remaining two levels as 1 in the treatment profiles where that level was shown and the excluded category was coded as 0 if it was not present in the treatment profile and -1 if it was present. In the effect coding, mean effect for each attribute is represented by zero (Bridges, 2011; Johnson, 2010). The negative sum of the parameter estimates that were included yields a parameter estimate for the excluded attribute level (Hensher, 2005).

Relative importance weights were calculated for each attribute with reference to the levels used for each of them. For example, relative Importance for an attribute (Number of relapses within 5 years) was estimated as the difference in the probability of highest level ( 0 relapse within next 5 years) and the lowest level (6 relapses within next 5 years). Using the same method, relative importance weights were calculated for other attribute. Importance weights were converted for the most important attribute to 10 and the importance scores were calculated for the remaining attributes relative to the most important attribute (Hauber, 2010b).

\section{Results}

\section{Survey Population Characteristics}

Email invitations were sent to a total of 3,743 subscribers in both panels. There were 1,097 individuals who accessed the survey. However, valid data for conjoint analysis was 
available for 897 respondents with a response rate of approximately $24 \%$ (Figure 3.2). A summary of respondents' sociodemographic characteristics is shown in table 3.2. A majority of respondents were female (85\%), living with the partner $(61.2 \%)$, White $(87 \%)$, post high school education. The mean age of respondents was 50.51 years (SD 9.89). Nearly half of the respondents reported an annual household income less than $\$ 50,000$. A majority of the participants were not employed out of which approximately $43 \%$ were not able to work due to their MS. Respondents represented different regions throughout the US.

A summary of respondents' multiple sclerosis and treatment related characteristics is shown in table 3.3. The mean duration since the MS diagnosis was 11.48 years $(S D=8.25)$. The mean age at which respondents were diagnosed with MS was 39.04 years (SD 9.89). More than half of respondents reported experiencing 6 or more symptoms associated with MS. The mean total number of relapses experienced in the last 12 months by the patients was 1.40 (SD=2.01). Patients were distributed across all disability levels. A majority of patients (73\%) reported current use of DMD for the treatment of their MS. Approximately $62 \%$ of the respondents reported past use of DMDs.

\section{Preference Weights}

Differences in demographic and MS related characteristics of the respondents from both panels were compared using chi square tests and analysis of variance (ANOVA) for independent samples. Significant differences were found in all sociodemographic and MS related characteristics, except in marital status and region. The parameter estimates for attribute levels were compared to determine whether the preference weights were significantly different across the two patient samples (Johnson, 2009). The data showed no 
difference in the preference weights of the two samples, hence we pooled the data from two panels and aggregate results were used for interpretation.

Parameter estimates for all attribute levels are presented in table 3.4. Preference weights showed a natural order of preference of levels confirming that patients comprehended the differences in the three levels of any given attribute in the choice tasks. Patients indicated their preferences for lower levels of severity for severe disability or death from PML within 5 years, severe liver dysfunction within 5 years, and flu-like symptoms (Figure 3.3). Preferences for attribute levels associated with benefits suggested higher utility for larger gains in terms of no relapse within the next 5 years and delaying progression of MS by 15 years (Figure 3.3). With respect to mode of treatment administration, patients preferred pills over injection and infusion, respectively. Patients also indicated a higher preference for treatments with stronger evidence on outcomes where a treatment with 15 years of research was preferred over 10 years of research and 5 years of research, respectively.

\section{Relative Importance}

Relative importance scores for all treatment attributes are presented in Figure 3.4. Of all the attributes included in this study, severe disability or death from PML within 5 years was ranked as the most important attribute followed by severe liver dysfunction within 5 years and within 5 years (relative importance score of 9.96). Remaining attributes were ranked in the following order: flu-like symptoms (importance score of 7.11), delaying progression of MS (importance score of 6.72), number of relapses within 5 years (importance score of 6.64), treatment administration (importance score of 4.13), and evidence on outcomes (importance score of 2.74). 


\section{Internal Validity Tests}

Choosing between hypothetical treatment profiles requires respondents to understand the purpose of experiment. This 'task' can be challenging to comprehend for some participants. Checking the quality of responses with respect to conjoint analysis data is an important step, especially in the case of MS patients as there is a possibility of difficulty in understanding the choice tasks, as MS could affect their cognition, limiting their ability to comprehend complex tasks. However, out of the 971 individuals who completed the survey, only $7.62 \%$ of the respondents did not pass the internal validity check. Seventy (7.20\%) respondents failed the stability test. Only 4 individuals were found to select either Treatment $A$ (or B) for all the 10 choice tasks.

\section{Discussion}

A majority of the currently approved DMDs for MS are used parenterally. Only one oral DMD has been approved so far. All available DMDs have their own set of benefits and side effects, other than differences in route and frequency of administration. The evidence on safety and efficacy data also varies in terms of number of years.

In the last two decades there has been a marked increase in the emergence of various DMDs for the treatment of MS. These agents help by reducing the relapses by about $30 \%$ (Goodin, 2003). However, efficacy of these immunomodulatory agents varies depending on several personal and MS related characteristics. Adherence and satisfaction with DMDs are surrounded by the complexity in choosing a DMD and individual needs of MS patients to 
manage disease progression and symptoms related to their condition. Clinical and health outcomes are associated with the use of DMDs.

Trade-offs observed between attributes in the patients' responses to hypothetical treatment choices implied that they understood the choice tasks. Patients made trade-offs between benefits, risks, mode of administration, and evidence on outcomes (in years). Risk attributes PML and liver failure were the most valued attributes, respectively. These two attributes had almost equal weight in terms of relative importance. Flu-like symptoms associated with DMDs are known to affect patient day to day activities following administration. Relapse frequency and disability progression are routinely used as treatment outcome measures in clinical trial and routine practice. Relapse rate reduction and delay in disability progression had just about equal weights. Treatment administration had relatively less effect on treatment preferences as compared to benefit and risk attributes. Patients placed high value on oral DMDs compared to parenteral DMDs. Evidence on outcomes was the least important attribute implying that although DMDs with stronger evidence were valued, safety; efficacy, and route of administration were more important in selecting a DMD in given hypothetical treatment choices.

Only one previous study evaluated MS patients' benefit risk preferences in the context of maximum acceptable risks (Johnson, 2009). In that study, five attributes were used to define a DMD. Two efficacy attributes were used: reduction in the number of relapses in the next 5 years and delay (in years) to disability progression. Three were related to DMD risks: death or severe disability from PML, death from liver failure, and death from leukemia. As per the authors' understanding, this is the second study to evaluate patient preferences for benefits 
and risks along with two key attributes, treatment administration and evidence on outcomes, respectively associated with DMDs used in the MS treatment. The three attributes that were not used in the previous study: Treatment administration, Evidence on outcome, and Flu-like symptoms, respectively, were derived from the in-depth focus group discussions with MS patients. Focus groups are a qualitative research method strongly recommended to generate list of attributes for conjoint analysis (Coast, 2007).

Although conjoint analysis allows the study of patients' valuation of treatment attributes, this method has some limitations. One of the main limitations, is that patients are asked to compare between treatment options that are hypothetical in nature. The treatment choices do not have any the real life consequences. However, this limitation was overcome to a certain extent by including treatment profiles that were realistic and clinically relevant (Hauber, 2010a). Patient preferences in conjoint analysis do not necessarily reflect real life decisions. In this study, preference weights are estimated for aggregate data. Stratification of data based on demographic or clinical factors might reveal different preference weights, which was beyond the scope of this study. In conjoint analysis, it is expected that respondents pay attention to all attributes and levels before selecting a treatment profile. It can be difficult to comprehend for respondents under many circumstances (Bridges, 2003). Data quality tests (described above) in our study were performed to overcome this limitation. The sample for this study was subscribers from the two panels who self-reported a clinician confirmed diagnosis of MS. Four regions in the US were represented in the sample. It is unknown if this is a representative national sample of MS patients. The results of this study should be interpreted in the context of attributes used to define DMDs used in MS. 


\section{Conclusion}

With one oral DMD for MS treatment already in the market, many more are anticipated in the future. These oral therapies are going to provide much needed relief to MS patients and clinicians, as far as ease of administration and adherence issues are concerned. However, just as these oral therapies would provide certain benefits, the long-term efficacy and side effect profile will not be fully known, as compared to the existing first line therapy. In this study, although patients preferred oral mode of administration over parenteral, it was evident that patients still place higher value on efficacy and safety attributes of DMDs. In the future, eliciting physician' benefit risk preferences for DMDs used in MS treatment would help in comparing patient and physician DMD benefit risk preferences. Such information, in turn, can be used to determine strategies to achieve medication concordance. Data from this study also encourage the use of stated preference methods in routine practice, as well as in clinical trials to better understand patients' treatment preferences and to design better benefit risk communication strategies. 
Table 3.1: Treatment attributes and levels

\begin{tabular}{|ll|}
\hline \multicolumn{1}{|c|}{ Attributes } & \multicolumn{1}{c|}{ Levels } \\
\hline 1. Treatment administration & $\begin{array}{l}\text { Pills at home } \\
\text { Injection at home } \\
\text { Infusion at clinic }\end{array}$ \\
2. Evidence on outcomes & 5 years of research \\
& 10 years of research \\
& 15 years of research \\
3. Number of relapses within 5 years & 0 relapse \\
& 3 relapses \\
& 6 relapses \\
4. Progression of MS & Delayed by 5 years \\
& Delayed by 10 years \\
& Delayed by 15 years \\
5. Severe disability or death from PML & None \\
within 5 years & 4 patients out of 1000 \\
& 8 patients out of 1000 \\
6. Severe liver dysfunction within 5 years & None \\
& 10 patients out of 1000 \\
& 20 patients out of 1000 \\
7. Flu-like symptoms & None \\
& Mild \\
& Severe \\
\hline
\end{tabular}


Table 3.2: Summary of participants' sociodemographic characteristics

\begin{tabular}{|c|c|c|c|c|}
\hline Sociodemographic Variable & $\mathbf{n}$ & Categories & Total Sample & $\% / S D$ \\
\hline Age (in years) & 883 & Range: $22-80$ & 50.51 & 9.89 \\
\hline \multirow{2}{*}{ Gender } & \multirow{2}{*}{883} & Female & 751 & 85.1 \\
\hline & & Male & 132 & 14.9 \\
\hline \multirow{2}{*}{ Marital Status } & \multirow{2}{*}{883} & Without partner & 343 & 38.8 \\
\hline & & With partner & 540 & 61.2 \\
\hline \multirow{2}{*}{ Race } & \multirow{2}{*}{884} & White & 769 & 87.0 \\
\hline & & Other & 115 & 13.0 \\
\hline \multirow{4}{*}{ Education } & \multirow{4}{*}{884} & High school or less & 145 & 16.4 \\
\hline & & Some college & 365 & 41.3 \\
\hline & & Bachelor & 262 & 29.6 \\
\hline & & Masters or above & 112 & 12.7 \\
\hline \multirow{5}{*}{ Income } & \multirow{5}{*}{883} & $<\$ 25,000$ & 226 & 25.6 \\
\hline & & $\$ 25,001-\$ 50,000$ & 253 & 28.7 \\
\hline & & $\$ 50,001-\$ 75,000$ & 202 & 22.9 \\
\hline & & $\$ 75,001-\$ 100,000$ & 112 & 12.7 \\
\hline & & $>\$ 100,000$ & 90 & 10.2 \\
\hline \multirow{4}{*}{ Employment } & \multirow{4}{*}{884} & Full time & 238 & 26.9 \\
\hline & & Part time & 97 & 11.0 \\
\hline & & Not Working & 168 & 19.0 \\
\hline & & Unable to work due to MS & 381 & 43.1 \\
\hline \multirow{4}{*}{ Region } & \multirow{4}{*}{884} & Northeast & 197 & 22.3 \\
\hline & & Midwest & 227 & 25.7 \\
\hline & & South & 289 & 32.7 \\
\hline & & West & 171 & 19.3 \\
\hline
\end{tabular}


Table 3.3: Summary of participants' multiple sclerosis related characteristics

\begin{tabular}{|c|c|c|c|c|}
\hline MS related Variable & $\mathbf{n}$ & Categories & $\begin{array}{c}\text { Total } \\
\text { Sample }\end{array}$ & $\% / S D$ \\
\hline Time since diagnosis of MS (in years) & 896 & Range: $<1-48$ & 11.48 & 8.25 \\
\hline Age at MS diagnosis (in years) & 882 & Range: 9-68 & 39.04 & 9.89 \\
\hline \multirow{5}{*}{ Total number of MS related symptoms } & \multirow{5}{*}{897} & 0 symptom & 15 & 1.7 \\
\hline & & 1-5 symptoms & 258 & 28.8 \\
\hline & & 6-10 symptoms & 344 & 38.4 \\
\hline & & $11-15$ symptoms & 216 & 24.1 \\
\hline & & $16-20$ symptoms & 64 & 7.1 \\
\hline Number of relapses in past 12 months & 893 & - & 1.40 & 2.02 \\
\hline \multirow{9}{*}{ Patient Determined Disability Status } & \multirow{9}{*}{897} & Normal & 158 & 17.6 \\
\hline & & Mild Disability & 161 & 17.9 \\
\hline & & Moderate Disability & 115 & 12.8 \\
\hline & & Gait Disability & 133 & 14.8 \\
\hline & & Early Cane & 124 & 13.8 \\
\hline & & Late Cane & 87 & 9.7 \\
\hline & & Bilateral Support & 61 & 6.8 \\
\hline & & Wheelchair / Scooter & 52 & 5.8 \\
\hline & & Bedridden & 6 & $>1.0$ \\
\hline \multirow{2}{*}{ Current DMD use } & \multirow{2}{*}{897} & No & 242 & 27.0 \\
\hline & & Yes & 655 & 73.0 \\
\hline \multirow{2}{*}{ Past use of DMD } & \multirow{2}{*}{897} & No & 337 & 37.6 \\
\hline & & Yes & 560 & 62.4 \\
\hline
\end{tabular}


Table 3.4: Parameter estimates for disease modifying drug attributes

\begin{tabular}{|c|c|c|c|c|c|}
\hline Attribute Name & Variable Name & Coefficient & SE & test-stat & Sig. \\
\hline $\begin{array}{l}\text { Treatment } \\
\text { administration }\end{array}$ & $\begin{array}{l}\text { Pills at home } \\
\text { Injection at home } \\
\text { Infusion at clinic }\end{array}$ & $\begin{array}{r}0.311 \\
-0.045 \\
-0.266\end{array}$ & $\begin{array}{l}0.026 \\
0.024 \\
0.025\end{array}$ & $\begin{array}{c}12.120 \\
-1.86 \\
-10.475\end{array}$ & $\begin{array}{c}* * * \\
0.063 \\
* * *\end{array}$ \\
\hline $\begin{array}{l}\text { Evidence on } \\
\text { outcomes (in Years) }\end{array}$ & $\begin{array}{l}5 \text { Years of research } \\
10 \text { Years of research } \\
15 \text { Years of research }\end{array}$ & $\begin{array}{l}-0.233 \\
0.082 \\
0.151\end{array}$ & $\begin{array}{l}0.026 \\
0.025 \\
0.026\end{array}$ & $\begin{array}{l}-8.940 \\
3.290 \\
5.918\end{array}$ & $\begin{array}{l}* * * \\
* * \\
* * *\end{array}$ \\
\hline $\begin{array}{l}\text { Number of relapses } \\
\text { within } 5 \text { years }\end{array}$ & $\begin{array}{l}0 \text { Relapses } \\
3 \text { Relapses } \\
6 \text { Relapses }\end{array}$ & $\begin{array}{l}0.492 \\
-0.056 \\
-0.436\end{array}$ & $\begin{array}{l}0.026 \\
0.025 \\
0.026\end{array}$ & $\begin{array}{l}18.750 \\
-2.250 \\
-16.473\end{array}$ & $\begin{array}{c}* * * \\
* \\
* * *\end{array}$ \\
\hline $\begin{array}{l}\text { Delaying } \\
\text { progression of MS }\end{array}$ & $\begin{array}{l}5 \text { Years of delay } \\
10 \text { Years of delay } \\
15 \text { Years of delay }\end{array}$ & $\begin{array}{l}-0.566 \\
0.192 \\
0.374\end{array}$ & $\begin{array}{l}0.026 \\
0.026 \\
0.025\end{array}$ & $\begin{array}{c}-21.520 \\
7.410 \\
14.682\end{array}$ & $\begin{array}{l}* * * \\
* * * \\
* * *\end{array}$ \\
\hline $\begin{array}{l}\text { Severe disability or } \\
\text { death from PML } \\
\text { within } 5 \text { years }\end{array}$ & $\begin{array}{l}0 \text { out of } 1000 \text { patients } \\
4 \text { out of } 1000 \text { patients } \\
8 \text { out of } 1000 \text { patients }\end{array}$ & $\begin{array}{l}0.757 \\
-0.116 \\
-0.641\end{array}$ & $\begin{array}{l}0.026 \\
0.025 \\
0.026\end{array}$ & $\begin{array}{l}29.090 \\
-4.670 \\
-25.099\end{array}$ & $\begin{array}{l}* * * \\
* * * \\
* * *\end{array}$ \\
\hline $\begin{array}{l}\text { Severe liver } \\
\text { dysfunction within } 5 \\
\text { years }\end{array}$ & $\begin{array}{l}0 \text { out of } 1000 \text { patients } \\
10 \text { out of } 1000 \text { patients } \\
20 \text { out of } 1000 \text { patients }\end{array}$ & $\begin{array}{l}0.772 \\
-0.151 \\
-0.621\end{array}$ & $\begin{array}{l}0.027 \\
0.025 \\
0.026\end{array}$ & $\begin{array}{l}28.660 \\
-6.030 \\
-23.714\end{array}$ & $\begin{array}{l}* * * \\
* * * \\
* * *\end{array}$ \\
\hline Flu-like symptoms & $\begin{array}{l}\text { None } \\
\text { Mild } \\
\text { Severe }\end{array}$ & $\begin{array}{r}0.355 \\
0.284 \\
-0.639\end{array}$ & $\begin{array}{l}0.025 \\
0.025 \\
0.026\end{array}$ & $\begin{array}{l}14.070 \\
11.350 \\
-24.169\end{array}$ & $\begin{array}{l}* * * \\
* * * \\
* * *\end{array}$ \\
\hline
\end{tabular}

$* 0.01 \leq p<0.05, * * 0.001 \leq p<0.01, * * * p<0.001$ 


\section{Figure 3.1: Example of conjoint task}

West VirginiaUniversity

ROBERT C. BYRD HEALTH SCIENCES CENTER

School of Pharmacy

Please choose one Medicine that you prefer the most by clicking the button at the bottom of the screen. There are no right or wrong answers.

Question 1 of 10

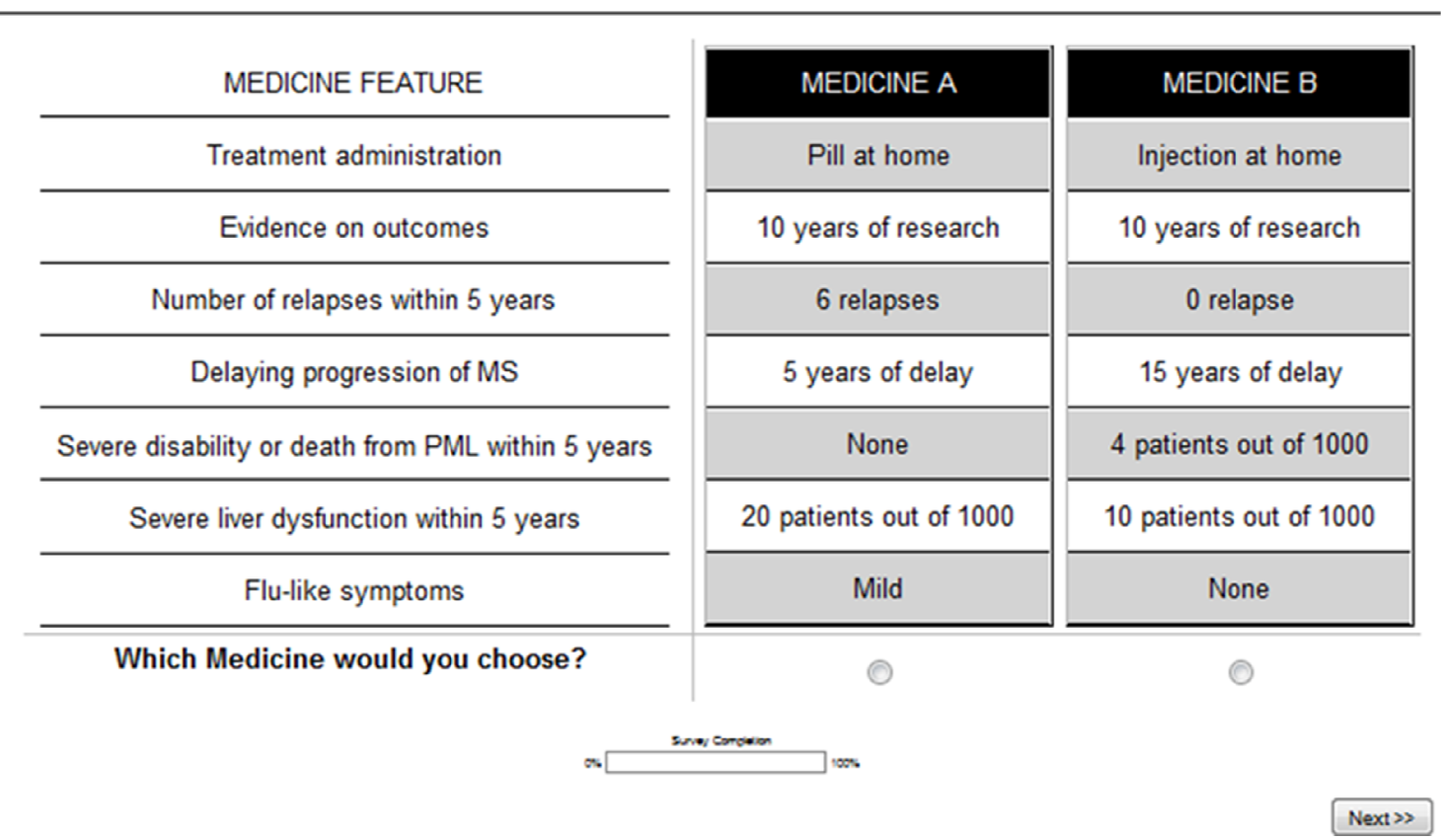


Figure 3.2: Survey population

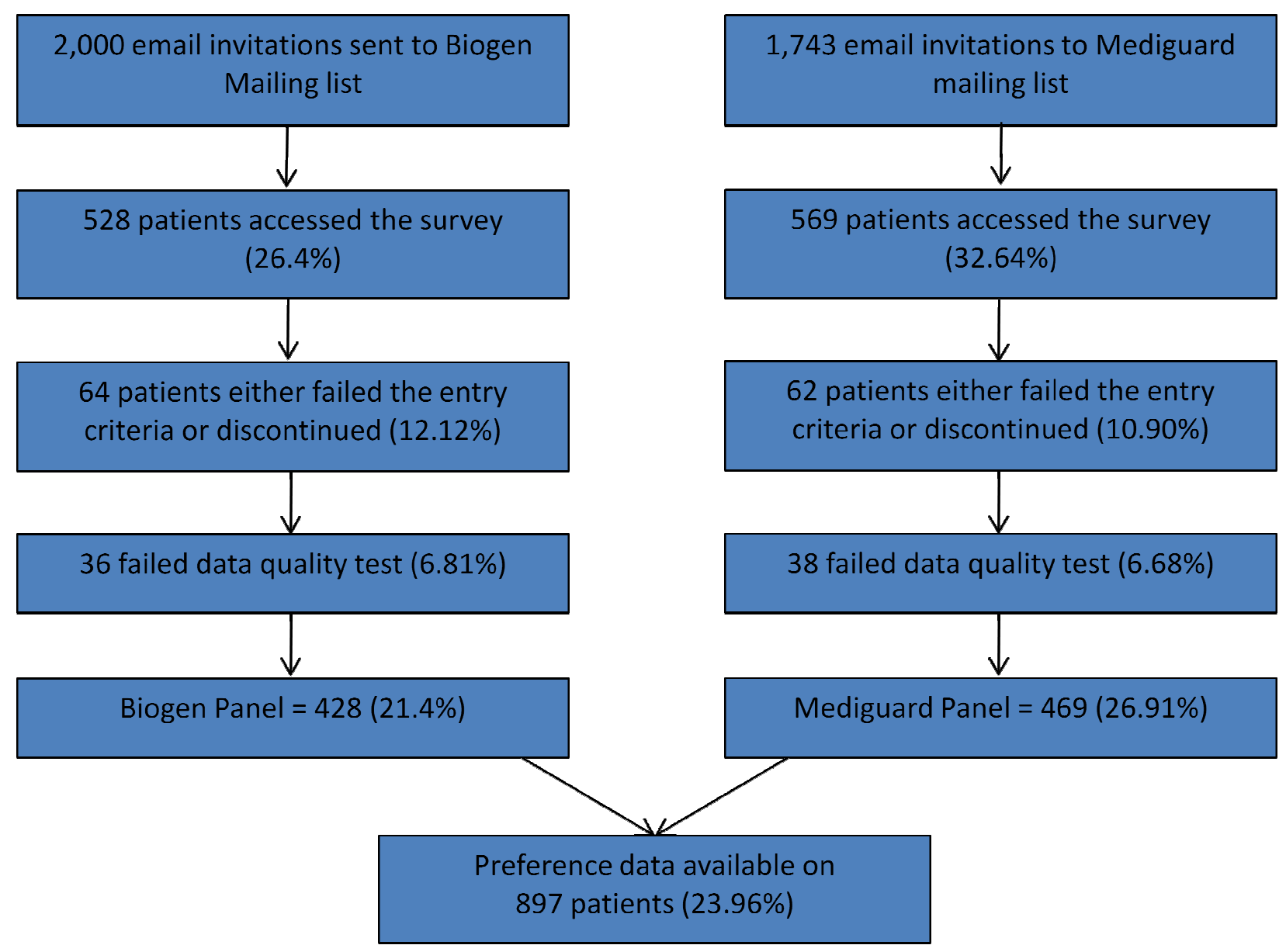


Figure 3.3: Disease modifying drug preference weights for multiple sclerosis patients

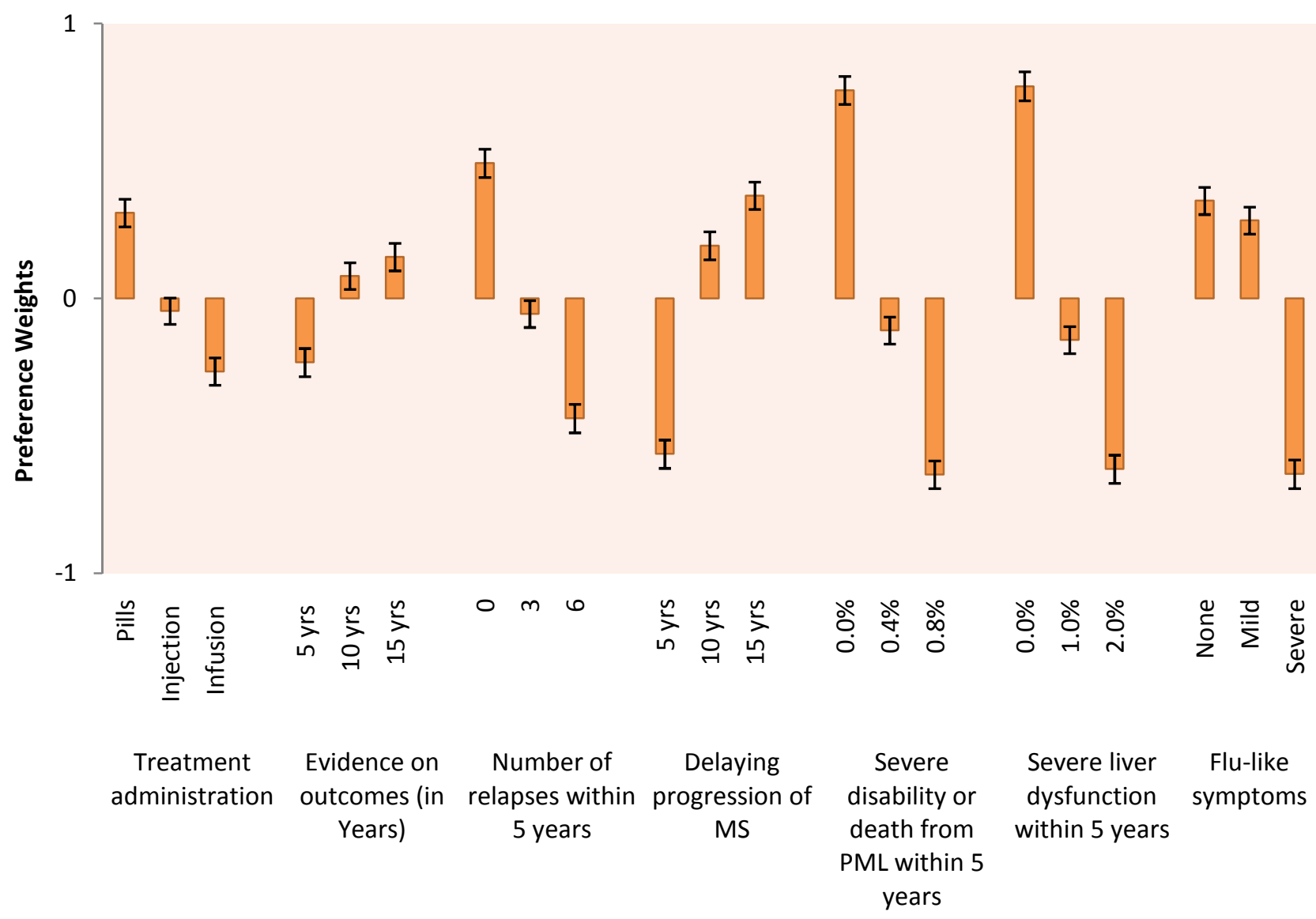


Figure 3.4: Relative importance of disease modifying drug attributes

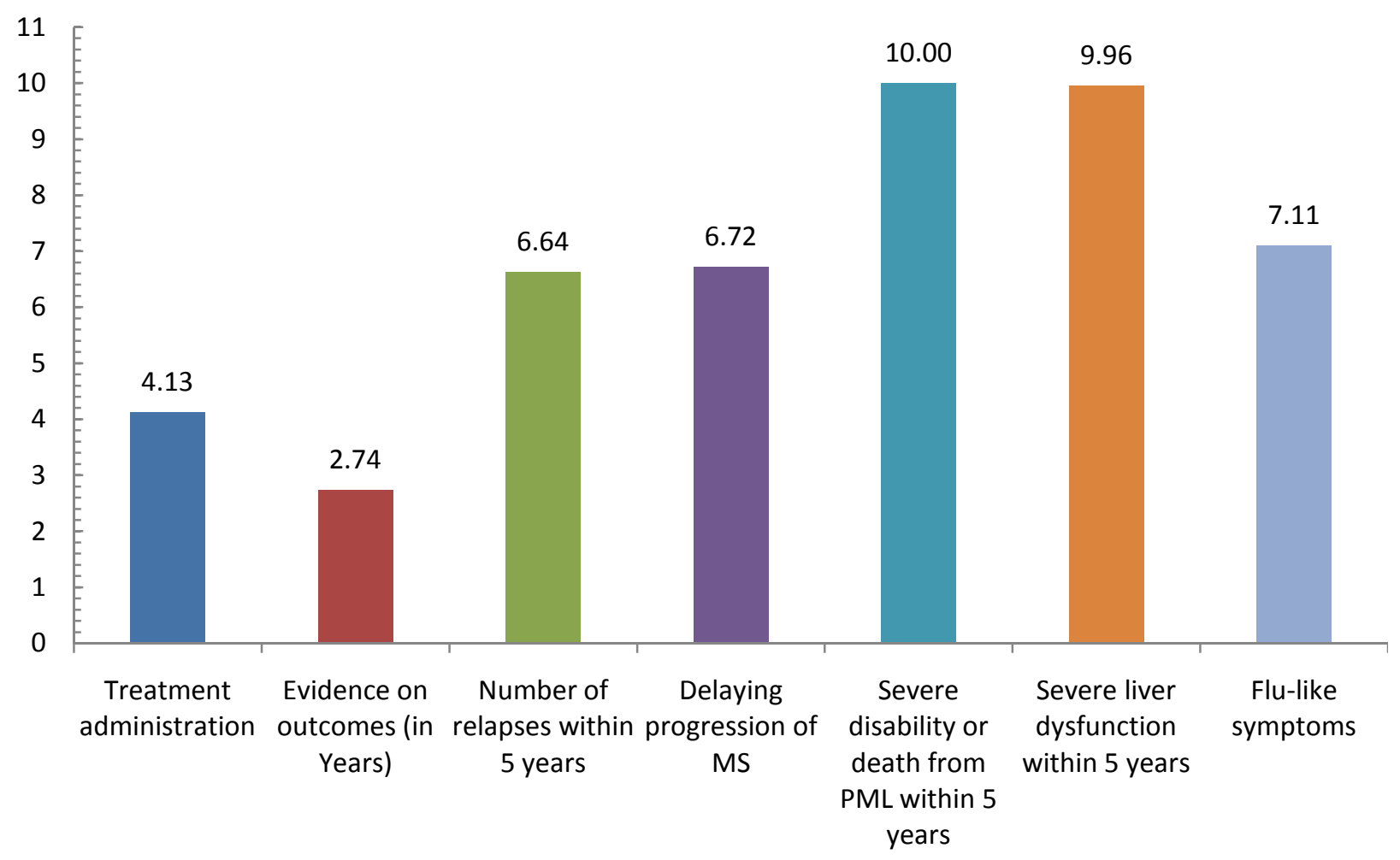




\section{References}

1. Anderson N. Functional measurement and psycho-physical judgement. Psychol Rev. 1977;77:153-70.

2. Bridges J. Stated preference methods in health care evaluation: an emerging methodological paradigm in health economics. Appl Health Econ Health Policy. $2003 ; 2: 213-24$.

3. Bridges J, Onukwugha E, Johnson F, Hauber A. Patient preference methods - A Patient centered evaluation paradigm. ISPOR Connect. 2007;13:4-7.

4. Bridges JFP, Kinter ET, Kidane L, Heinzen RR, McCormick C. Things are looking up since we started listening to patients: trends in the application of conjoint analysis in health 1982-2007. Patient. 2008;1(4):273-82.

5. Bridges JFP, Hauber AB, Marshall D, Lloyd A, Prosser LA, Regier DA, et al. Conjoint analysis applications in health - a checklist: a report of the ISPOR Good Research Practices for Conjoint Analysis Task Force. Value Health. 2011;14:403-11.

6. Bridges JF, Mohamed AF, Finnern HW, Woehl A, Hauber AB. Patients'preferences for treatment outcomes for advanced non-small cell lung cancer: A conjoint analysis. Lung Cancer. 2012 Feb 25. [Epub ahead of print]

7. Ch. Gan, E.J. Luzar. A conjoint analysis in waterfowl hunting in Lousiana. Journal of Agricultural and Applied Economics. 1993;25(2):36-45.

8. Coast J, Horrocks S. Developing attributes and levels for discrete choice experiments using qualitative methods. J Health Serv Res Policy. 2007;12:25-30. 
9. Confavreux C, Aimard G, Devic M. Course and prognosis of multiple sclerosis assessed by the computerized data Processing of 349 patients. Brain. 1980;103: 281-300.

10. Dutta R, Trapp BD. Pathogenesis of axonal and neuronal damage in multiple sclerosis. Neurology. 2007 May;29;68(22 Suppl 3):S22-31; discussion S43-54.

11. Goodin DS, Frohman EM, Garmany GP Jr, Halper J, et al. Disease modifying therapies in multiple sclerosis: report of the Therapeutics and Technology Assessment Subcommittee of the American Academy of Neurology and the MS Council for Clinical Practice Guidelines. Neurology. 2002 Jan 22;58(2):169-78.

12. Green PE, Srinivasan V. Conjoint analysis in consumer: Research issues and outlook. Journal of Consumer Research. 1978; 5:103-123.

13. Green PE, Srinivasan V. Conjoint analysis in marketing research new developments and directions. Journal of Marketing. 1990; 54(4):3-19.

14. Hauber AB (a), Johnson FR, Grotzinger KM, Ozdemir S. Patients' benefit-risk preferences for chronic idiopathic thrombocytopenic purpura therapies. Ann Pharmacother. 2010 Mar;44(3):479-88.

15. Hauber AB (b), Mohamed AF, Beam C, Medjedovic J, Mauskopf J. Patient preferences and assessment of likely adherence to hepatitis C virus treatment. J Viral Hepat. 2011 Sep;18(9):619-27.

16. Hensher DA, Rose JM, Greene WH. Applied Choice Analysis: A Primer. Cambridge: Cambridge University Press, 2005. 
17. Johnson FR, Ozdemir S, Manjunath R, Hauber AB, Burch SP, Thompson TR. Factors that affect adherence to bipolar disorder treatments: a stated-preference approach. Med Care. 2007 Jun;45(6):545-52.

18. Johnson FR, Van Houtven G, Ozdemir S, Hass S, White J, Francis G, Miller DW, Phillips JT. Multiple sclerosis patients' benefit-risk preferences: serious adverse event risks versus treatment efficacy. J Neurol. 2009 Apr;256(4):554-62.

19. Johnson FR, Hauber AB, Ozdemir S, Lynd L. Quantifying women's stated benefit-risk trade-off preferences for IBS treatment outcomes. Value Health. 2010 Jun-Jul;13(4):41823.

20. J. Louviere. Conjoint analysis modelling of stated preferences: A review of theory, methods, recent developments and external validity. Journal of Transport Economics and Policy. 1988;20:93-119.

21. McFadden D. Conditional logit analysis of qualitative choice behaviour. Berkeley, CA: University of California at Berkeley, 1973. (Working paper No 199/BART 10.)

22. Montalban X. MS treatment: postmarketing studies. J Neurol Sci. 2007 Aug;259(1-2):42-

5.

23. Ryan M, Hughes J. Using conjoint analysis to assess women's preferences for miscarriage management. Health Econ. 1997 May-Jun;6(3):261-73.

24. Ryan M, Farrar S. Using conjoint analysis to elicit preferences for health care. BMJ. 2000 Jun;320(7248):1530-3.

25. Ryan M, Gerard K, Amaya-Amaya M. Using Discrete Choice Experiments to Value Health and Health Care. 2008, Springer. 
CHAPTER 4 


\title{
CHAPTER 4
}

\section{ASSOCIATION OF DISEASE AND TREATMENT RELATED CHARACTERISTIC WITH TREATMENT SATISFACTION AMONG INDIVIDUALS WITH MULTIPLE SCLEROSIS}

\begin{abstract}
Objective: The aim of this study was to assess disease and treatment related factors associated satisfaction with treatment among individuals with multiple sclerosis (MS)

Methods: Email invitations requesting participation in a cross sectional web-based survey were sent to 3,743 individuals with MS. Individuals were affiliated with either an online medication monitoring service provider or with a mailing list owned by pharmaceutical company in the United States (US). Socio-demographic, MS related, and disease modifying drug (DMD) related information was collected in the survey. Patient satisfaction with DMD was assessed using a validated questionnaire - Treatment Satisfaction Questionnaire for Medication (TSQM) v.II, and disability associated with MS was assessed using Patient Determined Disease Steps (PDDS) scale. Sample differences between the two panels were evaluated. Associations between patients' socio-demographic, MS related, DMD related characteristics and the 3 TSQM domain scores (Side effects, Effectiveness, and Convenience) and the Global satisfaction score were analyzed. Multiple linear regression models were employed to determine MS and treatment related factors that were associated with satisfaction with DMDs.

Results: A total of 951 respondents completed the survey questionnaire (response rate of 25.4\%). Factors such as type of current DMD used, relapses, disability status, MS symptoms
\end{abstract}


experienced, and past experiences with DMDS were found to have negative associations with satisfaction scores. The overall satisfaction scores for individuals taking infusion (natalizumab) DMD did not differ from those who were using oral (fingolimod) DMD.

Conclusions: The findings of this study reflect that the type of DMD and clinical factors are associated with patient satisfaction among individuals with MS. Assessing treatment satisfaction can help better understand MS patients' value judgments with respect to their experiences with DMDs. 


\section{Introduction}

Multiple sclerosis (MS) is a chronic demyelinating disease that affects the central nervous systems and is characterized by relapses and remissions. The precise cause and cure for this disease are currently not known. MS is known to be the most common reason behind disability due to non-traumatic causes in young adults (Compston, 2002). The onset of MS usually occurs among individuals $20-50$ years of age, with the peak arising at 30 years of age, when they are typically most productive (Compston, 2006; Zwibel, 2011), have a busy social and family life, and financial commitments (Simmons, 2010). It has been known that acute relapses result in significant worsening of disability in many individuals with MS and nearly half do not experience complete recovery from it (Hirst, 2008). Disease modifying drugs (DMDs) used in the therapeutic management of the MS are the mainstay therapies known to reduce frequency of relapses thereby delaying worsening of MS and the resultant accumulation of the disability.

Currently available first-line DMD therapy for MS includes interferon beta-1a, interferon beta-1b, and glatiramer acetate and the second-line DMD therapy for MS includes natalizumab, fingolimod, and mitoxantrone. Except fingolimod, which is the only oral DMD available for MS, all other DMDs are delivered via parenteral mode of administration.

Interferon beta $1 \mathrm{a}$, interferon beta $1 \mathrm{~b}$, and glatiramer acetate are considered to be relatively safer but modestly efficacious (Goodin, 2002). Second-line DMDs exhibit significant efficacy in active MS but are limited in their use due to adverse events associated with them (Rudick, 2011). Adherence to DMDs is a major challenge in the therapeutic management of MS. Nonadherence to DMDs among individuals with MS is associated with DMD related factors such as 
perceived/experienced lack of efficacy, injection site reactions, pain at injection sites, side effects associated with DMDs, difficulty in self-injecting, and not being able to find someone to give injection (Treadaway, 2009). According to a recent systematic review by Giovannoni (2012), the average rate for stopping treatment with DMD among individuals with MS ranged between $16 \%$ and $27 \%$.

Satisfaction is the extent to which individual's experience match up to his or her expectations (Pascoe, 1983). Satisfaction with medication is a significant predictor for individuals to continue taking their medication, administering it in an appropriate manner, and conforming to their treatment regimens (Anderson, 1999; Awad, 1999; Diamond, 1985; No Author listed, 1998). Although studies have been done to assess satisfaction with specific injection devices (Cramer, 2006), information on factors affecting treatment satisfaction in a large sample of individuals with MS who are using different DMDs is still lacking. Clinical factors such as disability, relapses, and symptoms associated with MS are known to affect health related quality of life among individuals suffering from MS. Association of these factors with satisfaction is also not known. Given the potential for DMDs to influence different aspects of lives of individuals living with MS, it is essential to fill the current knowledge gaps with respect to factors affecting their satisfaction with treatments and other important MS related factors. Evaluating satisfaction levels among individuals with MS can help us understand whether implicit expectations with respect to their treatments and other MS related factors are being met are not. 


\section{Methods}

\section{Participants}

This was a cross sectional study among a group of individuals with a self-reported clinician confirmed diagnosis of MS. Study participants were recruited using two separate panels of individuals with MS in the US. Details of survey respondents are provided in Figure 4.1. The first panel comprised of individuals with MS who were subscribers of www.MediGuard.org, which is a free medication monitoring service that provides individuals with safety alerts, recalls, a check for drug interactions, and other drug related updates. The second panel comprised of individuals with MS from Biogen Idec mailing list. Participants were required to be 18 years of age or older, have a self-reported clinician confirmed diagnosis of MS, and have a current residence in the US. A web based survey was developed using Qualtrics survey builder and was administered from August 2011 through November 2011. All respondents completing the survey received a $\$ 25$ gift card as incentive for their participation. This study was approved by the West Virginia University Institutional Review Board.

\section{Study Variables}

In this study, we collected information on the following categories of variables: treatment satisfaction with medication, disability status, socio-demographic variables, MS related, and DMD related Variables.

Treatment Satisfaction Questionnaire for Medication (TSQM) v.II

TSQM was used in this study to determine satisfaction with their MS medication (DMDs if they were currently taking a DMD for treating their MS or non-DMD treatments in case patients were not on any DMDs). TSQM v.II is an 11-item scale which is routinely used to assess 
patient satisfaction with medications. This questionnaire provides scores on four scales: Sideeffects ( 4 items), Effectiveness ( 2 items), Convenience ( 5 items), and Global satisfaction. The psychometric properties of TSQM v.ll scale are tested using a diverse patient population visiting pharmacies to fill out a prescription for a new medication that they had never used previously (Atkinson, 2005). The TSQM version 1.4 from which TSQM v.II is adapted has been validated in a large population of individuals suffering from with eight different chronic conditions such as arthritis, asthma, major depression, type-I diabetes, high cholesterol, hypertension, migraine, and psoriasis (Atkinson, 2004).

\section{Patient Determined Disease Steps (PDDS)}

In this study, the PDDS scale was used to describe current disability status in individuals with MS. The advantage of using PDDS is that it is a self-administered scale which determines functional disability in individuals with MS. The Kurtzke Expanded Disability Status Scale (EDSS), a clinician based measure, is routinely used in clinical trials in MS as one of the clinical outcome measures to evaluate disability progression over time using standard neurological examination and to describe health states in MS. A strong correlation was observed between the EDSS and PDDS score (Spearman rank correlation coefficient $=0.958)($ Hohol, 1995). As PDDS scores were reported to be comparable to the clinically utilized EDSS scale (Hohol, 1995), hence PDDS was utilized as a surrogate measure for EDSS.

Socio-demographic Variables

The following patient demographic information was collected: age, gender, marital status, race, education, income, employment, region, insurance status, panel 
(Mediguard/Biogen), total number of visits to primary care physician (PCP) in the past 12 months, and total number of visits to neurologists in the past 12 months.

MS and DMD related Variables

Information on the following MS related variables was collected: type of MS, duration of MS, age at diagnosis, total number of MS related symptoms, total number of relapses experienced in the last 12 month, and total number of comorbid conditions. In addition to the disease related information, information on individuals' current and past use of DMDs was also obtained from self-report.

\section{Statistical Analysis}

Differences in socio-demographic, disease, and treatment related characteristics of the respondents from the two panels were assessed using Pearson's chi-square test for the categorical variables, t-tests for normally distributed continuous variables, and Kruskal-Wallis tests for continuous variables which did not have a normal distribution. Individuals' sociodemographic, disease, and treatment related characteristics are reported as frequencies and percentages for categorical variables, and continuous variables are presented with means and standard deviations. Associations between individual's characteristics and each of the 3 domains and the global satisfaction mean scores were analyzed using Mann-Whitney $U$ test and the Kruskal-Wallis one way ANOVA. Some of the variables were categorized in order to meaningfully interpreting the results of bivariate analysis. PDDS score representing disability is measured on an ordinal scale (Range 0-8). PDDS score was categorized into three categories, mild, moderate, and severe, respectively (Marrie, 2006). 
Separate linear regression models were developed to identify disease and treatment related factors that are significantly associated with 3 TSQM domain scores (Side effects, Effectiveness, and Convenience) and Global satisfaction score with medication. Covariates were entered into the model block-wise manner, first block included disease and treatment related factors and in the second block socio-demographic variables were added.

Disease and treatment related factors assessed in the regression models included: type of MS (RRMS as the reference category, SPMS, PPMS, PRMS), years since diagnosis of MS, current age, number of MS symptoms experienced, number of relapses experienced in the past 12 months, number of comorbid conditions, PDDS score, number of DMDs taken in the past, and type of current DMD used [Oral (Fingolimod) used as reference category, intramuscular (IM) (Interferon b-1a), subcutaneous (SC) (Interferon b-1b), subcutaneous (SC) (Glatiramer acetate), subcutaneous (SC) (Interferon b-1a), Infusion (Natalizumab), No DMD ]. Each regression model was controlled for the following variables: age, gender [male as the reference category, female], marital status [without a partner (single/living alone/divorced/widowed) as the reference category, with a partner (married/living with partner)], race [White as the reference category, Other], education [high school or less as the reference category, some college, bachelors degree, postgraduate degree], income $[\leq \$ 25,000$ as the reference category, $\$ 25,001$ to $\$ 50,000, \$ 50,001$ to $\$ 75,000, \$ 75,001$ to $\$ 100,000, \$ 100,001$ or above], employment [working full time as the reference category, working part time, not working (not working/unable to work due to ms], region [northeast as the reference category, midwest, south, west], prescription coverage [Not covered as the reference category, Covered, support 
program], panel [Biogen as the reference category, Mediguard], total PCP visits in the past 12 months, and total visits to neurologists in the past 12 months.

Individuals using mitoxantrone and those who were on the drugs from clinical trials were excluded from the analysis. Multicollinearity check was performed before running the regression models using the abovementioned independent variables.

The beta coefficients represent the degree to which treatment satisfaction scores with medication would change with one unit change in the independent variable where the variable is a continuous variable. Whereas if the independent variable is a categorical variable, the beta coefficients represent the degree to which treatment satisfaction scores with medication would change for a given category with respect to the reference category.

We had large enough sample size in comparison with the minimum sample size estimated using accepted conventions for building power in multivariate regression (Tabachnick, 1996; Pedhazur, 1997). All statistical analyses were conducted using IBM SPSS 20.0 (IBM Corp.).

\section{Results}

\section{Survey Population Characteristics}

Out of 3,743 individuals invited for participation from the two panels, 951 respondents completed the survey questionnaire for this study (response rate of 25.4\%). Breakdown of respondents by different socio-demographic is provided in table 4.1, and MS and treatment related characteristics are provided in table 4.2. A majority of the respondents were female (84.6\%), living with a partner (60.3\%), white (86.9\%), and with a mean age of 50.3 (SD \pm 9.9 ) 
years. Nearly one half of the respondents reported an annual household income of less than $\$ 50,000$. Very few $(17.2 \%)$ respondents had less than or equal to a high school level education. A majority of respondents (61.4\%) were not employed at the time of their participation in this survey. Respondents from all four geographical regions in the US participated in the survey. Mean self-reported duration of multiple sclerosis was 11.4 years (SD \pm 8.2 ). Approximately 80 percent of the survey respondents had relapsing-remitting form of MS. The mean reported value for relapses experienced in the last 12 months was 1.4 (SD \pm 2.0$), 8.2$ (SD \pm 4.5$)$ for experiencing MS related symptoms, 2.6 (SD \pm 2.2$)$ for co-morbid conditions, and 1.1 (SD \pm 1.1 ) for the number of DMDs used in the past. A majority of the respondents reported a current use of one of the approved DMDs to treat their MS. Mean score for self-reported disability status was found to be $2.7( \pm 2.1)$ for the respondents. The average number of visits to primary care physician in the past 12 months was $1.2( \pm 2.0)$ and the average number of visits to the neurologist in the past 12 months was 2.4 ( \pm 1.9$)$. A majority $(73.1 \%)$ of the individuals were taking a DMD at the time of the survey.

Comparison of respondent characteristics by panels (Biogen Vs Mediguard) is also provided in tables 4.1 and 4.2 , respectively. Respondents belonging to the Mediguard panel were older [Mediguard 51.6 years $( \pm 9.4)$ Vs. Biogen 48.9 years $( \pm 10.2), p=<0.001$ ], had been living with MS for a longer duration [Mediguard 13.8 years $( \pm 8.4)$ Vs. Biogen 8.9 years $( \pm 7.1)$, $p=<0.001$ ], and had experienced more number of relapses [Mediguard $1.8( \pm 2.3)$ Vs. Biogen 1.0 ( \pm 1.6$), p=<0.001$ ] in the past 12 months. Whereas respondents belonging to Biogen panel had relatively fewer MS related symptoms [Biogen $7.2( \pm 4.4)$ Vs. Mediguard $9.1( \pm 4.3), p=<0.001$ ], fewer co-morbid conditions [Biogen $2.0( \pm 1.9)$ Vs. Mediguard $3.2( \pm 2.4), p=<0.001$ ], lower levels 
of disability [Biogen $2.1( \pm 1.9)$ Vs. Mediguard $3.2( \pm 2.1), p=<0.001$ ], and fewer primary care physician visits in the past 12 months [Biogen $0.8( \pm 1.5)$ Vs. Mediguard $1.5( \pm 2.2), p=<0.001$ ] Average number of visits to neurologists in the past 12 months was higher for respondents in the Biogen panel [Biogen $2.5( \pm 2.0)$ Vs. Mediguard $2.2( \pm 1.8), p=<0.05$ ]. There were no significant difference in the respondents of the two panels with respect to marital status, region, and prescription coverage.

\section{Univariate Analysis}

Treatment satisfaction scores for Convenience, Side-effects, and Effectiveness domains along with the Global satisfaction scores by individual characteristics are reported in the table 4.3. The results suggest there is a statistically significant difference in the distribution of mean TSQM scale scores and Global satisfaction scores between individuals based on the type of current DMD used. [For example, the mean TSQM-global satisfaction scores based on the type of current DMD used: IM (Interferon b-1a) -78.5 ( \pm 18.4$)$ Vs SC (Interferon b-1b) - $68.5( \pm 13.5)$ Vs SC (Glatiramer acetate) - 72.9 ( \pm 20.8$)$ Vs Oral (Fingolimod)] - 85.6 ( \pm 19.2$)$ Vs SC (Interferon b-1a)

- $75.2( \pm 16.2)$ Vs Infusion (Natalizumab) - $83.5( \pm 17.2)$ Vs No DMD $-50.1( \pm 27.7), p=<0.001]$

\section{Linear Regression analyses}

Linear regression models were adjusted for the following covariates: gender, marital status, race, education, income, employment status, region, panel, prescription coverage, primary care physician visits in the past 12 months, and visits to neurologists in the past 12 months (Table 4.4). Type of current DMD used was significantly associated with Convenience, Effectiveness, and Global satisfaction scores. Respondents taking IM-interferon $b-1 a(\beta=-25.58$, $p<0.001)$, SC-interferon $b-1 b(\beta=-30.05, p<0.001)$, SC-glatiramer acetate $(\beta=-27.19, p<0.001)$, 
SC-interferon $b-1 a(\beta=-25.99, p<0.001)$, Infusion-natalizumab $(\beta=-15.49, p<0.001)$ (any of the available parenteral DMDs), and those who were not on any DMD $(\beta=-35.07, p<0.001)$ had lower Convenience scores as compared to those who were using oral (fingolimod) DMD. Those who were currently taking infusion-natalizumab $(\beta=7.95, p<0.05)$ had higher Effectiveness scores as compared to those who were using oral-fingolimod. Respondents currently not taking any DMD $(\beta=-23.06, p<0.001)$ had significantly lower Effectiveness domain scores as compared to those who were using oral-fingolimod. Respondents taking IM-interferon b-1a $(\beta=-15.76, p<0.001)$, SC-interferon $b-1 b(-21.13, p<0.001)$, SC-glatiramer acetate $(\beta=-16.66, p$ $<0.001)$, SC-interferon $b-1 a(\beta=-14.81, p<0.001)$, or no DMD $(\beta=-36.59, p<0.001)$ had significantly lower Global satisfaction scores as compared to those who were using oralfingolimod. The Global scores for those who were taking natalizumab-infusion did not differ from those who were using oral-fingolimod. Side-effect scores did not significantly differ between those who were taking oral-fingolimod and those who were users of other type of DMDs or the non users.

Increasing MS related symptoms experienced by an individual was negatively associated with the satisfaction scores in all the models (Convenience $\beta=-0.64, p<0.01$; Effectiveness $\beta=-$ 0.94, $p<0.05 ;$ Side-effects $\beta=-1.26, p<0.001 ;$ Global $\beta=-0.82, p<0.001$ ). Number of relapses experienced in the past 12 months was negatively associated with satisfaction scores (Convenience $\beta=-0.93, p<0.05$; Effectiveness $\beta=-1.89, p<0.05$; Side-effects $\beta=-1.06, p<0.05$; Global $\beta=-1.31, p<0.001)$. Presence of comorbid conditions had a negative association with Side-effects domain scores (Side-effects $\beta=-0.90, p<0.05$ ). Increase in the PDDS score (indicating increasing level of disability) was associated with lower Effectiveness and Global 
satisfaction scores (Effectiveness $\beta=-1.78, p<0.05$; Side-effects $\beta=-1.44, p<0.01$ ). Experience of using DMDs in the past was negatively associated with Effectiveness, Side-effects, and Global satisfaction scores (Effectiveness $\beta=-1.97, p<0.05$; Side-effects $\beta=-2.30, p<0.01$; Global $\beta=$ $2.16, p<0.01)$. The proportion of variance explained in the satisfaction scores did not change after the inclusion of socio-demographic factors in the models (Table 4.5).

\section{Discussion}

In this cross-sectional study of a national sample, we evaluated factors that are associated with treatment satisfaction among individuals living with MS. Of all the factors that were evaluated, number of MS related symptoms and number of relapses experienced in the past 12 months were found to be consistently and significantly associated with lower overall and domain specific satisfaction scores on TSQM. Disability status, number of DMDs taken in the past, and type of DMD that is used currently by the respondents were significantly associated with the overall treatment satisfaction.

Unpredictable relapses are characteristic of MS. Disability related to MS is the result of partial recovery following a relapse or worsening that is independent of relapse in case of progressive forms of MS (Tremlett, 2009). Lesions that are formed in the brain and the neuronal damage taking place in different parts of the central nervous system (CNS) in course of MS manifest into different types of physical and cognitive symptoms that eventually progress to some form of disability (Compston, 2002). Symptoms experienced in MS differ depending on the magnitude and the part of the CNS that is affected. Irrespective of the type of MS, patients often experience different types of symptoms which affect their quality of life (Rudick, 2008). 
Disease modifying drugs used in MS treatment are used to reduce relapse rates thereby delaying the accumulation of disability and the resultant progression of MS (Thompson, 2001). Thus, DMDs may also reduce the symptoms experienced by the individuals with MS (Zwibel, 2011).

In this study, disability status was evaluated using a self-reported measure (PDDS) for individuals with MS. Higher score on PDDS indicated higher levels of disability. Higher PDDS scores were found to be negatively associated with Effectiveness and Global satisfaction scores. This finding suggests that perceived or actual disability of individuals with MS is an important determinant for perceived effectiveness and overall satisfaction with their treatments. The number of relapses in the past 12 months and total number of MS symptoms experienced by the individuals also had a negative association with all the TSQM domain scores along with the global satisfaction score.

In this study, the number of comorbid conditions was negatively associated with the Side-effects score. Studies have shown that individuals with MS with other comorbid conditions experience a lower HRQoL (Marrie, 2011). Side effects, such as injection site reactions, flu-like symptoms, chill, fever, and nausea (Coles, 2009; Treadaway, 2009) are common to DMDs used in MS. Such side effects may possibly add to the overall HRQoL, clinical, economic burden on individuals if they are also suffering from other comorbid conditions. Total number of primary care physician visits in the past 12 months was negatively associated with Side-effects score. An explanation to this association could be that the individuals with MS experiencing side effects due to their treatments had to visit their primary care physicians more often than others to take care of the side effects related issues. 
Another factor that was found to be associated with lower Effectiveness, Side-effects, and Global scores was the number of DMDs taken in the past. Past use of multiple DMDs may imply switching/stopping behavior on part of individuals due to several reasons including, but not limited to, inefficacy of the DMD, side effects, and costs. Although evaluation of individual's treatment satisfaction with medication is targeted towards assessing experiences with current medication; individual's assessment of current medication could be influenced by their past medication experiences. Past medication experiences could play a role in setting expectations prior to initiating new medication (Atkinson, 2005).

Medications with oral route of administration are reported to have better mean satisfaction scores for convenience in chronic conditions (Atkinson, 2004). With almost all DMDs being parenteral, except fingolimod, inconvenience of administration is a major factor affecting adherence with at least the first line DMDs. In this study, individuals who were parenteral DMD users and DMD non-users had significantly lower mean scores for satisfaction with Convenience as compared to mean scores for those who were taking oral-fingolimod. Individuals with MS on once a month infusion-natalizumab indicated significantly higher satisfaction scores for effectiveness as compared to those who were on once a day oralfingolimod. Although there are no head-to-head comparisons for these two DMDs used in MS, a recent cost-effectiveness study comparing these two DMDs found that natalizumab is cheaper and more effective (O'Day, 2011). Global satisfaction scores were not significantly different for individuals who were on once a month infusion-natalizumab as compared to those who were on oral-fingolimod DMD. 
MS is a lifelong disease without a cure; hence, long-term treatment with DMDs is imperative. In addition, MS affects young adults hence they are expected to be on DMD early on and would be required to take these DMDs for longer durations. It is suggested that DMD initiation be done early in the course of MS in order to delay the progression. However problems associated with currently available DMDs such as, parenteral routes of administration, safety and tolerability issues, long duration of treatments, perceived lack of efficacy, and side effects associated with the DMDs have contributed considerably towards low treatment satisfaction possibly reducing adherence and persistence with DMD treatment. When individuals discontinue following their prescribed medication regimen, individuals fail to get optimum treatment benefits. Adherence with treatments has shown to improve clinical, quality of life, and economic outcomes for individuals with MS over a period of time. Hence, periodic evaluation of treatment satisfaction in individuals with MS with respect to DMDs will help providers better understand factors affecting adherence issues with treatment.

Following limitations of this study should be noted. As this study collected self-reported data from individuals with MS, there is a potential for social desirability or reporting bias. Data collection was carried out using two panels and the sample differences might introduce selection bias and can limit the generalizability of the results. However, the multivariate models were controlled for panel affiliation. This was a cross-sectional study hence causation cannot be established. Current adherence levels, perception of risks, and individual's experiences with past MS medications may affect expectations from current DMDs and in turn may affect satisfaction scores. Such information was not collected. Information related to respondents' expectations from their current treatment, reasons for stopping/switching 
previous treatments, and treatment related side effects experienced by them were not collected.

\section{Conclusion}

This cross-sectional survey suggests that treatment satisfaction among individuals with MS is related to factors such as relapse, disability status, MS symptoms, past experiences with DMDs, and primarily the type of current DMD. With the likely increase in DMD options and uncertainty with respect to the safety-efficacy profile of future DMDs, engagement of individuals with MS in treatment related decisions has become imperative. Assessing treatment satisfaction routinely can help clinicians and other care providers better understand value judgment of individuals with MS with respect to their DMDs. 
Table 4.1: Summary of participants' sociodemographic characteristics

\begin{tabular}{|c|c|c|c|c|c|}
\hline Characteristic & Categories & $\begin{array}{l}\text { Total } \\
\% / S D\end{array}$ & Biogen & Mediguard & Sig. \\
\hline Age & Mean (SD) & $50.3(9.9)$ & $48.9(10.2)$ & $51.6(9.4)$ & $* * *$ \\
\hline \multirow{2}{*}{ Gender } & Female & $798(84.6)$ & $371(82.1)$ & $427(82.1)$ & $*$ \\
\hline & Male & $145(15.4)$ & 81 (17.9) & $64(13.0)$ & \\
\hline \multirow{2}{*}{ Marital Status } & Without partner & 375 (39.7) & $170(37.4)$ & $205(41.8)$ & 0.160 \\
\hline & With partner & $570(60.3)$ & $285(62.6)$ & $285(58.2)$ & \\
\hline \multirow[t]{2}{*}{ Race } & White & 822 (86.9) & $375(82.4)$ & 447 (91.0) & $* * *$ \\
\hline & Other & $124(13.1)$ & $80(17.6)$ & $44(9.0)$ & \\
\hline \multirow{4}{*}{ Education } & High school or Less & $163(17.2)$ & $61(13.4)$ & $102(20.8)$ & $* * *$ \\
\hline & Some college & $392(41.4)$ & $178(39.1)$ & $214(43.6)$ & \\
\hline & Bachelors Degree & $276(29.2)$ & $146(32.1)$ & $130(26.5)$ & \\
\hline & Postgraduate Degree & $115(12.2)$ & $70(15.4)$ & $45(9.2)$ & \\
\hline \multirow{5}{*}{ Income } & $<\$ 25,000$ & $244(25.8)$ & $82(18.0)$ & $162(33.1)$ & $* * *$ \\
\hline & $\$ 25,001-\$ 50,000$ & $273(28.9)$ & $137(30.1)$ & $136(27.8)$ & \\
\hline & $\$ 50,001-\$ 75,000$ & $215(22.8)$ & $109(24.0)$ & $106(21.6)$ & \\
\hline & $\$ 75,001-\$ 100,000$ & $118(12.5)$ & $71(15.6)$ & 47 (9.6) & \\
\hline & $>\$ 100,000$ & $95(10.1)$ & $56(12.3)$ & $39(8.0)$ & \\
\hline \multirow{3}{*}{ Employment } & Full time & $255(27.0)$ & $169(37.1)$ & $86(17.5)$ & $* * *$ \\
\hline & Part time & $110(11.6)$ & $55(12.1)$ & $55(11.2)$ & \\
\hline & Not Working & $581(61.4)$ & $231(50.8)$ & $350(71.2)$ & \\
\hline \multirow{4}{*}{ Region } & Northeast & $204(21.6)$ & $92(20.2)$ & $112(22.8)$ & 0.222 \\
\hline & Midwest & $249(26.3)$ & $110(24.2)$ & $139(28.3)$ & \\
\hline & South & $307(32.5)$ & 159 (34.9) & $148(30.1)$ & \\
\hline & West & $186(19.7)$ & 94 (20.7) & $92(18.7)$ & \\
\hline \multirow{3}{*}{$\begin{array}{l}\text { Prescription } \\
\text { Coverage }\end{array}$} & Covered & $832(87.8)$ & $404(88.0)$ & $428(87.5)$ & 0.803 \\
\hline & Support Program & $43(4.5)$ & $22(4.8)$ & $21(4.3)$ & \\
\hline & Not Covered & $73(7.7)$ & $33(7.2)$ & $40(8.2)$ & \\
\hline
\end{tabular}


Table 4.2: Summary of participants' multiple sclerosis and treatment related characteristics

\begin{tabular}{|c|c|c|c|c|c|}
\hline Characteristic & Categories & $\begin{array}{l}\text { Total } \\
\% / S D\end{array}$ & Biogen & Mediguard & Sig. \\
\hline \multirow{4}{*}{ Type of MS } & RRMS & 769 (80.9) & $415(90.4)$ & $354(72.0)$ & $* * *$ \\
\hline & SPMS & $96(10.1)$ & $24(5.2)$ & $72(14.6)$ & \\
\hline & PPMS & $49(5.2)$ & $10(2.2)$ & 39 (7.9) & \\
\hline & PRMS & 37 (3.9) & $10(2.2)$ & $27(5.5)$ & \\
\hline Duration of MS & Mean (SD) & $11.4(8.2)$ & $8.9(7.1)$ & $13.8(8.4)$ & $* * *$ \\
\hline $\begin{array}{l}\text { Number of MS } \\
\text { symptoms }\end{array}$ & Mean (SD) & $8.2(4.5)$ & $7.2(4.4)$ & $9.1(4.3)$ & $* * *$ \\
\hline $\begin{array}{l}\text { Relapses in past } \\
12 \text { months }\end{array}$ & Mean (SD) & $1.4(2.0)$ & $1.0(1.6)$ & $1.8(2.3)$ & $* * *$ \\
\hline $\begin{array}{l}\text { Number of co- } \\
\text { morbidities }\end{array}$ & Mean (SD) & $2.6(2.2)$ & $2.0(1.9)$ & $3.2(2.4)$ & $* * *$ \\
\hline $\begin{array}{l}\text { Number of past } \\
\text { DMDs }\end{array}$ & Mean (SD) & $1.1(1.1)$ & $1.0(1.1)$ & $1.1(1.2)$ & $* * *$ \\
\hline \multirow{7}{*}{$\begin{array}{l}\text { Type of current } \\
\text { DMD used }\end{array}$} & IM (Interferon b-1a) & $258(27.1)$ & $201(43.8)$ & $57(11.6)$ & $* * *$ \\
\hline & SC (Interferon b-1b) & $40(4.2)$ & $12(2.6)$ & $28(5.7)$ & \\
\hline & SC (Glatiramer acetate) & $129(13.6)$ & $42(9.2)$ & $87(17.7)$ & \\
\hline & Oral (Fingolimod) & $44(4.6)$ & $21(4.6)$ & $23(4.7)$ & \\
\hline & SC (Interferon b-1a) & $79(8.3)$ & $23(11.4)$ & $56(5.0)$ & \\
\hline & Infusion (Natalizumab) & $145(15.2)$ & $126(27.5)$ & $19(3.9)$ & \\
\hline & No DMD & $256(26.9)$ & $34(7.4)$ & $222(45.1)$ & \\
\hline PDDS & Mean (SD) & $2.7(2.1)$ & $2.1(1.9)$ & $3.2(2.1)$ & $* * *$ \\
\hline $\begin{array}{l}\text { Primary care } \\
\text { physician visits } \\
\text { in past } 12 \\
\text { months }\end{array}$ & Mean (SD) & $1.2(2.0)$ & $0.8(1.5)$ & $1.5(2.2)$ & $* * *$ \\
\hline $\begin{array}{l}\text { Neurologist } \\
\text { visits in past } 12 \\
\text { months }\end{array}$ & Mean (SD) & $2.4(1.9)$ & $2.5(2.0)$ & $2.2(1.8)$ & $*$ \\
\hline
\end{tabular}

$* 0.01 \leq p<0.05, * * 0.001 \leq p<0.01, * * * p<0.001$ 


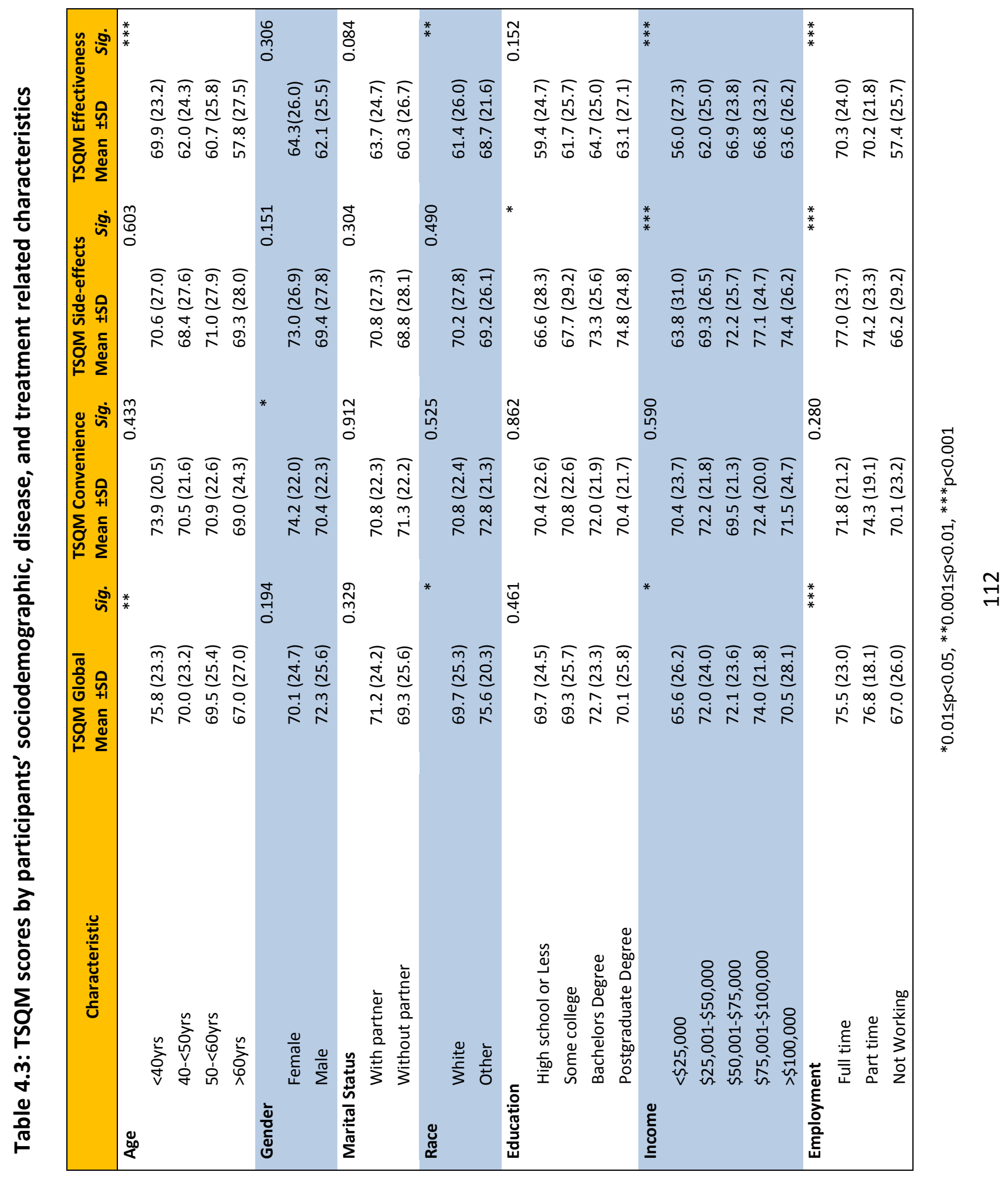




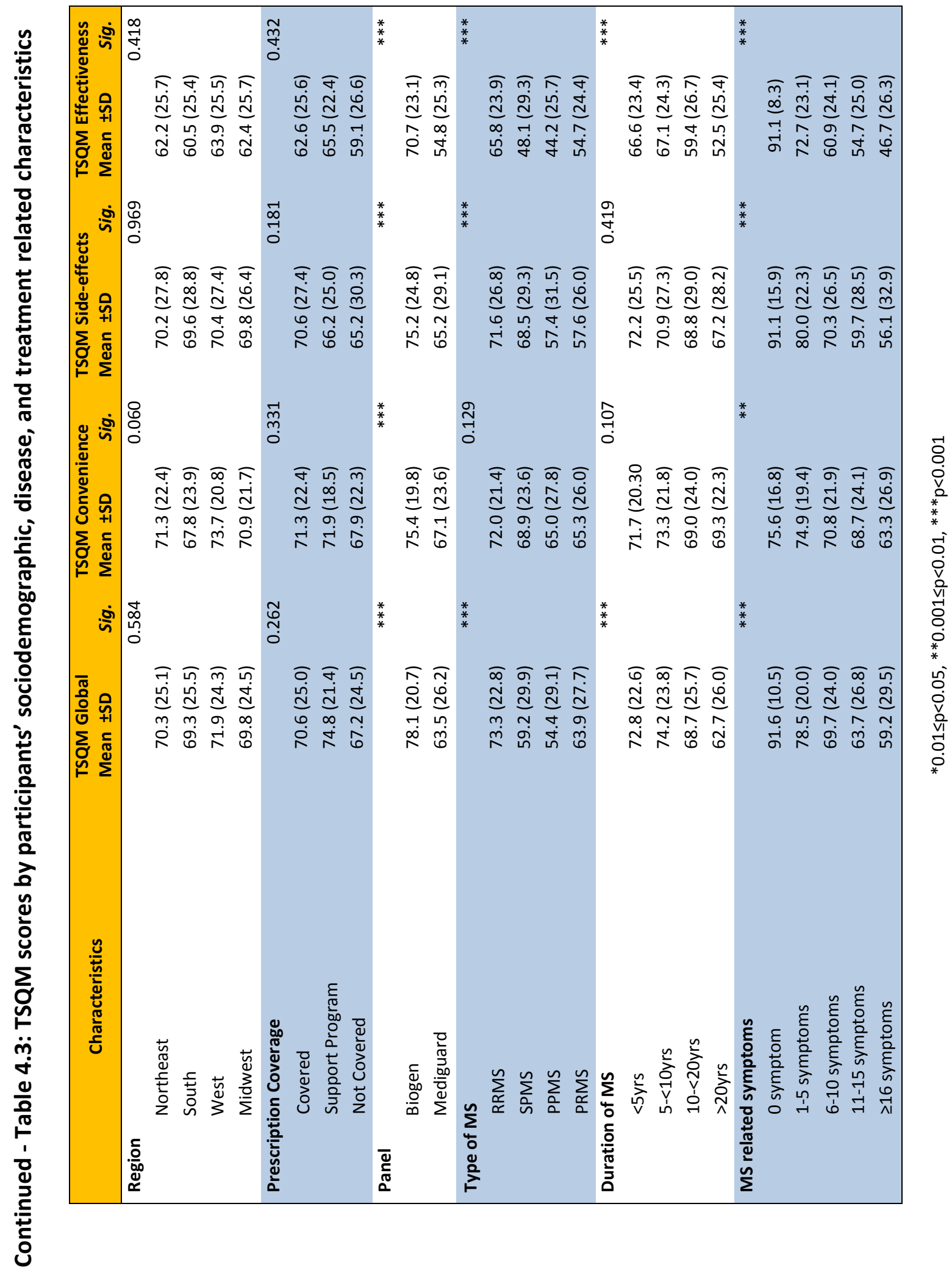




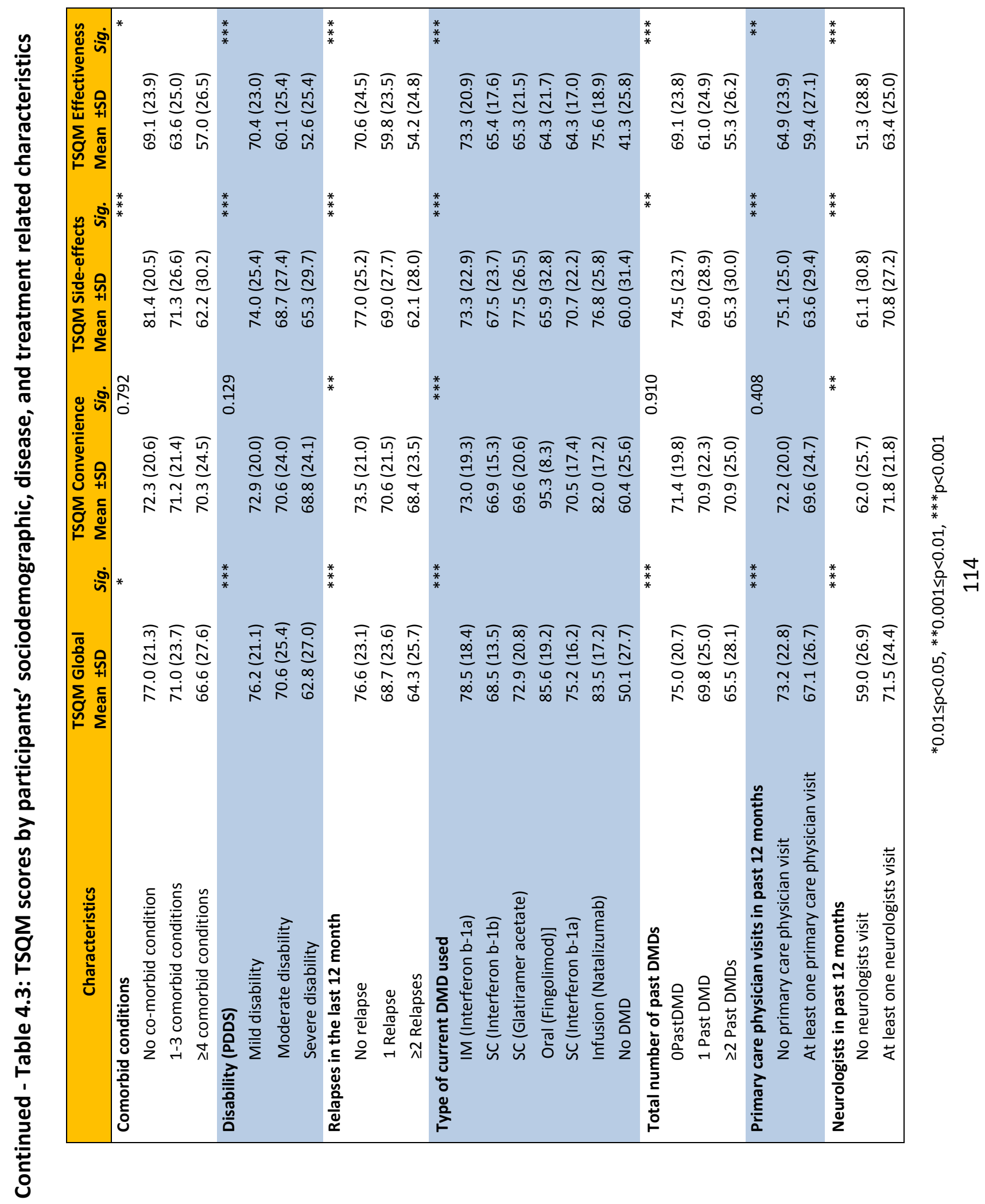


Table 4.4: Results of linear regression analysis

\begin{tabular}{|c|c|c|c|c|c|c|c|c|}
\hline \multirow{2}{*}{ Independent Variables } & \multicolumn{2}{|c|}{ TSQM Convenience } & \multicolumn{2}{|c|}{ TSQM Effectiveness } & \multicolumn{2}{|c|}{ TSQM Side-effects } & \multicolumn{2}{|c|}{ TSQM Global } \\
\hline & Model 1 & Model 2 & Model 1 & Model 2 & Model 1 & Model 2 & Model 1 & Model 2 \\
\hline \multicolumn{9}{|l|}{ Type of MS (Ref. RRMS) } \\
\hline SPMS & 2.13 & 2.06 & -2.64 & -2.45 & 3.57 & 2.58 & -2.33 & -1.74 \\
\hline PPMS & 2.52 & 2.11 & -1.62 & -1.36 & -3.01 & -2.94 & -0.79 & -0.68 \\
\hline PRMS & -0.73 & -1.17 & 3.11 & 2.92 & -5.49 & -4.19 & 2.28 & 2.72 \\
\hline Duration of MS & 0.17 & 0.19 & 0.01 & 0.02 & 0.05 & 0.09 & 0.16 & 0.17 \\
\hline Age in years & 0.01 & -0.01 & 0.01 & 0.02 & 0.19 & 0.14 & 0.05 & 0.07 \\
\hline No. of MS symptoms & $-0.58 * *$ & $-0.64 * *$ & $-0.88 * * *$ & $-0.94 *$ & $-1.39 * * *$ & $-1.26 * * *$ & $-0.76 * * *$ & $-0.82 * * *$ \\
\hline $\begin{array}{l}\text { No. of Relapses in last } 12 \\
\text { months }\end{array}$ & -0.68 & $-0.93^{*}$ & $-1.74 * * *$ & $-1.89 *$ & $-1.39 * *$ & $-1.06^{*}$ & $-1.14 * *$ & $-1.31 * * *$ \\
\hline No. of comorbid condition & 0.54 & 0.49 & 0.49 & 0.48 & $-1.10 * *$ & $-0.90^{*}$ & 0.43 & 0.43 \\
\hline PDDS & -0.17 & -0.47 & $-1.78 * * *$ & $-1.78^{*}$ & -0.13 & 0.31 & $-1.25^{* *}$ & $-1.44 * *$ \\
\hline $\begin{array}{l}\text { No. of DMDs taken in the } \\
\text { past }\end{array}$ & -1.02 & -1.29 & $-1.96 * *$ & $-1.97 *$ & $-2.33 * *$ & $-2.30 * *$ & $-1.98^{* *}$ & $-2.16^{* *}$ \\
\hline \multicolumn{9}{|c|}{ Type of current DMD used [Ref. Oral (Fingolimod)] } \\
\hline IM (Interferon b-1a) & $-26.19 * * *$ & $-25.58 * * *$ & -0.22 & -0.86 & -3.58 & -3.82 & $-15.05 * * *$ & $-15.76 * * *$ \\
\hline SC (Interferon b-1b) & $-31.13 * * *$ & $-30.05 * * *$ & -2.00 & -2.31 & -4.09 & -3.82 & $-21.00 * * *$ & $-21.13 * * *$ \\
\hline SC (Glatiramer acetate) & $-28.08 * * *$ & $-27.19 * * *$ & -2.75 & -3.05 & 5.99 & 7.04 & $-16.71 * * *$ & $-16.66 * * *$ \\
\hline SC (Interferon b-1a) & $-27.33 * * *$ & $-25.99 * * *$ & -4.03 & -4.31 & -1.79 & -0.25 & $-14.75^{* * *}$ & $-14.81 * * *$ \\
\hline Infusion (Natalizumab) & $-14.34 * * *$ & $-15.49 * * *$ & $8.66^{*}$ & $7.95^{*}$ & 5.89 & 5.62 & -4.22 & -5.32 \\
\hline No DMD & $-36.75 * * *$ & $-35.07 * * *$ & $-22.82 * * *$ & $-23.06 * * *$ & -8.10 & -7.02 & $-36.90 * * *$ & $-36.59 * * *$ \\
\hline Gender (Ref. Males) & & -2.19 & & -0.72 & & -0.63 & & -0.68 \\
\hline $\begin{array}{l}\text { Marital (Ref. without } \\
\text { partner) }\end{array}$ & & -0.65 & & 0.68 & & -1.57 & & -0.10 \\
\hline Race (Ref. White) & & -0.99 & & 1.47 & & -3.42 & & 1.14 \\
\hline \multicolumn{9}{|l|}{ Education (Ref. $\leq$ High school) } \\
\hline Some college & & -0.29 & & 0.43 & & 0.82 & & -1.88 \\
\hline Bachelors Degree & & -0.09 & & 0.49 & & 3.50 & & -0.63 \\
\hline Postgraduate Degree & & -0.73 & & -1.93 & & 1.65 & & -3.22 \\
\hline \multicolumn{9}{|l|}{ Income (Ref. $<\$ 25,000)$} \\
\hline$\$ 25,001-\$ 50,000$ & & -1.16 & & -0.69 & & 2.35 & & 0.62 \\
\hline$\$ 50,001-\$ 75,000$ & & -3.91 & & 0.99 & & 2.64 & & -1.22 \\
\hline$\$ 75,001-\$ 100,000$ & & -3.50 & & -2.37 & & 5.10 & & -2.31 \\
\hline$>\$ 100,000$ & & -3.14 & & -3.23 & & 4.07 & & -3.41 \\
\hline \multicolumn{9}{|l|}{ Employment (Ref. Full time) } \\
\hline Part time & & 2.05 & & 1.24 & & -2.67 & & 1.59 \\
\hline Not Working & & 2.58 & & -0.74 & & -2.04 & & 1.22 \\
\hline \multicolumn{9}{|l|}{ Region (Ref. Northeast) } \\
\hline Midwest & & -2.26 & & -0.82 & & 1.34 & & -0.33 \\
\hline South & & 2.04 & & 0.22 & & 0.33 & & -0.33 \\
\hline West & & -0.95 & & -1.27 & & -0.55 & & -2.33 \\
\hline Panel (Ref. Biogen) & & -1.91 & & -0.75 & & -2.58 & & -1.72 \\
\hline \multicolumn{9}{|c|}{ Prescription Coverage (Ref. Not covered) } \\
\hline Covered & & 1.06 & & -2.42 & & 0.22 & & -1.69 \\
\hline Support Program & & -0.12 & & -2.11 & & -2.51 & & -0.94 \\
\hline $\begin{array}{l}\text { No. of visits to PCP in past } \\
12 \text { months }\end{array}$ & & 0.08 & & 0.72 & & $-0.95^{*}$ & & 0.17 \\
\hline $\begin{array}{l}\text { No. of visits to Neurologists } \\
\text { in past } 12 \text { months }\end{array}$ & & 0.72 & & -0.02 & & -0.35 & & 0.28 \\
\hline
\end{tabular}

$* 0.01 \leq p<0.05, * * 0.001 \leq p<0.01, * * * p<0.001$ 
Table 4.5: Summary of the block-wise entry of covariates in the linear regression models

\begin{tabular}{|c|c|c|c|c|c|c|c|}
\hline Model & $\mathrm{R}^{2}$ & Adj. $R^{2}$ & $\mathrm{R}^{2}$ Change & F change & $\begin{array}{c}\text { F change } \\
\text { Sig. }\end{array}$ & $\begin{array}{l}\text { Model F } \\
\text { statistic }\end{array}$ & $\begin{array}{l}\text { Sig. F } \\
\text { Change }\end{array}$ \\
\hline \multicolumn{8}{|c|}{ Dependent variable: TSQM- Convenience domain score } \\
\hline 1 & 0.186 & 0.171 & 0.186 & 13.034 & $* * *$ & 13.034 & $* * *$ \\
\hline 2 & 0.204 & 0.172 & 0.019 & 1.051 & .398 & 6.383 & $* * *$ \\
\hline \multicolumn{8}{|c|}{ Dependent variable: TSQM- Effectiveness domain score } \\
\hline 1 & 0.390 & 0.379 & 0.390 & 36.574 & $* * *$ & 36.574 & $* * *$ \\
\hline 2 & 0.398 & 0.374 & 0.008 & 0.598 & .916 & 16.444 & $* * *$ \\
\hline \multicolumn{8}{|c|}{ Dependent variable: TSQM- Side-effects domain score } \\
\hline 1 & 0.178 & 0.164 & 0.178 & 12.379 & $* * *$ & 12.379 & $* * *$ \\
\hline 2 & 0.195 & 0.163 & 0.017 & 0.970 & .497 & 6.037 & $* * *$ \\
\hline \multicolumn{8}{|c|}{ Dependent variable: TSQM- Global score } \\
\hline 1 & 0.345 & 0.333 & 0.345 & 30.064 & $* * *$ & 30.064 & $* * *$ \\
\hline 2 & 0.353 & 0.327 & 0.009 & 0.607 & .910 & 13.584 & $* * *$ \\
\hline
\end{tabular}

$* 0.01 \leq p<0.05, * * 0.001 \leq p<0.01, * * * p<0.001$ 
Figure 4.1: Survey population

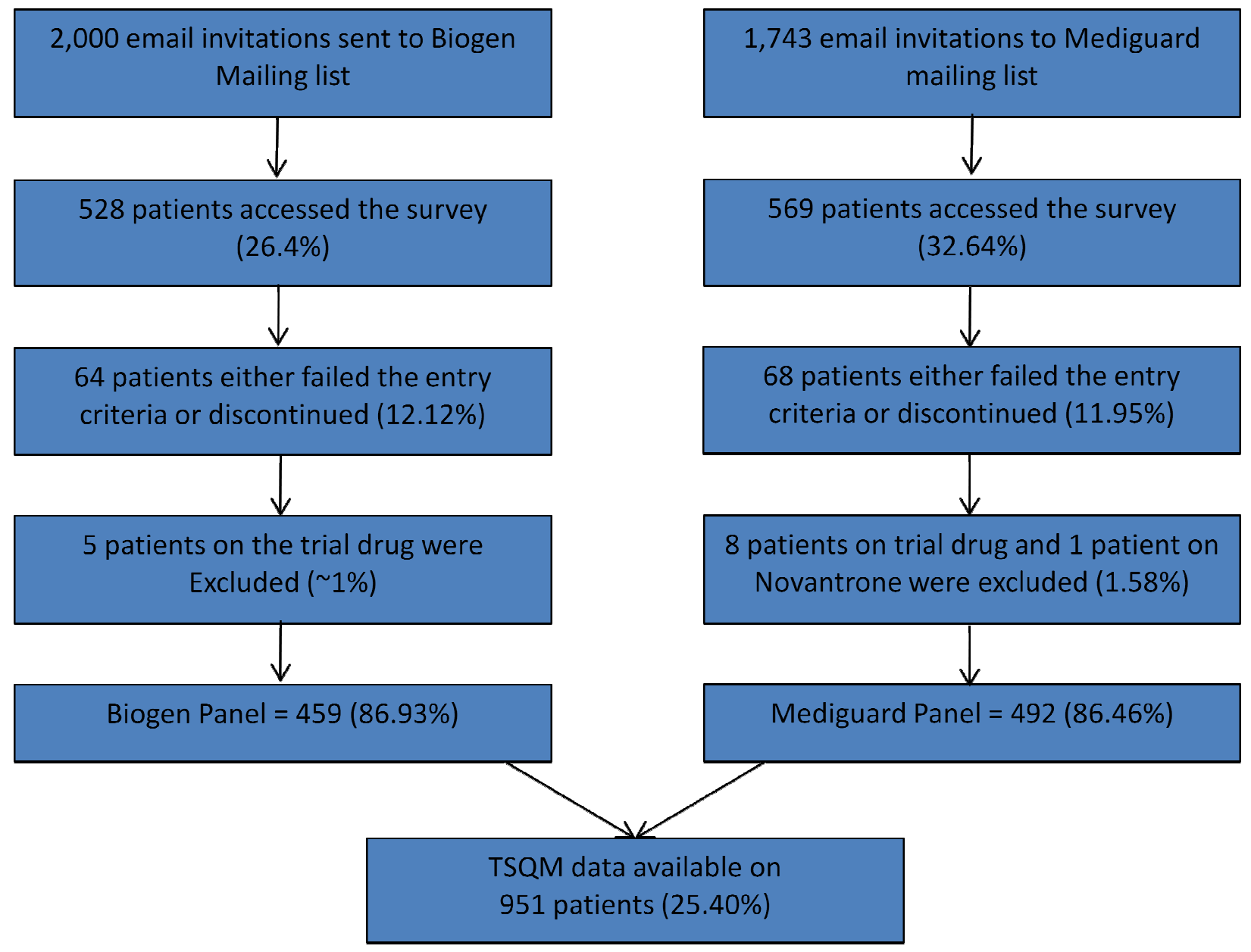




\section{References}

1. Anderson RB, Hollenberg NK, Williams GH: Physical Symptoms Distress Index: a sensitive tool to evaluate the impact of pharmacological agents on quality of life. Archives of Internal Medicine. 1999; 159:693-700.

2. Atkinson MJ, Sinha A, Hass SL, Colman SS, Kumar RN, Brod M, Rowland CR. Validation of a general measure of treatment satisfaction, the Treatment Satisfaction Questionnaire for Medication (TSQM), using a national panel study of chronic disease. Health Qual Life Outcomes. 2004 Feb; 2:12.

3. Atkinson MJ, Kumar R, Cappelleri JC, Hass SL. Hierarchical construct validity of the treatment satisfaction questionnaire for medication (TSQM version II) among outpatient pharmacy consumers. Value Health. 2005 Nov-Dec;8 Suppl 1:S9-S24.

4. Awad AG, Voruganti LN: Quality of life and new antipsychotics in schizophrenia. Are patients better off? Int J Soc Psychiatry. 1999;45:268-275.

5. Coles A. Multiple sclerosis. Pract Neurol. 2009 Apr;9(2):118-26.

6. Compston A, Coles A. Multiple sclerosis. Lancet. 2002;359 (9313):1221-1231.

7. Compston A, Confavreux C, Lassmann H, McDonald I, Miller D, Noseworthy J, et al. McAlpine's multiple sclerosis. Philadelphia: Churchill Livingstone/Elsevier; 2006.

8. Cramer JA, Cuffel BJ, Divan V, Al-Sabbagh A, Glassman M. Patient satisfaction with an injection device for multiple sclerosis treatment. Acta Neurol Scand. 2006 Mar;113(3):156-62.

9. Diamond R: Drugs and the quality of life: the patient's point of view. Journal of Clinical Psychiatry. 1985, 46:29-35 
10. Giovannoni G, Southam E, Waubant E. Systematic review of disease-modifying-therapies to assess unmet needs in multiple sclerosis: tolerability and adherence. Mult Scler. 2012 Jan 16. [Epub ahead of print] PubMed PMID22249762.

11. Goodin DS, Frohman EM, Garmany GP Jr, Halper J, et al. Disease modifying therapies in multiple sclerosis: report of the Therapeutics and Technology Assessment Subcommittee of the American Academy of Neurology and the MS Council for Clinical Practice Guidelines. Neurology. $2002 \operatorname{Jan} 22 ; 58(2): 169-78$.

12. Hirst C, Ingram G, Pearson O, Pickersgill T, Scolding N, Robertson N. Contribution of relapses to disability in multiple sclerosis. J Neurol. 2008 Feb;255(2):280-7.

13. Hohol MJ, Orav EJ, Weiner HL. Disease steps in multiple sclerosis: a simple approach to evaluate disease progression. Neurology. 1995;45:251-55.

14. Marrie RA, Horwitz R, Cutter G, Tyry T. Cumulative impact on comorbidity on quality of life in MS. Acta Neurol Scand. 2012 Mar;125(3):180-6.

15. Marrie RA, Cutter G, Tyry T, Vollmer T, Campagnolo D. Does multiple sclerosis-associated disability differ between races? Neurology. 2006;66:1235-1240.

16. No Author listed. Adverse effects of the atypical antipsychotics. Collaborative Working Group on Clinical Trial Evaluations. J Clin Psychiatry. 1998; 59(Suppl 12):17-22.

17. O'Day K, Meyer K, Miller RM, Agarwal S, Franklin M. Cost-effectiveness of natalizumab versus fingolimod for the treatment of relapsing multiple sclerosis. J Med Econ. 2011;14(5):617-27.

18. Pascoe GC: Patient satisfaction in primary health care: a literature review and analysis. Eval Program Plann. 1983; 6:185-210.

19. Pedhazur EJ. Multiple Regression in Behavioral Research. Orlando, FL: Harcourt Brace, 1997. 
20. Rudick RA, Miller DM. Health-related quality of life in multiple sclerosis: current evidence, measurement and effects of disease severity and treatment. CNS Drugs. 2008;22(10):827-39.

21. Rudick RA. Multiple sclerosis, natalizumab, and PML: Helping patients decide. Cleve Clin J Med. 2011 Nov;78 Suppl 2:S18-23.

22. Simmons RD. Life issues in multiple sclerosis. Nat Rev Neurol. 2010 Nov;6(11):603-10.

23. Tabachnick BG, Fidell LS. Using Multivariate Statistics. New York: Harper Collins, 1996. 47.

24. Thompson AJ. Symptomatic management and rehabilitation in multiple sclerosis. J Neurol Neurosurg Psychiatry. 2001;71 Suppl 2:ii22-ii27.

25. Treadaway K, Cutter G, Salter A, et al. Factors that influence adherence with disease-modifying therapy in MS. J Neurol. 2009;256(4):568-576.

26. Tremlett H, Yousefi M, Devonshire V, Rieckmann P, Zhao Y, on behalf of the UBC Neurologists. Impact of multiple sclerosis relapses on progression diminishes with time. Neurology. 2009; 73:1616-1623.

27. Zwibel HL, Smrtka J. Improving quality of life in multiple sclerosis: an unmet need. Am J Manag Care. 2011 May;17 Suppl 5:S139-45. 
CHAPTER 5 


\section{CHAPTER 5}

\section{SUMMARY AND CONCLUSION}

\section{Rational and Objective}

Although incurable in nature, multiple sclerosis (MS) can be effectively managed with strategies that primarily include use of treatments intended for modifying the course of the disease, reducing frequency of relapses, and managing symptoms effectively. Disease modifying drugs (DMDs) used in MS are clinically proven to decrease the occurrence of relapses and delaying worsening of condition which eventually help keeping physical and cognitive disabilities at bay. Improvements in the magnetic resonance imaging techniques and the changes in the criteria used for diagnosis allow early diagnosis of MS in individuals (Cohen, 2006) thereby increasing the possibility of treating individuals with MS early with DMDs. Early initiation of DMDs in the clinical course of the disease is expected to prevent irreversible damage (Alkhawajah, 2011). Currently available first line injectable DMDs (interferon beta $1 \mathrm{a} / 1 \mathrm{~b}$ and glatiramer acetate) are relatively less effective than the second line DMDs (natalizumab and mitoxantrone) but are relatively safer than the second line DMDs. Fingolimod, the first ever oral DMD for MS, was approved by the United States Food and Drug Administration (USFDA) in 2010 as a first line therapy whereas it was approved as a second line therapy by the European Medicines Agency (EMA). However, it came under tough scrutiny of regulators in the US and Europe after receiving reports of deaths among individuals with MS who were on it. It is likely that the regulators may provide fingolimod under restricted access programs and will increase monitoring for individuals who will use it. 
Adhering and continuing to take prescribed DMD as suggested by the clinician is one of the best possible approach individuals with MS can adopt in successfully managing their MS. As therapeutic management of MS requires patients to take their DMDs for an extended period time, adherence with DMDs may become challenging. Adherence to the DMDs is affected due to the side-effects associated with them. Patients have often reported factors associated DMDs such as needle phobia, difficulty in self injecting, injection site reactions, discomfort in self injecting, perceived/experienced lack of efficacy, injection site reactions, pain at injection sites, side effects associated with DMDs (flu-like symptoms, headaches, and nausea), not being able find someone to give injection, and perceived risk of adverse events associated DMDs (Panitch, 2002; Cox, 2006; Rio, 2005; Samuel, 2006; Cramer, 2006; Treadaway, 2009). Non-adherence to DMDs may have clinical, economics, physical, psychological, and social consequences.

Selection of DMDs is an important step in forming an effective treatment strategy in MS. Due to the a) increasing choices for DMDs, b) concerns around uncertainty of the safety-efficacy profiles, and c) the unavailability of the long term data on the newer DMDs; participation of individuals with MS in the process of treatment selection have become ever more important. Involvement of patients in making decisions related to DMD is necessary in order to provide patient centered care (Edwards, 1999). Rigorous assessment of individual's experiences with current/past DMDs, expectations from future DMDs, understanding of risks and benefits, preferences for benefits and risks, and different factors associated with treatment satisfaction are required. This dissertation project utilizes qualitative and quantitative research methods to study important aspects associated with DMDs. The objective of the first study of this project was to do a qualitative assessment of experiences, perceptions, and expectations of individuals with MS with 
DMDs. The second study focused on quantifying preference weights and relative importance of attributes related to DMDs used in the treatment of MS using conjoint analysis. Lastly, the purpose of the third study was to determine disease and treatment related factors associated with treatment satisfaction in individuals with multiple sclerosis. Qualitative data collection for the first study involved focus group discussions with MS patients in an academic hospital setting and the remaining two studies included web based self-report surveys of individuals with MS living in the US. The research design employed in this project was cross sectional.

\section{Summary of Findings}

A total of 18 individuals with confirmed diagnosis of MS participated in the qualitative study. Content analysis of the focus group transcripts revealed five major themes: a) positive experiences of DMDs, b). negative experiences of DMDs, c) DMD adherence, d) perceived/actual value of DMDs, e) expectations from future DMDs. All participants of the focus group had a good understanding of the role of DMDs in the overall MS treatment. A majority of participants believed that the DMDs they were taking were effective in preventing their relapses and progression of the disease. Participants believed that reduction in frequency of relapses was the most significant benefit that they had experienced, followed by improvements in quality of life, physical health, cognitive health, and energy levels. Perceived or experienced lack of efficacy, injection site reactions, and side effects of DMDs that affected individuals' day to day lives were the negative experiences that participants believed are associated with DMDs.

Although none of the participants in our study had previously experienced any adverse events from DMDs, they expressed a general concerns about the risks associated with DMDs. 
Adherence with DMDs among participants was affected due to perceived/actual efficacy, convenience of administration, dosage frequency, administration flexibility, perceived quality of life, ability to self-inject, finding help to give injections, forgetting to take it, insurance coverage, and not having enough medicine. Majority of the participants reported having some form of health insurance and prescription coverage. Hence cost of DMD was not an issue them. They hoped that their coverage and co-pays do not increase in the future and remain the same. Participants' perceived non-monetary valuation of DMDs was related to perceived clinical benefit, quality of life, and severe adverse events, perceived cost of missed opportunity to initiate treatment with DMD after initial diagnosis, and perceived diminishing benefit from DMDs. Participants expected to see newer DMDs that would repair damaged myelin, more oral treatments, improve quality of life, and treatments serve as a cure for MS. Although, a majority of the participants indicated that they would prefer oral DMDs over injectable DMDs, interestingly, they expressed their hesitation and concerns over the strength of safety-efficacy data associated with the newer DMDs.

The second study utilized a choice based, stated preference method to estimate preference weights and relative importance of attributes for DMDs used in the treatment of MS. DMDs were defined using seven characteristics unique to DMDs indicating mode of administration, evidence on treatment outcomes in years, number of relapses expected within 5 years, delay in disability progression by ' $n$ ' years, chances of severe disability or death from PML in within 5 years, chances of severe liver dysfunction within 5 years, and chances of flu-like symptoms following DMD administration. Each DMD had three levels. Estimated preference weight indicated a natural order of preference suggesting that respondents understood the differences in the three attribute levels 
in the choice tasks. Respondents placed a higher utility for lower levels associated with risk related attributes (PML, liver dysfunction, and flu-like symptoms). Higher utility was indicated for benefits providing larger gains in terms of no relapse within next 5 years and delaying progression of MS by 15 years. Respondents also indicated higher preferences for DMD with oral route of administration over parenteral DMDs. The need for DMDs with better safety-efficacy is data is reflected in patients' choice of DMDs with 15 years of research over relatively less studied DMDs. Attributes indicating risk related DMDs; such as liver dysfunction and PML were relatively the most important to the respondents. Remaining attributes were ranked in the following order-flu-like symptoms, delaying progression of MS, relapses within 5 years, treatment administration, and evidence on outcomes.

The objective of the third study was to assess disease and treatment related factors associated satisfaction of treatment in individuals with MS. Respondents currently not taking any DMD had consistently lowest mean treatment satisfaction scores for all the three domains and the global satisfaction scores as compared those who were on DMDs. After controlling for various socio-demographic factors, type of current DMD used, total number of DMDs taken in the past, number of relapses MS symptoms experienced, number of relapses experienced in the past 12 months, and the disability status score were found to have significant negative association with the treatment satisfaction scores. Satisfaction score for convenience of administration were significantly better for those who were on once a day oral (fingolimod) formulation than for those respondents who were on injectable DMDs or on no DMD. This confirms that for MS patients, oral treatments are associated with higher levels satisfaction with convenience of administration. Respondents who were on once a month infusion (natalizumab) had significantly better 
effectiveness scores as compared to the latest oral (fingolimod) DMD. None of the treatments (DMD/No DMD) had significantly different satisfaction score for Side-effects as compared to oral (fingolimod) DMD. This suggests that the satisfaction associated with effectiveness of treatments were no different for those who were taking older injectable DMDs (interferons and glatiramer acetate) as compared with those who were on newer oral DMDs. Overall satisfaction scores were not significantly different for those who were on once a month infusion (natalizumab) or one a day pill (fingolimod).

\section{Significance}

Understanding experiences, perception, and expectations of individuals with MS with respect to DMDs has a key role in improving overall MS treatment management. Awareness of the issues related to DMDs based on subjective (i.e. patients' own) evaluation may help identify advantages or obstacles that can interact with adherence to treatment plans involving DMDs. The qualitative evaluation in this study indicates that individuals with MS have adapted themselves to the current management of MS with DMDs. However individuals expect to see more benefits in terms of convenience of administration, reduced dosage frequency, more clinical benefits in terms of overall quality of life, myelin repair, and lastly a cure. Apart from Individual understanding of the disease, beliefs and past experiences derive their expectations from the treatments they receive. Knowledge gained for this study can be used to address patients' concerns, improve patients' understanding regarding DMDs, encourage involvement in decisions related to DMDs, and build realistic expectations from the DMDs to optimize treatment selection. 
Participation of individuals with MS in treatment related decision making is always encouraged and is also considered as the need for improving health outcomes. In order to select the best possible DMD for individuals with MS, it is important for treating clinicians to understand their preferences related to DMDs. However, it is not clear how individuals with MS perceive risks, benefits, and other attributes related to convenience. This is the first study that evaluated preferences for DMDs with respect to mode of administration, evidence on outcomes preferred in a DMD, and flu-like symptoms along with benefit and risk related attributes. The results of this study give us insights into how individuals with MS place higher importance on risks related characteristics as opposed to the benefits provided by the DMDs. Newer DMDs and the ones that are expected to be marketed in the future will have insufficient data related to benefits and risks. Relative importance of risks associated with DMDs indicated by MS patients in this study supports need for assessing how MS patients understand risks and uncertainties associated DMDs.

Treatment satisfaction is an important patient reported outcome. It is an important indicator for evaluating acceptability of treatments or treatment related attributes for patients' perspective. Disease conditions like MS, where a patient has to continue to take the treatment for a longer duration, periodic objective evaluation with treatment satisfaction can be used to determine adherence and persistence with the treatment. Satisfaction evaluation may allow identification of individuals who would require a treatment change. The results of this study suggest that patients' overall satisfaction with MS treatment is mainly driven by treatment related factors such as the type of DMD. One of the factors associated with switching or stopping DMDs is the lack of treatment effectiveness. The results suggests that individuals who used different DMDs in the past had lower satisfaction scores on Effectiveness and Side-effect scales, suggesting that the 
DMDs either were not clinically effective in those patients or could be due to nonadherence/switching. Negative association between satisfaction and clinical factors such as relapses, disability status, and MS symptoms suggest that patients despite taking DMDs experience relapses and progression of MS, a likely reason for patients to become non-adherent, switch, or stop medication in the future.

\section{Strengths}

The strengths of the three studies conducted in this dissertation project include sound use of qualitative and quantitative methods. Focus group discussion used in the first study is a highly recommended and validated method for evaluation of subjective experiences, opinions, and expectations regarding various aspects of healthcare. The uniqueness of the first study is that, as per the author's knowledge, this is one of first studies that explored aspects such as experiences, perceptions, and expectations from the DMDs in MS. Preferences typically can be evaluated using two different methods, revealed preference method and stated preference method, respectively (Bridges, 2007). Revealed preferences of patients are evaluated when they are actually making a treatment decision or have already made one. Administrative claims data for prescription filling is one example where revealed preferences of patients are determined. However, such preferences may be affected by extraneous factors such as patients' socio-economic status, prescription coverage, clinician preferences, etc and may not reflect patients' true treatment preferences. On the contrary, stated preference method focuses on eliciting preferences directly from patients using survey questionnaire (Bridges, 2003). Also, the number of respondents in conjoint study was high ( $n=897)$ as compared to other published studies utilizing conjoint analysis. This is one of few 
studies that evaluated treatment satisfaction among MS patients taking different DMDs using large, national sample $(n=951)$ with a response rate of approximately $25 \%$.

\section{Limitations}

Limitations for individual studies have been discussed earlier at the end of respective study chapters. This section provides overview of limitations for the entire project. This project involved series of studies which were exploratory in nature. Moreover, the data collection process was cross-sectional. Therefore causal relationship cannot be established.

In the qualitative study, the views of participants may be emergent in nature due to the group dynamics and may not necessarily reflect participants 'own opinions and expectations (Sim, 1998). The conclusions drawn from the focus group data can only indicate whether a particular opinion was present or not. Assessment of relative magnitude of views, opinions, expectations, and experiences cannot be established. Generalization of the interpretation of focus group data can be debatable. Theoretical generalization of the results is relatively more acceptable than practical generalization (Sim, 1998). Restricting sample to those who were taking a DMD at the time of focus group discussion may not capture views of those who never used any DMD or were not taking the DMD at the time of the study. All participants in focus group were White and the views of MS patients from other racial origins may not overlap with the findings of this study. Generally people who are more talkative, social, or interactive (extrovert) will be the ones who participate in a focus group; therefore, some self-selection bias further limiting generalizability may also be present.

Data collection for study 2 and 3 were done using web based survey. Majority of the 
respondents in these studies were college educated, therefore may limit the generalizability of the studies 2 and 3, respectively. Conjoint analysis involves hypothetical choice tasks that patients have to respond to. Although it is best suited method for eliciting patient preferences, it does not necessarily mean that in the real life patients would make the same choices. Hypothetical nature of conjoint tasks should be kept in perspective while interpreting the results of this study. Data collection for conjoint analysis study was also cross-sectional.

\section{Direction for the Future Research}

Despite having quite a few DMD options around, selection of a DMD that is efficacious, safe, and the one that is well tolerated by the individual patient is challenging. Treatment related decisions in MS are likely to become even more complex with the possibility of increase in the choices of DMDs that are more efficacious but more risky as well.

Success of DMDs mainly depends on patients taking it as they are supposed to, remaining on the therapy for as long as they are supposed to, and by not dropping out. However the reasons behind stopping or switching DMDs can be different for MS patients. In order to provide patient centered care in MS, patient's perspective on variety of outcomes associated with DMDs needs to be evaluated using qualitative and quantitative methods. This study collected data crosssectionally. The future research should focus on evaluation interrelation of factors such as patients' knowledge about disease and treatments, past experiences, treatment expectations, benefit risk preferences, satisfaction with DMDs, quality of life, adherence, and persistence in a single, possibly in a large multi-center study with prospective data collection. 
A comparison between physicians' preferences and patients' preferences for benefits and risks associated with DMDs can provide differences in respective valuation of DMDs. Differences in the benefit and risk valuation might provide information for developing better shared decision making tools.

\section{Conclusion}

Individuals with MS understand the role of currently available DMDs in therapeutic management of their condition and adapt themselves to available treatments; however, they have greater expectations from emerging DMDs. DMDs with convenient routes of administration are preferred by MS patients, but the side-effects and efficacy of these treatments are still the most important factors. Patient satisfaction with the DMDs is associated with the type of currently used DMD, relapses experienced, disabilility status, number of symptoms experienced, and the number of DMDs used in the past. Routine evaluation of MS patients' experiences, expectations, benefitrisk knowledge, benefit-risk preferences, and satisfaction with the current DMD can improve understanding of unmet needs related to DMDs, and also inform developing effective therapeutic management strategies to provide patient centered care. 


\section{References}

1. Alkhawajah $\mathrm{M}$, Oger J. When to initiate disease-modifying drugs for relapsing remitting multiple sclerosis in adults? Mult Scler Int. 2011; 2011: 724871.

2. Bridges J. Stated preference methods in health care evaluation: an emerging methodological paradigm in health economics. Appl Health Econ Health Policy. 2003;2:21324.

3. Bridges J, Onukwugha E, Johnson F, Hauber A. Patient preference methods - a patient centered evaluation paradigm. ISPOR Connect. 2007;13:4-7.

4. Cohen B. Adherence to Disease-Modifying Therapy for Multiple Sclerosis. International Journal of MS Care. 2006 February; Supplement:32-37.

5. Cox D, Stone J. Managing self-injection difficulties in patients with relapsing-remitting multiple sclerosis. J Neurosci Nurs. 2006;38:167-71.

6. Cramer JA. Consequences of intermittent treatment for hypertension: the case for medication compliance and persistence. Am J Manag Care. 1998;4:1563-68.

7. Edwards AGK, Elwyn G. How should effectiveness of risk communication to aid patients' decisions be judged? A review of the literature. Med Decis Making. 1999;19:428-34.

8. Panitch H, Goodin DS, Francis G, Chang P, Coyle PK, O'Connor P et al. Randomized, comparative study of interferon beta-1a treatment regimens in MS: The EVIDENCE Trial. Neurology. 2002;59:1496-506.

9. Rio J, Porcel J, Tellez N, Sanchez-Betancourt A, Tintore M, Arevalo MJ et al. Factors related with treatment adherence to interferon beta and glatiramer acetate therapy in multiple sclerosis. Mult Scler. 2005;11:306-9. 
10. Samuel L, Lowenstein EJ. Recurrent injection site reactions from interferon beta 1-b. J Drugs Dermatol. 2006;5:366-67.

11. Treadaway K, Cutter G, Salter A, et al. Factors that influence adherence with diseasemodifying therapy in MS. J Neurol. 2009;256(4):568-576.

12. Sim J. Collecting and analysing qualitative data: issues raised by the focus group. J Adv Nurs. 1998 Aug;28(2):345-52. 
APPENDICES 


\section{Appendix A: Focus Group - Script for Telephonic Invitation}

Instructions: Telephone script - Contacting patients for the focus group interviews.

This brief recruitment script will be read to a convenience sample of approximately 35 - 40 multiple sclerosis (MS) patients who will be contacted to determine their willingness to participate in the focus group discussion.

(Read)

Hello, my name is (name of the research team member) and I am calling from Drs. Gauri Pawar/Ludwig Gutmann/Tracy Weimer/John Brick's office at the Neurology Clinic at West Virginia University. Could I please speak with Mr. /Ms. /Mrs. (NAME OF THE PATIENT). We would like to see if he/she/you would be willing to participate in a focus group discussion.

\section{[TO BE READ TO THE PATIENT]}

Researchers from the Neurology Clinic at the West Virginia University in collaboration with West Virginia University School of Pharmacy are conducting a research study to determine patient preferences for characteristics of disease modifying treatments used in multiple sclerosis, such as treatment benefits, side effects, serious adverse events, and route of administration. This research study is part of a doctoral (Ph.D.) research project, and has been acknowledged by the Institutional Review Board of West Virginia University.

We are recruiting patients with multiple sclerosis, who have visited our neurology clinic in the past one year to participate in the focus groups. The focus group will be a discussion involving about 10 individuals with multiple sclerosis. Participants will be asked about their experiences with disease modifying drugs (such as Avonex, Rebif, Copaxone, and Tysabri) used in the treatment of multiple sclerosis, in addition to other aspects such as health related quality of life, treatment satisfaction, health concerns, and expectations from newer disease modifying treatments for multiple sclerosis. The information collected during the focus group discussions will be used to develop a questionnaire. This questionnaire will then be used in a national survey to evaluate patients' preferences for disease modifying treatments.

Participation in this study is completely voluntary. Refusal to participate will not affect your relationship and or the care you receive from the Neurology Clinic at the West Virginia University in any way. All information collected from the focus group discussion will be kept confidential. You do not have to answer any question that you don't wish to. The information discussed during this focus group will be analyzed as a whole, and no names will be used in the analysis of the discussion content. If you agree to participate, you will receive a letter in the mail with study and contact information from the investigators prior to the focus group.

Focus groups will be conducted in the $-4^{\text {th }}$ week of February and $1^{\text {st }}$ week of March (2010) in a conference room in the Department of Pharmaceutical Systems and Policy at the West Virginia 
University School of Pharmacy. The focus group will last no longer than 2 hours. Upon completion of the focus group, you will receive a $\$ 25$ Walmart gift card as a token of appreciation for your time and participation.

Would you be interested in participating in our focus group study?

Yes |

NO I

If $\mathrm{NO}, \ldots .$.

We appreciate you taking the time to talk to us today. In case you change your mind and are willing to participate in the focus group, please call us at 304-293-1639 at your earliest convenience so that we can schedule you. [END CALL]

If YES, ......

In order to determine your eligibility for participating in the focus group, I would like to ask you a few screening questions.

\begin{tabular}{|c|c|c|}
\hline Focus Group Screening Questions & Yes & No \\
\hline Q1. Are you 18 years of age or older? & Continue & $\begin{array}{l}\text { Stop - } \\
\text { Does not } \\
\text { qualify }\end{array}$ \\
\hline Q2. Do you have a confirmed diagnosis of MS? & Continue & $\begin{array}{l}\text { Stop - } \\
\text { Does not } \\
\text { qualify }\end{array}$ \\
\hline $\begin{array}{l}\text { Q3. Have you visited the outpatient neurology clinic at WVU at least } \\
\text { once within the last one year? }\end{array}$ & Continue & $\begin{array}{l}\text { Stop - } \\
\text { Does not } \\
\text { qualify }\end{array}$ \\
\hline Q4. Are you currently experiencing a relapse? & $\begin{array}{l}\text { Stop - } \\
\text { Does not } \\
\text { qualify }\end{array}$ & Continue \\
\hline $\begin{array}{l}\text { Q5. Disease modifying drugs are the medicines that are used to } \\
\text { control the progression of MS and to prevent relapses associated with } \\
\text { MS. Have you ever used a disease modifying treatment (such as Rebif, } \\
\text { Avonex, Copaxone, Betaseron, Mitoxantrone or Tysabri) in the past to } \\
\text { treat your MS? }\end{array}$ & Continue & $\begin{array}{l}\text { Stop - } \\
\text { Does not } \\
\text { qualify }\end{array}$ \\
\hline $\begin{array}{l}\text { Q6. Are you currently taking a disease modifying treatment (such as } \\
\text { Rebif, Avonex, Copaxone, Betaseron, Mitoxantrone or Tysabri) to treat } \\
\text { your MS? }\end{array}$ & Continue & $\begin{array}{l}\text { Stop - } \\
\text { Does not } \\
\text { qualify }\end{array}$ \\
\hline
\end{tabular}

If the individual is not eligible to participate in the focus group discussion: Thank you for your time. Unfortunately, based on the answers you provided, you do not meet the criteria for participation in the focus group discussion. Thank you once again for your interest and time and have a great day. 
If the individual is eligible to participate in the focus group discussion: Thank you. Based on the answers you provided, you are eligible to participate in the focus group discussion. Would it be alright with you if we go over the available times and dates now for you to attend the focus group discussion?

If "No": When can I contact you to go over the available times and dates for focus group discussion? Confirm contact number.

If "Yes": Discuss availability using following information

Which of the following dates and times are you available during the week of week of March $1^{\text {st }}$ and March $8^{\text {th }}$ ?

CHECK MARK AVAILABLE DATES AND TIMES BASED ON OPTIONS BELOW

\begin{tabular}{|l|l|l|l|l|l|l|l|}
\hline & $\begin{array}{l}\text { Monday } \\
1^{\text {st }} \text { Mar }\end{array}$ & $\begin{array}{l}\text { Tuesday } \\
2^{\text {nd }} \text { Mar }\end{array}$ & $\begin{array}{l}\text { Wednesday } \\
3^{\text {rd }} \text { Mar }\end{array}$ & $\begin{array}{l}\text { Thursday } \\
4^{\text {th }} \text { Mar }\end{array}$ & $\begin{array}{l}\text { Friday } \\
5^{\text {th }} \text { Mar }\end{array}$ & $\begin{array}{l}\text { Saturday } \\
6^{\text {th }} \text { Mar }\end{array}$ & $\begin{array}{l}\text { Sunday } \\
7^{\text {th }} \text { Mar }\end{array}$ \\
\hline $\begin{array}{l}\text { 10:00AM - } \\
\text { 12:30 PM }\end{array}$ & & & & & & & \\
\hline $\begin{array}{l}12: 30 \text { PM - } \\
3: 00 \text { PM }\end{array}$ & & & & & & & \\
\hline $\begin{array}{l}3: 00 \text { AM - 5:30 } \\
\text { PM }\end{array}$ & & & & & & & \\
\hline $\begin{array}{l}\text { 5:30AM - 8:00 } \\
\text { PM }\end{array}$ & & & & & & & \\
\hline
\end{tabular}

\begin{tabular}{|l|l|l|l|l|l|l|l|}
\hline & $\begin{array}{l}\text { Monday } \\
8^{\text {th }} \text { Mar }\end{array}$ & $\begin{array}{l}\text { Tuesday } \\
9^{\text {th }} \text { Mar }\end{array}$ & $\begin{array}{l}\text { Wednesday } \\
10^{\text {th }} \text { Mar }\end{array}$ & $\begin{array}{l}\text { Thursday } \\
11^{\text {th }} \text { Mar }\end{array}$ & $\begin{array}{l}\text { Friday } \\
12^{\text {th }} \text { Mar }\end{array}$ & $\begin{array}{l}\text { Saturday } \\
13^{\text {th }} \text { Mar }\end{array}$ & $\begin{array}{l}\text { Sunday } \\
14^{\text {th }} \text { Mar }\end{array}$ \\
\hline $\begin{array}{l}\text { 10:00AM - } \\
12: 30 \text { PM }\end{array}$ & & & & & & & \\
\hline $\begin{array}{l}12: 30 \text { PM - } \\
3: 00 \text { PM }\end{array}$ & & & & & & & \\
\hline $\begin{array}{l}3: 00 A M-5: 30 \\
\text { PM }\end{array}$ & & & & & & & \\
\hline $\begin{array}{l}5: 30 A M-8: 00 \\
\text { PM }\end{array}$ & & & & & & & \\
\hline
\end{tabular}

Thank you for your interest in participating. We will contact you when a date and time has been identified that is convenient to most of the individuals we are inviting. It is possible that the date and time we select may not be convenient to you. We apologize if that happens and you cannot participate. I would like to confirm your contact information (confirm name, email, and address of the patient). Thank you and we will be contacting you with a scheduled focus group discussion date and time in the next few weeks. 
[Investigator contact information to be given only on the request of the participants and will not be verbally communicated otherwise]

$\underline{\text { Investigator Contact Information: }}$

Gauri Pawar, M.D. (Co-Investigator)

Associate Professor, Vice-Chair of Business Affairs and Compliance, Medical Director

Department of Neurology, School of Medicine

West Virginia University

Room 7500 HSS

P.O. Box 9180

Morgantown, WV 26506-9180

Phone: (304) 293-3527

Abhijeet Bhanegaonkar, MPH (Co-Investigator)

Doctoral Candidate

Department of Pharmaceutical Systems and Policy

West Virginia University School of Pharmacy

P.O. Box 9510

Morgantown WV 26506-9510

Phone: (304) 293-1442

S. Suresh Madhavan, MBA, Ph.D. (Principal Investigator)

Professor and Chair Department of Pharmaceutical Systems and Policy

West Virginia University School of Pharmacy

P.O. Box 9510

Morgantown WV 26506-9510

Phone: (304) 293-1652 


\section{Appendix B: Focus Group - Invitation Letter}

Dear Mr/Ms/Mrs (NAME OF THE PATIENT),

The Department of Neurology at West Virginia University School of Medicine and Department of Pharmaceutical Systems and Policy at West Virginia University School of Pharmacy are conducting a research study about multiple sclerosis to determine patients' preferences associated with disease modifying treatments. This research study is part of a doctoral (Ph.D.) research project. This study has been acknowledged and approved by the Institutional Review Board of West Virginia University.

Based on your willingness to participate in our focus group discussion, we have scheduled you for the following date, time, and location:

DATE - DAY/DATE/MONTH (TBD)

TIME - TIME am/pm to TIME am/pm (TBD)

ADDRESS - ROOM \# (TBD), Department of Pharmaceutical Systems and Policy, School of Pharmacy, Health Science Center North, 1 Medical Center Drive, Morgantown WV 26506.

You will meet a designated person with a sign at the front entrance of the Family Medicine/Dental Clinic of the Robert C. Byrd Health Sciences Center and he/she will guide you to the conference room. If you are not able to attend the focus group on scheduled date/time for any reason or if you experience a relapse between now and the focus group date, please let us know at (304) 293-1639 at your earliest convenience to cancel your enrollment in the focus group discussion.

Your participation in this study is completely voluntary, and refusal to participate will not affect the service that you receive at Neurology Clinic at West Virginia University in any way. All information collected during the focus group discussions will be kept confidential, and you do not have to answer any question that you do not wish to answer. The information discussed during this focus group will be analyzed as a whole, and no names will be used in the analysis of discussion content. We will not ask any information that will reveal your identity as a participant. However, it is possible that focus group participants may talk to each other and others about what will be discussed during the focus group. If it happens we cannot bear any responsibility. You will receive study and contact information from the investigators prior to the focus group.

The focus group discussion will take about 2 hours to complete. Upon completion of the session, we will present you with a \$25 Wal-Mart gift card as a token of our appreciation for your time and participation. 
If you have any questions or need more information, please do not hesitate to contact, Dr. Gauri Pawar at (304) 293-3527, Abhijeet Bhanegaonkar at (304) 293-1442, or Dr. Suresh Madhavan at 304-293-1652.

Sincerely,

Gauri Pawar M.D.

Associate Professor

Department of Neurology

WVU School of Medicine
Abhijeet Bhanegaonkar MPH

Ph.D. Candidate

Department of Pharmaceutical

Systems and Policy

WVU School of Pharmacy
S. Suresh Madhavan, MBA, Ph.D.

Professor and Chair

Department of Pharmaceutical

Systems and Policy

WVU School of Pharmacy 


\section{Appendix C: Focus Group - Moderator Script}

The focus group time required: Approximately 2 hours

Moderator (script):

Hello, my name is Abhijeet Bhanegaonkar (you can call me AB), I am a doctoral candidate in the Department of Pharmaceutical Systems and Policy at West Virginia University School of Pharmacy. First, I would like to thank you all for taking time off from your busy schedules to come here today and participate in this focus group discussion. For that we are very grateful to you.

This research is being conducted to determine patient preferences for characteristics of disease modifying treatments used in multiple sclerosis such as Rebif, Avonex, Tysabri, etc. The results of this study will improve our understanding about the disease modifying treatment characteristics that are important to multiple sclerosis patients and what they expect from a future disease modifying treatment.

Participation in this study is completely voluntary, and refusal to participate will not affect your relationship and/or care that you receive at the Neurology Clinic at West Virginia University School of Medicine in any way. The study has been acknowledged and approved by the Institutional Review Board of West Virginia University.

Your involvement in this project will be kept as confidential as legally possible. The focus group discussion will be audio-recorded so that the data can be transcribed; however, responses will be kept confidential and individual names will not be associated with any reported data. We will not ask any information that will reveal your identity as a participant. It is possible that focus group participants may talk to each other or others about what will be discussed at this meeting. If that happens we cannot bear any responsibility for that. You may refuse to answer any question, or skip any question that you do not wish to answer. You may discontinue participation at any time.

This [at this point, the moderator will provide participants a handout of list of referral services] is the contact information for counseling facilities in the event that you experience any emotional discomfort or stress due to this focus group discussion.

Before I begin with the discussion, I would like you to complete a very brief questionnaire. That should take less than 5 minutes.

(After participants hand in the questionnaires, moderator will go over following guidelines for the discussion)

Thank you, now we will begin the discussion. But, before we begin, I would like to list the following guidelines to make our discussion more productive. 
- During the discussion, we will not use names. Each participant will be given a number. Please say your number loudly before you talk each time.

- My role here is to ask questions and to listen. I will also take notes at times. I won't be actively participating in the conversation, only guiding it. I want you to feel free to talk to the group and interact with each other and not just to me. I will ask questions about your multiple sclerosis and treatment. There are no right or wrong answers. We are interested in your experiences, opinions, and expectations associated with disease modifying drugs. It is important that you relate your comments back to the questions. I will move the discussion from one question to the next to try to keep us on track so that we can finish on time.

- Only one person should talk at a time. Please speak up since we are recording the session and we don't want to miss any of your comments. If you have trouble hearing any of the comments, please let the group know.

- There are just a few other things that I want you to know. I am not a medical doctor, so I am not qualified to give out medical advice.

- Your $\$ 25$ payment will only be made at the completion of the focus group discussion.

- Just so you know, the bathrooms are (directions will be pointed out). Once we start, we will not be taking any breaks for the next 2 hours. If you need to go to the bathroom or want to get up and get something more to drink please feel free to do so.

- Do you have any questions before we begin the discussion?

(If patients have any additional questions, they will be answered. Once everyone is ready, we will initiate the discussion using the following questions outlined below)

1. How long have you been living with multiple sclerosis?

2. How has your quality of life changed over the period of time (since the diagnosis of MS)? What was it like before the diagnosis of MS and how is it now?

3. Can you tell me what disease modifying treatments you have taken in the past? Which disease modifying treatment are you currently taking? (If patients are not taking the same DMD now then ask the following question) What were some of the reasons for you to switch/stop using your treatment with previous $\mathrm{DMD} / \mathrm{s}$ ?

4. How has your quality of life changed since you began taking DMD/s? How does the current DMD you are taking affect your quality of life?

5. Overall, how would you describe your experience with the DMD (or DMDs) you had used in the past? 
6. Overall, how would you describe your experience with the DMD that you are currently using?

7. How has your past/current use of DMD (DMDs) helped alleviate your MS (in terms of relapses, disease symptoms, functioning, daily activities of life, stress, etc)?

8. What are your minor (immediate) health concerns when it comes to treating your MS with DMDs? (Such as side effects that affect your daily activities of life)

9. What are your major (long term) health concerns when it comes to treating your MS with DMDs? (Such as adverse events including liver failure, progressive multifocal leukoencephalopathy, leukemia etc.)

10. What are your financial concerns when it comes to treating your MS with DMDs? (Cost of DMDs, co-pay, coverage of DMDs etc.)

11. What are your general ideas about the convenience of administration of the DMD (or DMDs) you have previously used? (Self-injecting, using needles on a regular basis, visiting hospitals each month to get infusion, etc.). Were these treatments easily accessible?

12. Would you consider yourself to be satisfied with the DMDs you have used to treat your MS? Why or why not (Probe)?

13. Do you feel that you take your DMD as prescribed regularly? What factors contribute to your being able to take it/not take it regularly?

14. What are your expectations from the future DMDs (oral therapies, combination therapies, etc) that may come on the market? What characteristics would you like these new DMDs to have?

15. Are there any final thoughts about your experiences with DMDs that you would like to share?

Other questions may be asked as a follow-up to responses received from participants or if a new line of inquiry is necessary. 


\section{Appendix D: Focus Group - Sociodemographic Questionnaire}

Participation in this study is completely voluntary, and refusal to participate will not affect in any way your relationship and/or care that you receive from the Department of Neurology at the West Virginia University. You may refuse to answer any question, or skip any question that you do not wish to answer. You may discontinue participation at any time. The information provided by you will be kept as confidential as legally possible.

INSTRUCTIONS: This questionnaire gathers basic information about you and your condition. Please check mark $(V)$ your responses.

1 Are you -

Male

Female

2 What is your age?

3 What is your marital status?

$\square \quad$ Single

Married

Divorced/separated

Widowed

Not married, living with a partner

Other (please Specify)

Refuse to answer

$4 \quad$ Your ethnicity?

White/ Caucasian
Black/ African American
Hispanic/ Latino
Pacific Islander
Asian
American Indian/ Native Indian/ Alaskan Native
Other (please specify)
Refuse to answer


5 What is the highest level of education that you have completed?

$\square$ Some high school or less

$\square$ High school graduate or GED

$\square$ Vocational college or some college

$\square$ College degree

$\square$ Graduate/professional degree

Other (please specify)

$\square$ Refuse to answer

6 What type of health insurance do you have?

$\square$ Private health insurance

Government health insurance (such a Medicaid/ Medicaid)

$\square$ Other (please specify)

Uninsured

$\square$ Refuse to answer

7 Which of the following best describes your employment status?

$\square$ Employed/self-employed full time

$\square$ Employed/self-employed part time

Retired

Homemaker

Student

Unable to work due MS

Unemployed

Seeking work

Other (please specify)

Refuse to answer

8 What is your annual household income?
$\square<\$ 25,000$
$\square \$ 25,000-\$ 49,999$
$\square \$ 50,000-\$ 99,999$
$\square \geq \$ 100,000$
Refuse to answer

9 How long ago were you diagnosed with MS?

Months/Year 
10 What was your year of diagnosis?

11 What is your primary diagnosis?

$\square$ Primary progressive MS

$\square$ Secondary progressive MS

$\square$ Relapsing remitting MS

$\square$ Progressive relapsing MS

$\square$ Don't know

12 Does your health insurance cover at least some of the cost of your prescription medications (like your disease modifying treatment)?

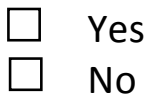

13 How long have you been taking ANY type of disease modifying drug for treating your MS? (Specify number of years and months)

Years Months

14 Which of the following disease modifying drug/s you took in the PAST to treat your MS? (you can check more than one box if you have taken more than one disease modifying drugs in the past)

$\begin{array}{lll}\square \text { Avonex } & \square \text { Copaxone } & \square \text { Don't know } \\ \square \text { Rebif } & \square \text { Novantrone } & \\ \square \text { Betaseron } & \square \text { Tysabri }\end{array}$

15 Which of the following disease modifying drug you are CURRENTLY using to treat your MS?
Avonex
Rebif
Betaseron

Copaxone

Novantrone

Tysabri 


\section{Appendix E: Focus Group - Acknowledgement}

Dear Principal Investigator,

I acknowledge the receipt of a gift card in the amount of $\$ 25$ for my participation in the focus group discussion for the study titled "Patient Preferences for Benefits and Risks Associated with Disease Modifying Drugs in Multiple Sclerosis". I also understand that it is my responsibility to verify if any action regarding the taxation of said gift card is needed.

Thank you,

Name:

Signature

Date 


\section{Appendix F: Focus Group - Important Resources for Emotional Discomfort}

Following is contact information for local counseling facilities in the event that you experience any emotional discomfort as a result of the focus group discussion.

$\begin{array}{lll}\text { Morgantown Pastoral } & \text { Chestnut Ridge Hospital of } & \text { Valley Healthcare System } \\ \text { Counseling } & \text { Morgantown WV } & 301 \text { Scott Ave } \\ 1062 \text { Maple Dr \#1 } & 930 \text { Chestnut Ridge Rd } & \text { Morgantown, WV 26508 } \\ \text { Morgantown, WV 26505 } & \text { Morgantown, WV 26505 } & \text { Phone - (304) 296-1731 } \\ \text { Phone }-(304) \text { 599-5751 } & \text { Phone }-(304) \text { 598-6400 } & \end{array}$

Fremouw Psychological Associates

1224 Pineview Dr \#B

Morgantown, WV 26505

Phone - (304) 598-2300
Chestnut Ridge Counseling Services

Suite 116, 100 New Salem Road

Uniontown, PA 15401 


\section{Appendix G: Web-based Survey - Email Invitation}

\section{(To be sent by Biogen Idec to MS patients in their registry)}

Subject: Survey on Multiple Sclerosis - \$25 for your participation

Dear Biogen Idec Registry Member:

Biogen Idec is partnering with the West Virginia University School of Pharmacy to conduct an online research survey to better understand health related quality of life, work productivity, treatment satisfaction, and preferences for different treatments used to treat multiple sclerosis.

This research study is part of a doctoral (Ph.D.) research project and is sponsored by Biogen Idec Inc. This research survey is anonymous and the information provided will be kept as confidential as legally possible. The survey results will be grouped together with others completing the survey. This research study has been acknowledged by the Institutional Review Board of West Virginia University. You must be 18 years of age or older to participate in this research survey.

Participation in this survey is entirely voluntary. However, your participation in this survey is vital to make this research truly meaningful. The completion of this survey will take approximately 20 minutes. Please help us by completing the entire survey.

Upon survey completion from eligible respondents, researchers at West Virginia University will send you a $\$ 25$ gift card. Please respond quickly - this survey will only be open for a limited time.

\section{[SURVEY URL]}

We THANK YOU in advance, for your time and your contributions to a greater understanding of the health matters of individuals with MS. If you have any questions regarding the survey or need more information about the study, please email the research team members Dr. S. Suresh Madhavan (PI) on (304) 293-1652 or Abhijeet Bhanegaonkar on (404) 434-4575 or email us at MSstudy@hsc.wvu.edu.

Have a great day!

Sincerely, Your Biogen Idec team

NOTE: You must complete the three questions on the eligibility screen before completing this survey. Completing the eligibility screen alone does NOT qualify you for the \$25 gift card. 
Appendix H. Web-Based Survey - Survey Questionnaire 


\section{$\underline{\text { Treatment Preference in Multiple Sclerosis Survey }}$}

We appreciate your participation this research survey.

\section{[SCREENING QUESTIONS]}

We appreciate your interest in this research survey.

Please answer the following THREE screening questions before moving on to the actual survey.

\begin{tabular}{|l|l|l|}
\hline \multicolumn{1}{|c|}{ Screening Questions } & Yes & No \\
\hline Q1. Do you have a confirmed diagnosis of MS? & $\square 1$ & $\square 2$ \\
\hline Q2. Are you 18 years of age or older? & $\square 1$ & $\square 2$ \\
\hline Q3. Are you a resident of United States & $\square 1$ & $\square 2$ \\
\hline
\end{tabular}

If $N O \geq 1$ then participants do not qualify. Thank and terminate. If $Y E S=3$ then participants qualify. Proceed to the survey. 


\section{ABOUT YOUR MS...}

4. When were you first diagnosed with MS?

Month

Month
Year

5. What type of MS do you have?

6. Are you currently experiencing a relapse?

[Provide dropdown]

[Provide dropdown]

$\square 1 \quad$ Relapsing remitting MS

2 Primary progressive MS

3 Secondary progressive MS

4 Progressive relapsing MS

$\square 1 \quad$ Yes

2 No 
IF Q6=Yes

7. Which of the following MS categories best describes your illness before this most recent relapse?

Please select category that best describes your answer.

Normal: I may have some mild symptoms, mostly sensory due to MS but they do

0 not limit my activity. If I do have an attack, I return to normal when the attack has passed.

$\square 1 \quad 1$ Mild Disability: I have some noticeable symptoms from my MS but they are minor and have only a small effect on my lifestyle.

Q2 2 Moderate Disability: I don't have any limitations in my walking ability. However, I do have significant problems due to MS that limit daily activities in other ways. Gait Disability: MS does interfere with my activities, especially my walking. I can

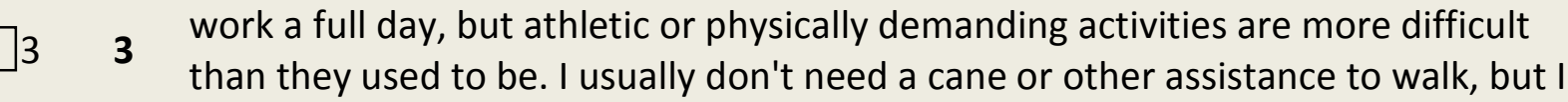
might need some assistance during an attack.

Early Cane: I use a cane or a single crutch or some other form of support (such as touching a wall or leaning on someone's arm) for walking all the time or part of the

$\square 44$ time, especially when walking outside. I think I can walk 25 feet in 20 seconds without a cane or crutch. I always need some assistance (cane or crutch) if I want to walk as far as 3 blocks.

Late Cane: To be able to walk 25 feet, I have to have a cane, crutch or someone to

5
5 $\begin{aligned} & \text { hold onto. I can get around the house or other buildings by holding onto furniture } \\ & \text { or touching the walls for support. I may use a scooter or wheelchair if I want to go }\end{aligned}$

55 hold onto. I can get around the house or other buildings by holding onto furniture
or touching the walls for support. I may use a scooter or wheelchair if I want to go greater distances.

66 Bilateral Support: To be able to walk as far as 25 feet I must have 2 canes or crutches or a walker. I may use a scooter or wheelchair for longer distances.

Wheelchair / Scooter: My main form of mobility is a wheelchair. I may be able to

$77 \quad 7$ stand and/or take one or two steps, but I can't walk 25 feet, even with crutches or a walker.

$\square 8 \quad 8$ Bedridden: Unable to sit in a wheelchair for more than one hour. 
IF Q6=Yes

\section{Which of the following MS categories best describes your current illness?}

Please select a category that best describes your situation.

Normal: I may have some mild symptoms, mostly sensory due to MS but they do

$\square 0 \quad \mathbf{0}$ not limit my activity. If I do have an attack, I return to normal when the attack has passed.

11 Mild Disability: I have some noticeable symptoms from my MS but they are minor and have only a small effect on my lifestyle.

22 2 Moderate Disability: I don't have any limitations in my walking ability. However, I do have significant problems due to MS that limit daily activities in other ways. Gait Disability: MS does interfere with my activities, especially my walking. I can work a full day, but athletic or physically demanding activities are more difficult than they used to be. I usually don't need a cane or other assistance to walk, but I might need some assistance during an attack.

Early Cane: I use a cane or a single crutch or some other form of support (such as touching a wall or leaning on someone's arm) for walking all the time or part of the

$\square 44$ time, especially when walking outside. I think I can walk 25 feet in 20 seconds without a cane or crutch. I always need some assistance (cane or crutch) if I want to walk as far as 3 blocks.

Late Cane: To be able to walk 25 feet, I have to have a cane, crutch or someone to

55 hold onto. I can get around the house or other buildings by holding onto furniture
or touching the walls for support. I may use a scooter or wheelchair if I want to go

5
5 $\begin{aligned} & \text { hold onto. I can get around the house or other buildings by holding onto furniture } \\ & \text { or touching the walls for support. I may use a scooter or wheelchair if I want to go }\end{aligned}$ greater distances.

06 6 Bilateral Support: To be able to walk as far as 25 feet I must have 2 canes or crutches or a walker. I may use a scooter or wheelchair for longer distances. Wheelchair / Scooter: My main form of mobility is a wheelchair. I may be able to

77 stand and/or take one or two steps, but I can't walk $25 \mathrm{feet}$, even with crutches or a walker.

$\square 8 \quad 8$ Bedridden: Unable to sit in a wheelchair for more than one hour. 
9. Which of the following disease modifying drugs you are CURRENTLY using to treat your MS?

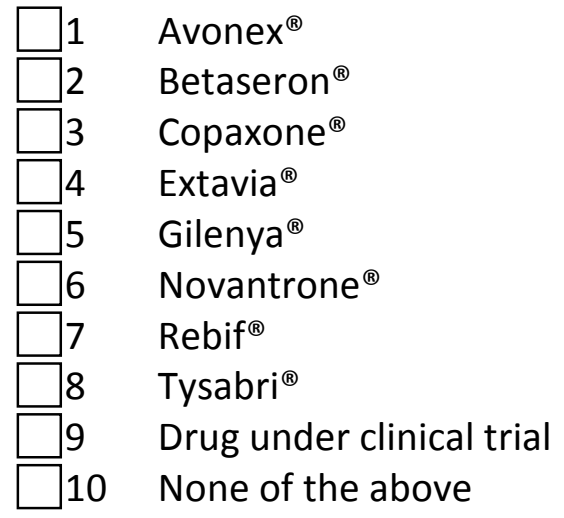

10. Since when have you been taking (Q9=Current DMD) to treat your MS?

Year $\quad$ [Provide dropdown]

Month___ [Provide dropdown]

IF Q9 None of the above

11. Which of the following disease modifying drugs did you take in the past before starting on (Q9=Current DMD)? (Check more than one box if you took more than one disease modifying drugs in the past)

\begin{tabular}{ll}
$\square 1$ & Avonex $^{\circledR}$ \\
\hline$\square 2$ & Betaseron $^{\circledR}$ \\
\hline$\square 3$ & Copaxone $^{\circledR}$ \\
\hline$\square 4$ & Extavia $^{\circledR}$ \\
\hline$\square 5$ & Gilenya $^{\circledR}$ \\
\hline$\square 6$ & Novantrone $^{\circledR}$ \\
\hline$\square 7$ & Rebif $^{\circledR}$ \\
\hline$\square 8$ & Tysabri $^{\circledR}$ \\
\hline$\square 9$ & Drug under clinical trial \\
\hline$\square 10$ & Other (Please specify) \\
\hline$\square 11$ & None of the above
\end{tabular}


IF Q9=None of the above

12. Which of the following disease modifying drugs have you taken in the PAST to treat your MS? (Check more than one box if you took more than one disease modifying drugs in the past

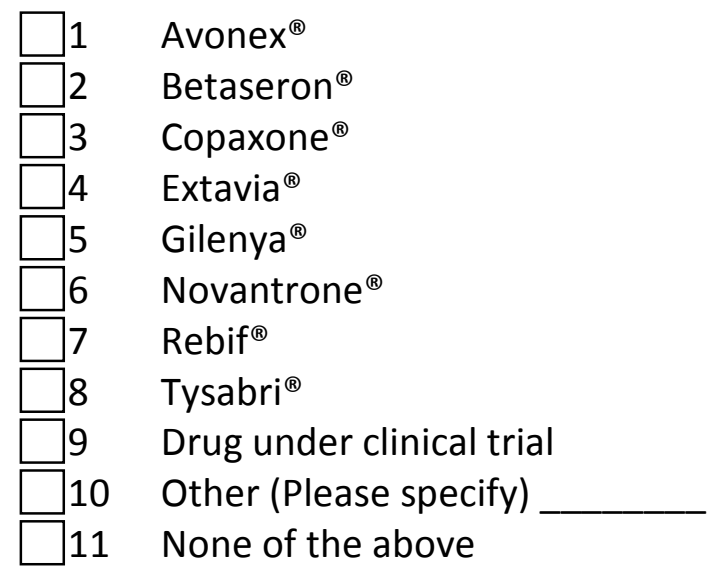

13. What type of health insurance do you have?

\begin{tabular}{lll}
$\square 1$ & Private health insurance \\
\hline$\square 2$ & Medicaid \\
\hline$\square 3$ & Medicare \\
\hline$\square 4$ & Uninsured \\
\hline$\square 5$ & Other (Please specify)
\end{tabular}

14. Which of the following statements best describes your situation?

$\square 1$ My health insurance covers ALL of the cost of my MS medicines

12 My health insurance covers MOST of the cost of my MS medicines

3 My health insurance covers SOME of the cost of my MS medicines

4 My health insurance DOES NOT COVER any of the costs of my MS medicines

5 I get my MS medicines through a SUPPORT PROGRAM of a Pharmaceutical company as I have no health insurance

$\square 6 \quad$ I DO NOT TAKE MY MS medicines as I have no health insurance to pay for them 
15. How many MS relapses you have experienced in the last 12 months?

Select a number [Provide a dropdown]

16. In the last $\mathbf{1 2}$ months, how many times have you seen a primary care physician for your MS? Select a number [Provide a dropdown]

17. In the last $\mathbf{1 2}$ months, how many times have you seen a neurologist for your MS?

Select a number [Provide a dropdown]

18. Do you have a family history of MS in blood relatives?

$\begin{array}{ll}\square & \text { Yes } \\ \square 2 & \text { No }\end{array}$

IF Q18 = Yes then show Q19.

19. Specify the relation (Brother, Sister, etc.)

IF Q18 = Yes then show Q20.

20. Is the relative mentioned above a twin?

$\square 1 \quad$ Not a twin

2 Fraternal

3 Identical

21. Are you a twin?

\begin{tabular}{|ll}
$\square 1$ & Not a twin \\
\hline$\square 2$ & Fraternal \\
\hline$\square 3$ & Identical
\end{tabular}


22. Has a doctor ever told you that you have or treated you for any of the following conditions in the past? (Please select all that applies)

\begin{tabular}{l}
$\square$ Hypertension \\
\hline$\square$ Heart disease \\
\hline$\square$ Cataracts \\
\hline peptic ulcer disease \\
$\square$ Inflammatory bowel \\
disease \\
$\square$ rheumatoid arthritis \\
\hline Arthritis \\
\hline$\square$ knee/hip replacements \\
\hline bipolar disorder \\
\hline Hearing loss \\
,$\quad$ Her
\end{tabular}

\begin{tabular}{l}
$\square$ Cancer (Specify) \\
\hline$\square$ Peripheral vascular disease \\
\hline Glaucoma \\
\hline Liver disease \\
$\square$ Autoimmune thyroid \\
disease \\
$\square$ Sjogren's disease \\
\hline Fibromyalgia \\
$\square$ Depression \\
$\square$ Schizophrenia \\
$\square$ Hepatitis
\end{tabular}

\begin{tabular}{l}
$\square$ Diabetes \\
\hline$\square$ Lung disease \\
\hline$\square$ Uveitis \\
\hline$\square$ Irritable bowel syndrome \\
\hline Systemic lupus \\
erythematosus \\
$\square$ Kidney disease \\
\hline$\square$ anemia \\
\hline$\square$ Anxiety \\
\hline$\square$ Seizures \\
\hline$\square$ Other (Specify)
\end{tabular}

23. During the last one month, have you experienced any of the following symptoms as a result of your MS? (Please select all the symptoms that you experienced)

\begin{tabular}{l}
$\square$ Memory and attention problems \\
\hline$\square$ Depression (feeling down) or mood \\
Vision problems \\
Slurred speech \\
\hline Problems with swallowing \\
\hline Tremor \\
\hline$\square$ Spasticity (muscle stiffness) \\
\hline Problem in walking \\
\hline$\square$ Bladder problems
\end{tabular}

\begin{tabular}{|l}
$\square$ Bowel problems \\
\hline$\square$ Sexual dysfunction \\
\hline$\square$ Fatigue \\
\hline$\square$ Numbness, Tingling, Burning Sensations \\
\hline$\square$ Balance/Coordination \\
\hline$\square$ Dizziness \\
\hline$\square$ Chronic pain \\
\hline \hline Other (Please specify)
\end{tabular}




\section{FEATURES OF MS TREATMENTS}

Next few screens will describe features of the commonly used MS medications. Please read the following description carefully. This information will help you in answering questions later in this survey.

Treatment Administration: MS treatments vary by their mode of administration. Three most common ways to take MS medicines are pill at home, injection at home, or infusion at the clinic.

\section{For my MS I take...}

$\square 1$ Pill at home

$\square 2$ Injection at home

3 Infusion at clinic

Evidence on Outcomes: The longer a treatment is on the market, the more the information is available about its safety and benefits. Therefore our understanding of the benefits and safety outcomes of these treatments improve with the passage of time. Later in the survey you will be asked to consider different MS treatments with evidence on outcomes gathered after: 5 years of research, 10 years of research, or 15 years of research.

\section{How important is evidence on outcomes to you?}

\begin{tabular}{|ll}
$\square 1$ & Extremely \\
\hline$\square 2$ & Somewhat \\
\hline$\square 3$ & Not at all
\end{tabular}

Number of Relapses: Current MS treatments reduce occurrence of relapses. An average MS patient experiences 6 relapses over 5 years. Assume that you will have 6 relapses over the next 5 years with your current treatment. Later in the survey you will be asked to consider different MS treatments with 0 Relapse, 3 Relapses, or 6 Relapses within next 5 years.

\section{How concerned are you about your future MS relapses?}

\begin{tabular}{|ll}
$\square 1$ & Extremely \\
\hline$\square 2$ & Somewhat \\
$\square 3$ & Not at all
\end{tabular}


Delaying Progression of MS: MS affects physical functioning (example: walking ability) and neurological functioning (example: memory, eyesight) and causes disability over time. MS treatments slow down disability progression.

Previously you indicated your current level of functioning as:

[PUT THE LEVEL (n) OF DISABILITY AS INDICATED FROM Q.7 or 8]

If your illness worsens, you are most likely to experience a level of functioning best described as: [PUT THE NEXT LEVEL $(n+1)$ OF AS DISABILITY FROM Q.7 or 8]

An average patient not taking any MS medicine advances to higher level of illness category in 5 or more years.

Later in this survey you will be asked to consider different treatments delaying progression of MS by 5 Years, 10 Years, or 15 Years.

27. How satisfied are you with your current treatment's ability to delay progression of your MS?

D1 Extremely

2 Somewhat

3 Not at all

Severe Disability or Death from Progressive Multifocal Leukoencephalopathy (PML): PML is a rare but serious viral infection of the brain that can cause death or severe disability. Some MS treatments increase the chance of PML. Later in the survey you will be asked you to consider MS treatments with the following chances of death or severe disability associated with PML within the next 5 years: None, 4 patients out of 1,000, or 8 patients out of 1,000.

28. If a MS treatment caused PML in 5 patients out of 1000, how concerned would you be to take that medicine?

$\square 1$ Extremely

2 Somewhat

3 Not at all 
Severe Liver Dysfunction within 5 Years: MS treatments can affect liver function which may cause jaundice, nausea, fatigue, and vomiting. Later in the survey you will be asked to consider different treatments with severe liver dysfunction in the next 5 years in none, 10 patients out of 1000, or 20 patients out of 1000 .

29. If a MS medicine caused severe liver dysfunction in 15 patients out of 1000, how worried would you be to take that medicine?

\begin{tabular}{|ll}
$\square 1$ & Extremely \\
\hline$\square 2$ & Somewhat \\
\hline$\square 3$ & Not at all
\end{tabular}

Flu-like Symptoms: MS patients frequently experience flu-like symptoms after taking MS medications. These symptoms may include fever, chills, sweating, muscle aches, and fatigue. Later in this survey you will be asked to consider different MS treatments with none, mild, or severe flu like symptoms.

30. Have you ever experienced flu-like symptoms with your MS medicine?

\begin{tabular}{ll}
$\square$ & Yes \\
\hline$\square 2$ & No
\end{tabular} 
Below is an example of the treatment option. In this example, Medicine $A$ is preferred to Medicine B (as shown by the RED ARROW).

You will see on the similar choice questions in the next few screens. Choose your preferred Medicine by clicking the box at the bottom of the screen

EXAMPLE OF CHOICE QUESITON

West VirginiaUniversity

ROBERT C. BITD HEALTH SCIENCES CENTER

School of Pharmacy

MEDICINE FEATURE

Treatment administration

Evidence on outcomes

Number of relapses within 5 years

Delaying progression of MS

Severe disability or death from PML within 5 years

Severe liver dysfunction within 5 years

Flu-like symptoms
MEDICINE A

Pill at home

15 years of research

0 relapse

10 years of delay

None

None

None
MEDICINE B

Injection at home

10 years of research

6 relapse

5 years of delay

4 patients out of 1000

10 patients out of 1000

None

Which Medicine would you choose? 


\section{Choice Question 31}

(Block 1 Run 1)

\section{MEDICINE FEATURE}

Treatment administration

Evidence on outcomes

Number of relapses within 5 years

Delaying progression of MS

Severe disability or death from PML within 5 years

Severe liver dysfunction within 5 years

Flu-like symptoms
MEDICINE A

MEDICINE B

\begin{tabular}{|c|c|}
\hline MEDICINE A & MEDICINE B \\
\hline Pill at home ${ }^{0}$ & Injection at home ${ }^{1}$ \\
\hline 10 years of research ${ }^{1}$ & 10 years of research ${ }^{1}$ \\
\hline 6 relapses $^{2}$ & 0 relapses $^{0}$ \\
\hline 5 years of delay ${ }^{0}$ & 15 years of delay ${ }^{2}$ \\
\hline None $^{0}$ & 4 patients out of $1000^{1}$ \\
\hline $\begin{array}{l}20 \text { patients out of } \\
1000^{2}\end{array}$ & 10 patients out of $1000^{1}$ \\
\hline Mild $^{1}$ & None $^{0}$ \\
\hline
\end{tabular}

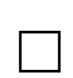

Which medicine would you choose? 


\section{Choice Question 32}

(Block 1 Run 2)

\section{MEDICINE FEATURE}

Treatment administration

Evidence on outcomes

Number of relapses within 5 years

Delaying progression of MS

Severe disability or death from PML within 5 years

Severe liver dysfunction within 5 years

Flu-like symptoms

\begin{tabular}{|c|c|}
\hline MEDICINE A & MEDICINE B \\
\hline Pill at home ${ }^{0}$ & $\begin{array}{l}\text { Infusion at the } \\
\text { clinic }^{2}\end{array}$ \\
\hline 15 years of research ${ }^{2}$ & $\begin{array}{c}15 \text { years of } \\
\text { research }\end{array}$ \\
\hline 6 relapses $^{2}$ & 6 relapses $^{2}$ \\
\hline 15 years of delay ${ }^{2}$ & 15 years of delay ${ }^{2}$ \\
\hline None $^{0}$ & None $^{0}$ \\
\hline $\begin{array}{l}20 \text { patients out of } \\
1000^{2}\end{array}$ & $\begin{array}{c}10 \text { patients out of } \\
1000^{1}\end{array}$ \\
\hline None $^{0}$ & Severe $^{2}$ \\
\hline
\end{tabular}

Which medicine would you choose? 


\section{Choice Question 33}

(Block 1 Run 3)

\section{MEDICINE FEATURE}

Treatment administration

Evidence on outcomes

Number of relapses within 5 years

Delaying progression of MS

Severe disability or death from PML within 5 years

Severe liver dysfunction within 5 years

Flu-like symptoms

\section{MEDICINE A}

MEDICINE B

\begin{tabular}{|l|l|} 
Infusion at the clinic $^{2}$ & Infusion at the clinic $^{2}$ \\
\hline 10 years of research & 10 years of research
\end{tabular}

10 years of research 10 years of research ${ }^{1}$

\begin{tabular}{|l|l|} 
& \\
\hline &
\end{tabular}

\begin{tabular}{|l|l|}
3 relapses $^{1}$ & 6 relapses $^{2}$ \\
\hline &
\end{tabular}

\begin{tabular}{|l|l|}
15 years of delay & \\
\hline & 15 years of delay \\
\end{tabular}

\begin{tabular}{|c|c|}
\hline None $^{0}$ & $\begin{array}{c}8 \text { patients out of } \\
1000^{2}\end{array}$ \\
\hline $\begin{array}{c}10 \text { patients out of }_{1000^{1}} \\
\text { Severe }^{2}\end{array}$ & None $^{0}$ \\
\hline & None $^{0}$ \\
\hline
\end{tabular}

Which medicine would you choose? 


\section{Choice Question 34}

(Block 1 Run 4)

\section{MEDICINE FEATURE}

Treatment administration

Evidence on outcomes

Number of relapses within 5 years

Delaying progression of MS

Severe disability or death from PML within 5 years

Severe liver dysfunction within 5 years

Flu-like symptoms
Which medicine would you choose?
MEDICINE A

MEDICINE B

\begin{tabular}{|c|c|}
\hline MEDICINE A & MEDICINE B \\
\hline Injection at home ${ }^{1}$ & Injection at home ${ }^{1}$ \\
\hline 5 years of research ${ }^{0}$ & 15 years of research ${ }^{2}$ \\
\hline 0 relapses $^{0}$ & 6 relapses $^{2}$ \\
\hline 10 years of delay ${ }^{1}$ & 10 years of delay ${ }^{1}$ \\
\hline None $^{0}$ & $\begin{array}{c}8 \text { patients out of } \\
1000^{2}\end{array}$ \\
\hline $\begin{array}{l}20 \text { patients out of } \\
1000^{2}\end{array}$ & $\begin{array}{l}10 \text { patients out of } \\
1000^{1}\end{array}$ \\
\hline Mild $^{1}$ & Mild $^{1}$ \\
\hline
\end{tabular}

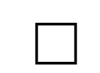




\section{Choice Question 35}

(Block 1 Run 5)

\author{
MEDICINE FEATURE \\ Treatment administration \\ Evidence on outcomes \\ Number of relapses within 5 years \\ Delaying progression of MS
}

Severe disability or death from PML within 5 years

Severe liver dysfunction within 5 years

Flu-like symptoms

\begin{tabular}{|c|c|}
\hline MEDICINE A & MEDICINE B \\
\hline Infusion at the clinic ${ }^{2}$ & Injection at home ${ }^{1}$ \\
\hline 15 years of research ${ }^{2}$ & $\begin{array}{l}10 \text { years of } \\
\text { research }^{1}\end{array}$ \\
\hline 6 relapses $^{2}$ & 0 relapse $^{0}$ \\
\hline 15 years of delay ${ }^{2}$ & 10 years of delay ${ }^{1}$ \\
\hline None $^{0}$ & $\begin{array}{c}8 \text { patients out of } \\
1000^{2}\end{array}$ \\
\hline $\begin{array}{l}10 \text { patients out of } \\
11000^{1}\end{array}$ & $\begin{array}{l}20 \text { patients out of } \\
11000^{2}\end{array}$ \\
\hline None $^{0}$ & Severe $^{2}$ \\
\hline
\end{tabular}

\section{Which medicine would you choose?}




\section{Choice Question 36}

(Block 1 Run 6)

\section{MEDICINE FEATURE}

Treatment administration

Evidence on outcomes

Number of relapses within 5 years

Delaying progression of MS

Severe disability or death from PML within 5 years

Severe liver dysfunction within 5 years

Flu-like symptoms

\section{MEDICINE A}

MEDICINE B

\begin{tabular}{|c|c|}
\hline MEDICINE A & MEDICINE B \\
\hline Injection at home ${ }^{1}$ & Pill at home ${ }^{0}$ \\
\hline 5 years of research ${ }^{0}$ & 5 years of research ${ }^{0}$ \\
\hline 6 relapses $^{2}$ & 6 relapses $^{2}$ \\
\hline 5 years of delay ${ }^{0}$ & 15 years of delay ${ }^{2}$ \\
\hline $\begin{array}{l}4 \text { patients out of } \\
1000^{1}\end{array}$ & $\begin{array}{l}4 \text { patients out of } \\
1000^{1}\end{array}$ \\
\hline $\begin{array}{l}10 \text { patients out of } \\
1000^{1}\end{array}$ & $\begin{array}{l}20 \text { patients out of } \\
1000^{2}\end{array}$ \\
\hline Severe $^{2}$ & Mild $^{1}$ \\
\hline
\end{tabular}

Which medicine would you choose? 


\section{Choice Question 37}

(Block 1 Run 7)

\section{MEDICINE FEATURE}

Treatment administration

Evidence on outcomes

Number of relapses within 5 years

Delaying progression of MS

Severe disability or death from PML within 5 years

Severe liver dysfunction within 5 years

Flu-like symptoms

\begin{tabular}{|c|c|}
\hline MEDICINE A & MEDICINE B \\
\hline Injection at home ${ }^{1}$ & Pill at home ${ }^{0}$ \\
\hline 15 years of research ${ }^{2}$ & $\begin{array}{l}10 \text { years of } \\
\text { research }^{1}\end{array}$ \\
\hline 0 relapses $^{0}$ & 0 relapses $^{0}$ \\
\hline 15 years of delay ${ }^{2}$ & 15 years of delay ${ }^{2}$ \\
\hline None $^{0}$ & $\begin{array}{l}4 \text { patients out of } \\
1000^{1}\end{array}$ \\
\hline None $^{0}$ & $\begin{array}{l}10 \text { patients out of } \\
1000^{1}\end{array}$ \\
\hline None $^{0}$ & None $^{0}$ \\
\hline
\end{tabular}

Which medicine would you choose? 


\section{Choice Question 38}

(Block 1 Run 8)

\section{MEDICINE FEATURE}

Treatment administration

Evidence on outcomes

Number of relapses within 5 years

Delaying progression of MS

Severe disability or death from PML within 5 years

Severe liver dysfunction within 5 years

Flu-like symptoms
MEDICINE A

MEDICINE B clinic $^{2}$

Injection at home ${ }^{1}$

\begin{tabular}{|c|c|}
\hline clinic $^{2}$ & injection ac nome \\
\hline $\begin{array}{l}15 \text { years of } \\
\text { research }^{2}\end{array}$ & 15 years of research ${ }^{2}$ \\
\hline 3 relapses $^{1}$ & 6 relapses $^{2}$ \\
\hline 10 years of delay ${ }^{1}$ & 15 years of delay ${ }^{2}$ \\
\hline $\begin{array}{l}8 \text { patients out of } \\
1000^{2}\end{array}$ & 4 patients out of $1000^{1}$ \\
\hline None $^{0}$ & None $^{0}$ \\
\hline Mild $^{1}$ & None $^{0}$ \\
\hline
\end{tabular}

Which medicine would you choose? 


\section{Choice Question 39}

(Block 1 Run 9)

MEDICINE FEATURE
Treatment administration
Evidence on outcomes

Number of relapses within 5 years

Delaying progression of MS

Severe disability or death from PML within 5 years

Severe liver dysfunction within 5 years

Flu-like symptoms

\begin{tabular}{|c|c|}
\hline MEDICINE A & MEDICINE B \\
\hline Infusion at the clinic ${ }^{2}$ & Pill at home ${ }^{0}$ \\
\hline 10 years of research ${ }^{1}$ & 5 years of research ${ }^{0}$ \\
\hline 0 relapse $^{0}$ & 6 relapses $^{2}$ \\
\hline 15 years of delay ${ }^{2}$ & 15 years of delay ${ }^{2}$ \\
\hline $\begin{array}{l}4 \text { patients out of } \\
1000^{1}\end{array}$ & $\begin{array}{l}4 \text { patients out of } \\
1000^{1}\end{array}$ \\
\hline None $^{0}$ & None $^{0}$ \\
\hline Mild $^{1}$ & Severe $^{2}$ \\
\hline
\end{tabular}

Which medicine would you choose? 
Choice Question 40

(Block 1 Run 7)

(Repeat Question\#7)

\begin{tabular}{|c|c|c|}
\hline MEDICINE FEATURE & MEDICINE A & MEDICINE B \\
\hline Treatment administration & Injection at home ${ }^{1}$ & Pill at home ${ }^{0}$ \\
\hline Evidence on outcomes & 15 years of research ${ }^{2}$ & 10 years of research ${ }^{1}$ \\
\hline Number of relapses within 5 years & 0 relapse $^{0}$ & 0 relapse $^{0}$ \\
\hline Delaying progression of MS & 15 years of delay ${ }^{2}$ & 15 years of delay ${ }^{2}$ \\
\hline $\begin{array}{l}\text { Severe disability or death from PML } \\
\text { within } 5 \text { years }\end{array}$ & None $^{0}$ & $\begin{array}{l}4 \text { patients out of } \\
1000^{1}\end{array}$ \\
\hline Severe liver dysfunction within 5 years & None $^{0}$ & $\begin{array}{l}10 \text { patients out of } \\
11000^{1}\end{array}$ \\
\hline Flu-like symptoms & None $^{0}$ & None $^{0}$ \\
\hline
\end{tabular}

Which medicine would you choose? 


\section{ABOUT YOUR QUALITY OF LIFE...}

The following questions ask for your views on the impact of MS on your day-to-day life during the past 2 weeks. For each statement, please circle the one number that best describes your situation. Please answer all questions.

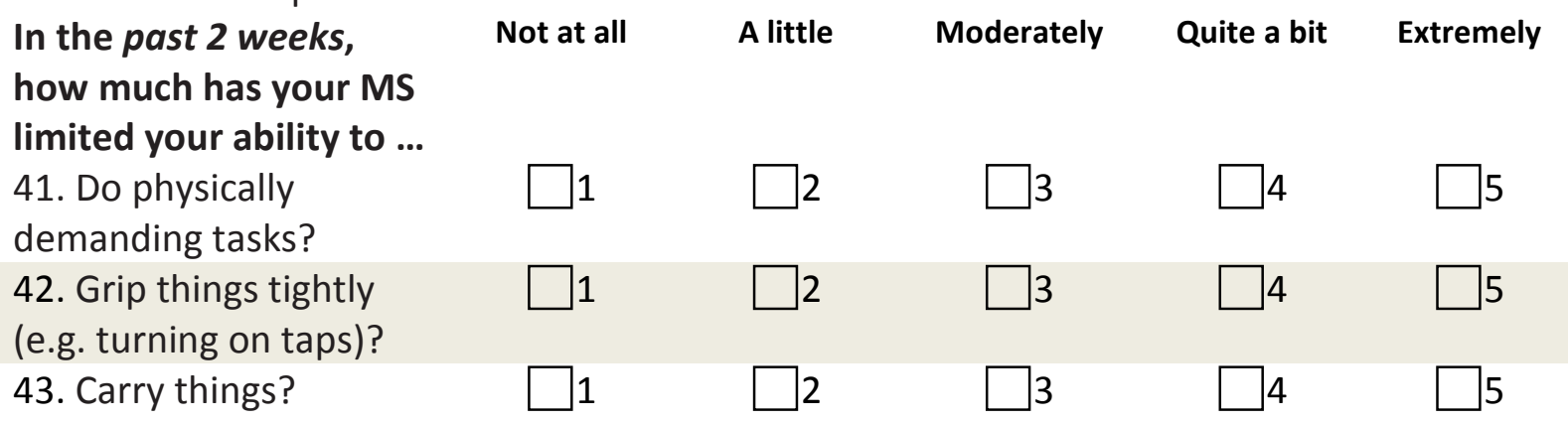

In the past 2 weeks, Not at all A little Moderately Quite a bit Extremely how much have you been bothered by ...

44. Problems with your

balance?

45. Difficulties moving about indoors?

46. Being clumsy?

$\square$

$\square 2$

$\square 3$

$\square 4$

$\square 5$

47. Stiffness?

$\square 1$

$\square 2$

$\square 3$

$\square 4$

$\square 5$

47. Stiffness?

$\square$

$\square 2$

$\square 3$

$\square 4$

$\square 5$

$\square 2$

$\square 3$

$\square 4$

$\square 5$

48. Heavy arms and/or

legs?

49. Tremor of your arms

$\square 1$

$\square 2$

$\square 3$

$\square 4$

$\square 5$

or legs?

50. Spasms in your

$\square 1$

$\square 2$

$\square 3$

$\square 5$

$\square 1$

$\square 2$

$\square 3$

$\square 5$

limbs?

51. Your body not doing

what you want it to do?

52. Having to depend on

$\square 1$

$\square 2$

$\square 3$

$\square 5$

others to do things for

you?

53. Limitations in your

social and leisure

$\square 1$

$\square 2$

$\square 3$

$\square 5$

activities at home?

54. Being stuck at home

more than you would

like to be? 
In the past 2 weeks, how much have you been bothered by ...
Not at all

A little

Moderately

Quite a

Extremely bit

55. Difficulties using your hands in everyday tasks?

56. Having to cut down the amount of time you spent on work or other daily activities?

57. Problems using transport (e.g. car, bus, train, taxi, etc.)?

58. Taking longer to do things?

59. Difficulty doing things spontaneously (e.g. going out on the spur of the moment)? 60 . Needing to go to the toilet urgently?

61 . Feeling unwell?

62. Problems sleeping?

63. Feeling mentally fatigued?

64. Worries related to your MS?

65. Feeling anxious or tense?

66. Feeling irritable, impatient or shorttempered?

67. Problems concentrating?

68. Lack of confidence?

69. Feeling depressed?

$\square 1$<smiles>C1C[Te]C1</smiles><smiles>[CH]1[CH]CC1</smiles><smiles>C1CCC1</smiles><smiles>[131I-]</smiles><smiles>C1CCC1</smiles><smiles>C1CCC1</smiles><smiles>[CH]1[CH]CC1</smiles><smiles>C1CCC1</smiles><smiles>C1C[AsH]C1</smiles>

.
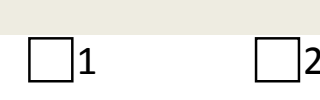

$\square 3$
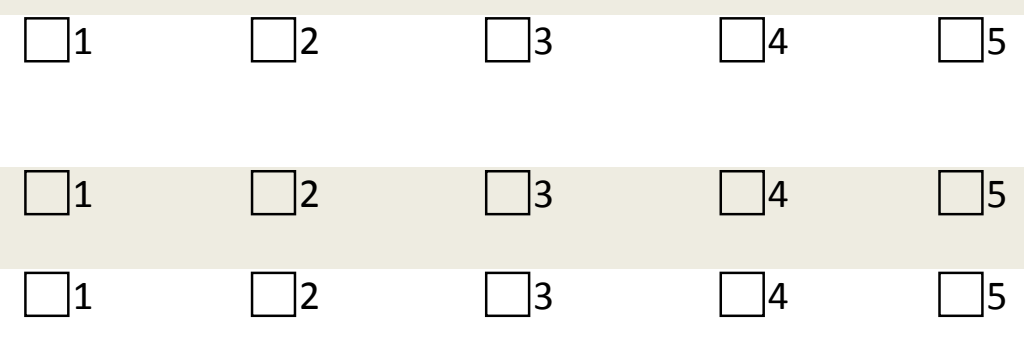

\section{5}

5
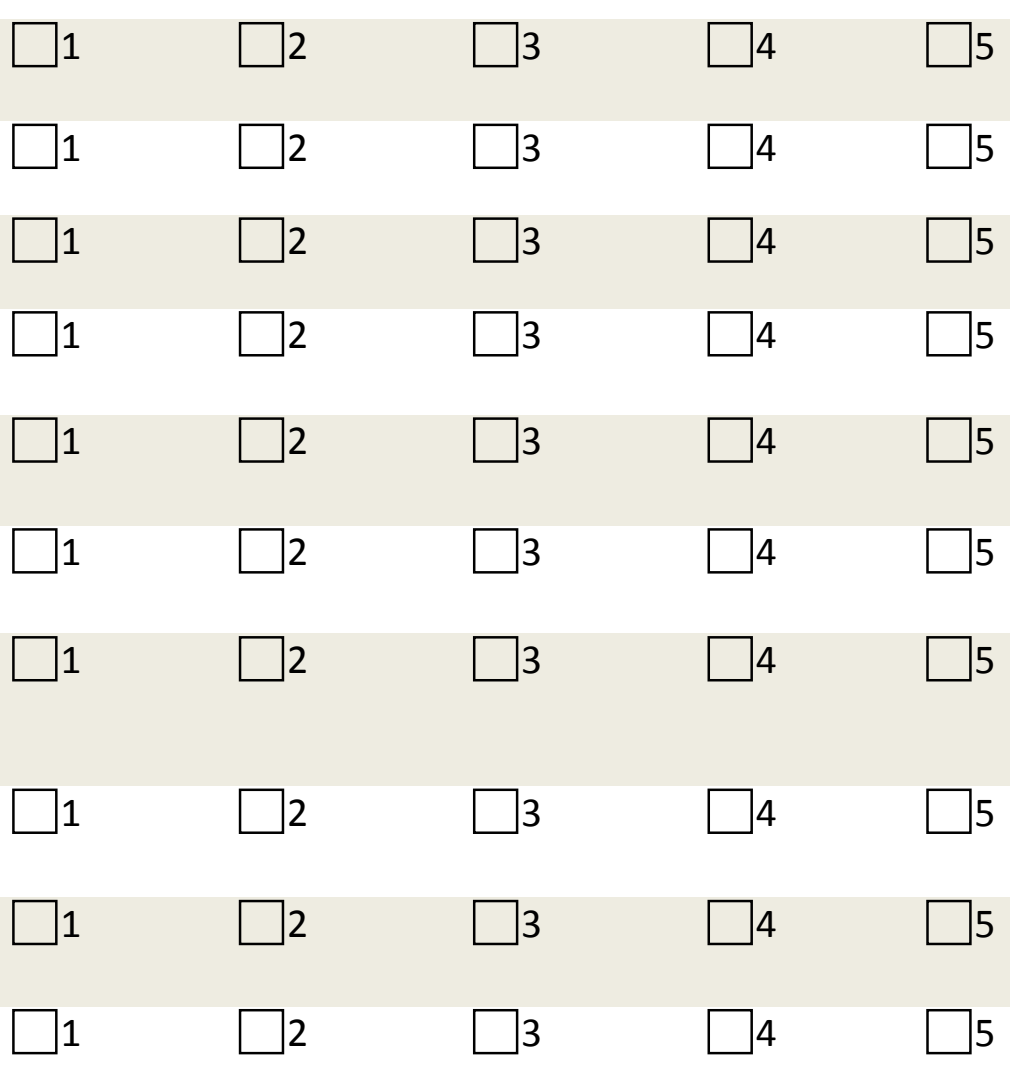


\section{ABOUT YOUR HEALTH...}

This section of the survey asks you for your views about your health. This information will help us understand how you feel and how well you are able to do your usual activities.

70. In general, would you say your health is:

\begin{tabular}{|ccccc|}
\hline Excellent & Very good & Good & Fair & Poor \\
$\square 1$ & $\square 2$ & $\square 3$ & $\square 4$ & $\square 5$
\end{tabular}

71. The following questions are about activities you might do during a typical day. Does your health now limit you in these activities? If so, how much?

a Moderate activities, such as moving a table, pushing

a vacuum cleaner, bowling, or playing golf

\begin{tabular}{|ccc|}
\hline Yes, & Yes, & No, not \\
limited & limited & limited \\
a lot & a little & at all
\end{tabular}

b Climbing several flights of stairs... 
72. During the past 4 weeks, how much of the time have you had any of the following problems with your work or other regular daily activities as a result of your physical health?

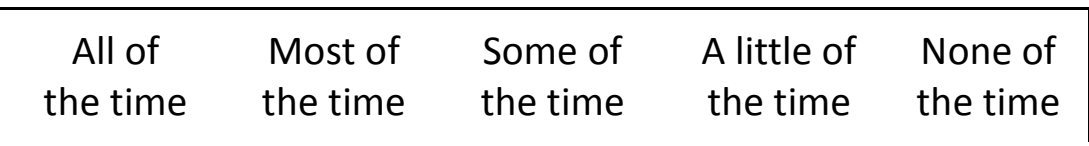

a Accomplished less than you would like.<smiles>C1CCC(C2CCC(C3CCC3)C2)C1</smiles><smiles>[Hg]C1CCC1</smiles><smiles>[Te]C1C2CSC12</smiles>

b Were limited in the kind of work or other activities.<smiles>C1=[W]CCC1</smiles><smiles>C1CCC1</smiles><smiles>C1CCC1</smiles><smiles>C1C[As]C1</smiles>

73. During the past 4 weeks, how much of the time have you had any of the following problems with your work or other regular daily activities as a result of any emotional problems (such as feeling depressed or anxious)?

\begin{tabular}{|cccc} 
All of & Most of \\
the time & Some of & A little of & None of \\
the time & the time
\end{tabular}

a Accomplished less than you would like.<smiles>C1CC2CCC12</smiles><smiles>C1CCC1</smiles>

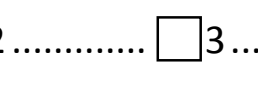

b Did work or other activities

less carefully than usual......

74. During the past 4 weeks, how much did pain interfere with your normal work (including both work outside the home and housework)?

\begin{tabular}{|ccccc|}
\hline Not at all & A little bit & Moderately & Quite a bit & Extremely \\
$\square 1$ & $\square 2$ & $\square 3$ & $\square 4$ & $\square 5$
\end{tabular}


75. These questions are about how you feel and how things have been with you during the past 4 weeks. For each question, please give the one answer that comes closest to the way you have been feeling. How much of the time during the past 4 weeks...

a Have you felt calm and peaceful?

\begin{tabular}{|ccccc|}
\hline $\begin{array}{c}\text { All of } \\
\text { the time }\end{array}$ & $\begin{array}{c}\text { Most of } \\
\text { the time }\end{array}$ & $\begin{array}{c}\text { Some of } \\
\text { the time }\end{array}$ & $\begin{array}{c}\text { A little of } \\
\text { the time }\end{array}$ & $\begin{array}{c}\text { None of } \\
\text { the time }\end{array}$
\end{tabular}
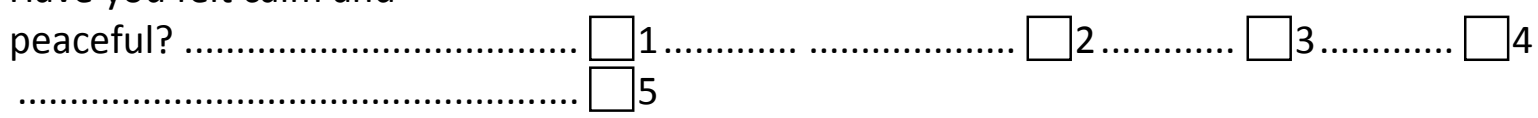

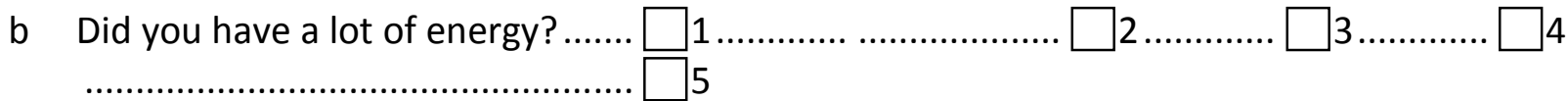

c Have you felt downhearted and depressed?.

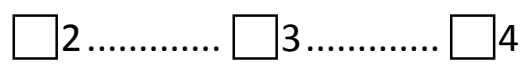

$\begin{array}{|ccccc|}\begin{array}{c}\text { All of } \\ \text { the time }\end{array} & \begin{array}{c}\text { Most of } \\ \text { the time }\end{array} & \begin{array}{c}\text { Some of } \\ \text { the time }\end{array} & \begin{array}{c}\text { A little of } \\ \text { the time }\end{array} & \begin{array}{c}\text { None of } \\ \text { the time }\end{array} \\ \square 1 & \square 2 & \square 3 & \square 4 & \square 5\end{array}$

76. During the past 4 weeks, how much of the time has your physical health or emotional problems interfered with your social activities (like visiting with friends, relatives, etc.)? 


\section{ABOUT SATISFACTION WITH YOUR MS TREATMENT...}

Please take some time to think about your level of satisfaction or dissatisfaction with the MS treatment you are currently taking. We are interested in your evaluation of the effectiveness, side effects, and convenience of the MS treatment over the past two to three weeks, or since you last used it. For each question, please place a single check mark next to the response that most closely corresponds to your own experiences.

77. How satisfied or dissatisfied are you with the ability of the MS treatment to prevent or treat the condition?

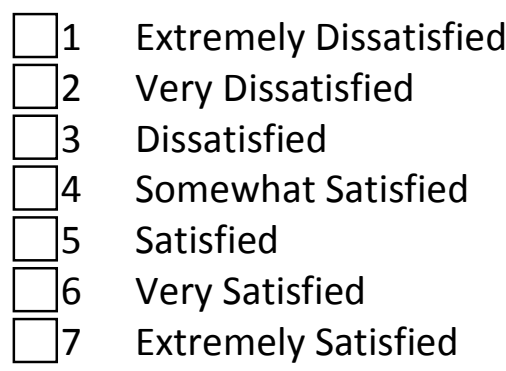

78. How satisfied or dissatisfied are you with the way the MS treatment relieves symptoms?

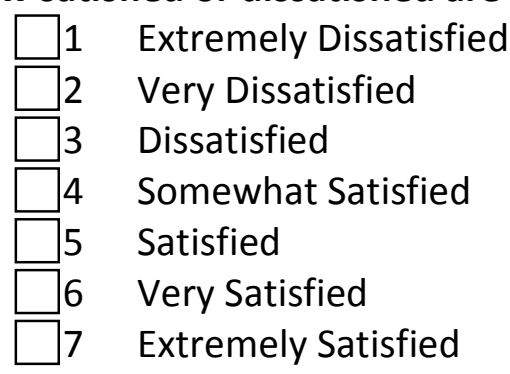

79. As a result of taking your MS treatment, do you experience any side effects at all?

\begin{tabular}{ll}
$\square$ & Yes \\
\hline$\square 0$ & No
\end{tabular}

80. How dissatisfied are you by side effects that interfere with your physical health and ability to function (e.g. strength, energy levels)?

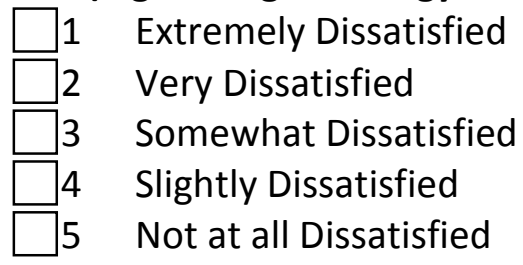


81. How dissatisfied are you by side effects that interfere with your mental function (e.g. ability to think clearly, stay awake)?

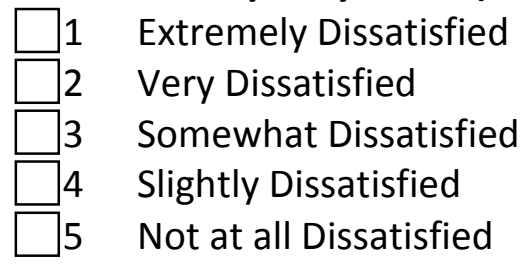

82. How dissatisfied are you by side effects that interfere with your mood or emotions (e.g. anxiety/fear, sadness, irritation/anger)?

$\square 1$ Extremely Dissatisfied

$\square 2$ Very Dissatisfied

3 Somewhat Dissatisfied

4 Slightly Dissatisfied

5 Not at all Dissatisfied

83. How satisfied or dissatisfied are you with how easy the MS treatment is to use?

\begin{tabular}{|ll}
$\square 1$ & Extremely Dissatisfied \\
\hline$\square 2$ & Very Dissatisfied \\
\hline$\square 3$ & Dissatisfied \\
\hline$\square 4$ & Somewhat Satisfied \\
\hline$\square 5$ & Satisfied \\
\hline$\square 6$ & Very Satisfied \\
\hline$\square 7$ & Extremely Satisfied
\end{tabular}

84. How satisfied or dissatisfied are you with how easy it is to plan when you will use the MS treatment each time?

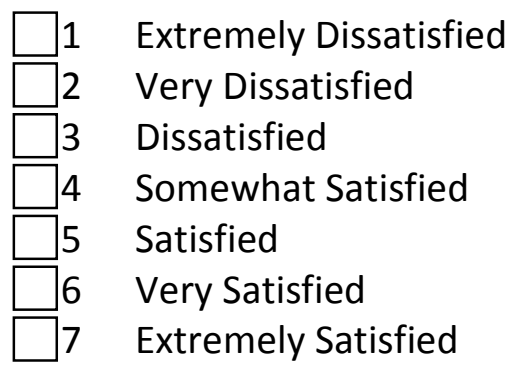

85. How satisfied or dissatisfied are you by how often you are expected to use/take the MS treatment?

\begin{tabular}{|ll}
$\square 1$ & Extremely Dissatisfied \\
\hline$\square 2$ & Very Dissatisfied \\
\hline$\square 3$ & Dissatisfied \\
\hline$\square 4$ & Somewhat Satisfied \\
\hline$\square 5$ & Satisfied
\end{tabular}




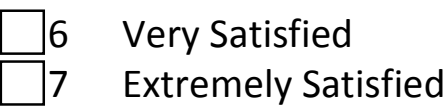

86. How satisfied are you that the good things about your MS treatment outweigh the bad things?

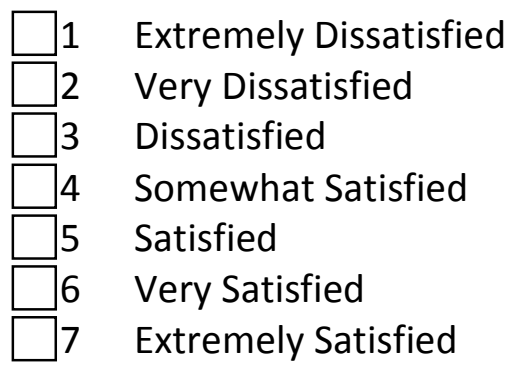

87. Taking all things into account, how satisfied or dissatisfied are you with your MS treatment?

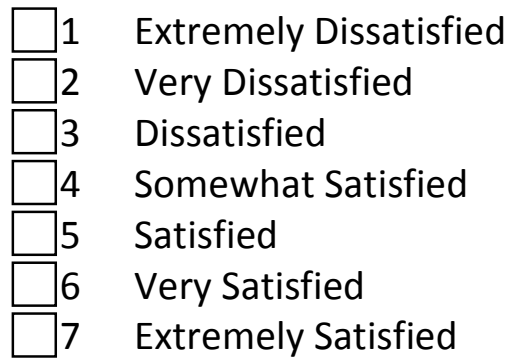

WORK PRODUCTIVITY AND ACTIVITY IMPAIRMENT (WPAI)

Time at Work: The following questions ask you about the effect of your MS on your ability to work and perform regular daily activities.

88. Are you currently employed (working for pay)?

$\square 0$ NO $\quad \square 1$ YES

[IF NO, CHECK “NO” AND SKIP TO QUESTION 88.]

The next questions are about the past seven days, not including today.

89. During the past seven days, how many hours did you miss from work because of PROBLEMS ASSOCIATED WITH YOUR MS? Include hours you missed on sick days, times you went in late, left early, etc., because of your health problems. Do not include time you missed to participate in this study.

HOURS

[PROVIDE A DROPDOWN BOX] 
90. During the past seven days, how many hours did you miss from work because of any other reason, such as vacation, holidays; time off to participate in this study?

HOURS

\section{[PROVIDE A DROPDOWN BOX]}

91. During the past seven days, how many hours did you actually work?

HOURS

[PROVIDE A DROPDOWN BOX]

[IF “0”, SKIP TO QUESTION 88]

When answering the next question, please think about days you were limited in the amount or kind of work you could do, days you accomplished less than you would like, or days you could not do your work as carefully as usual. Choose by checking a box.

If symptoms of MS affected your work only a little, choose a low number. Choose a high number if health problems affected your work a great deal.

92. During the past seven days, how much did your MS affect your productivity while you were working?

Consider only how much your MS affected productivity while you were working.

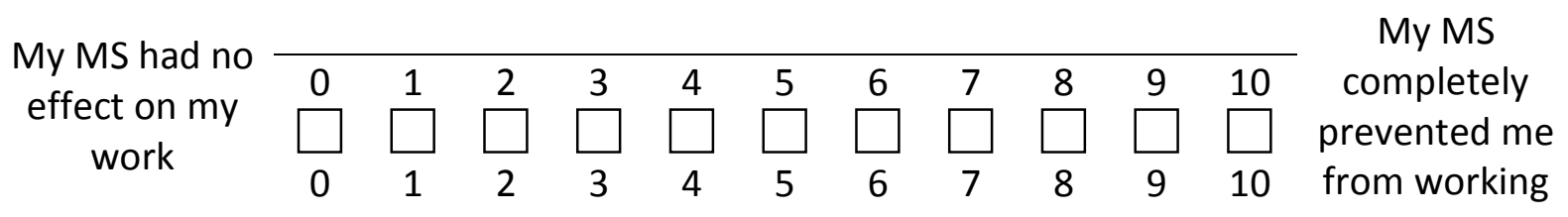

When answering the next question, by regular activities, we mean the usual activities you do, such as work around the house, shopping, childcare, exercising, studying, etc.

93. During the past seven days, how much did your MS affect your ability to do your regular daily activities, other than work at a job? 
Think about times you were limited in the amount or kind of activities you could do and times you accomplished less than you would like.

If MS affected your activities only a little, choose a low number. Choose a high number if health problems affected your activities a great deal.

Consider only how much $\underline{\text { MS }}$ affected your ability

to do your regular daily activities, other than work at a job.

\begin{tabular}{|c|c|c|c|c|c|c|c|c|c|c|c|c|c|}
\hline & & & & & & & & & & & & & \\
\hline My MS had no & 0 & 1 & 2 & 3 & 4 & 5 & 6 & 7 & & 8 & 9 & 10 & completely \\
\hline $\begin{array}{l}\text { effect on my } \\
\text { daily activities }\end{array}$ & 0 & 1 & 2 & 3 & 4 & 5 & 6 & 7 & & 8 & 9 & 10 & $\begin{array}{l}\text { from doing } \\
\text { my daily } \\
\text { activities }\end{array}$ \\
\hline
\end{tabular}

\section{A FEW QUESTIONS ABOUT YOURSELF...}

94. Your gender is...

$\square 1$ Male

$\square 2$ Female

95. You were born in...

Year ___ Month

96. Your marital status is...

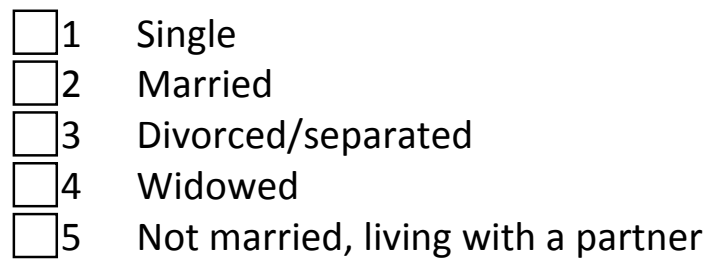

97. Your race is

\begin{aligned}$\square 1 &$ White/Caucasian \\ \hline$\square 2 &$ Black/ African American \\ \hline$\square 3 &$ Hispanic/ Latino \\ \hline$\square 4 &$ Asian \\ \hline$\square 5 &$ Others \end{aligned}

98. Your educational qualification? 


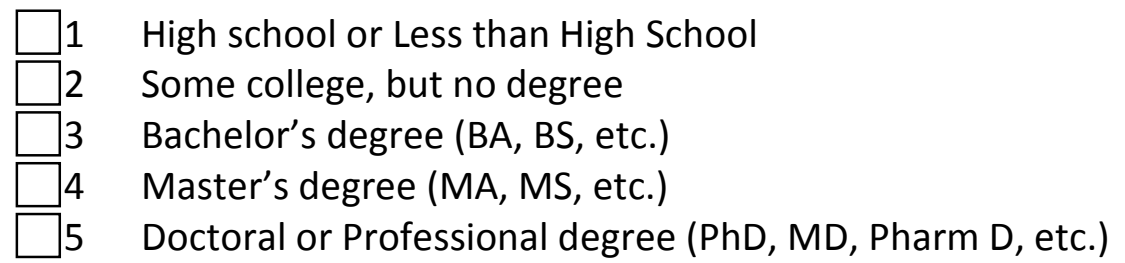

99. What is your current employment status?

\begin{tabular}{lll}
$\square 1$ & Employed full time \\
\hline$\square 2$ & Employed part time \\
\hline$\square 3$ & Homemaker \\
$\square 4$ & Student \\
$\square 5$ & Retired \\
$\square 6$ & Unable to work due to MS \\
\hline$\square 7$ & Unemployed
\end{tabular}

100. What is your annual household income?

\begin{tabular}{|ll}
\hline 1 & $<\$ 25,000$ \\
\hline$\square 2$ & $\$ 25,001-\$ 50,000$ \\
\hline$\square 3$ & $\$ 50,001-\$ 75,000$ \\
\hline$\square 4$ & $\$ 75,001-\$ 100,000$ \\
\hline$\square 5$ & $>\$ 100,000$
\end{tabular}

101. What type of health insurance do you have?

\begin{tabular}{|ll}
$\square 1$ & Private health insurance \\
\hline$\square 2$ & Medicaid \\
\hline$\square 3$ & Medicare \\
\hline$\square 4$ & Uninsured \\
$\square 5$ & Other (please specify)
\end{tabular}

102. Your Height is...

103. Your Weight is ...

104. Are you a current smoker?

$\square$ No $\quad \square 1$ Yes

105. Which State do you currently reside in? 


\section{Appendix I: Web-Based Survey - First Reminder}

\section{Dear (Name of the recipient),}

You are receiving this email because you have previously expressed interest to Biogen Idec in receiving emails regarding products, services, and programs that may be of interest to you. Biogen Idec has provided funding for our multiple sclerosis study that is part of a doctoral (Ph.D.) research project with The School of Medicine and the School of Pharmacy at West Virginia University, and the research includes an on-line survey designed to gain a better understanding of health-related quality of life, work productivity, treatment satisfaction, and treatment preferences among people living with multiple sclerosis. This study has been acknowledged by the Institutional Review Board of West Virginia University, and we are reaching out to you to invite you to participate in the study by completing the on-line survey linked to this email.

Participation in this survey is entirely voluntary and any information you choose to provide will be kept confidential. All results will be presented grouped together with others completing the survey so that no individual responses are shared. The survey does not require any information that will reveal your identity as a participant and you do not need to answer any questions with which you are not comfortable. Refusal to participate or withdrawal from the study will in no way affect your future care, however, your participation is extremely valuable because your responses and opinions are necessary to make the results of this study truly meaningful. Please help us by completing the survey. Please click on the link below to access the survey.

Take the Survey: https://wvusop.us2.qualtrics.com/SE/?SID=SV bdA6SMdCZIXQMa8\&id=22222

The completion of this survey will take approximately 15-20 minutes. As a token of our appreciation for your participation, a $\$ 25$ gift card can be mailed to you after fully completing the survey. Individuals completing the survey will be requested to provide their name and address at the end of the survey for the sole purpose of mailing the $\$ 25$ gift card. You may elect not to share your mailing address if you do not wish to share any personal information, but we will then be unable to send a gift card for your participation.

We THANK YOU in advance, for your time and your contributions to a greater understanding of the health matters of individuals with MS. If you have any questions regarding the survey or need more information, please email us at MSstudy@hsc.wvu.edu or call us at (404) 434-4575. 
Take the Survey:https://wvusop.us2.qualtrics.com/SE/?SID=SV bdA6SMdCZIXQMa8\&id=22222

Sincerely,

Abhijeet Bhanegaonkar MPH

Ph.D. Candidate

Department of Pharmaceutical Systems and Policy

WVU School of Pharmacy

Morgantown, WV - 26506
S. Suresh Madhavan, MBA, Ph.D.

Professor and Chair

Department of Pharmaceutical Systems and Policy

WVU School of Pharmacy

Morgantown, WV - 26506

Do not reply to this message. This is a notification-only mailbox that cannot accept incoming email.

You received this e-mail because you indicated that you wanted to receive information from Biogen Idec and Elan Pharmaceuticals, Inc., the sponsors of MS ActiveSource. Your name, address, and other personally identifiable information you provide will not be sold to any third party. If you do not wish to receive information from MS ActiveSource, please unsubscribe. 


\section{Appendix J: Web-Based Survey - Thank You Letter}

\section{Date}

Dear Participant,

We want to THANK YOU for your recent participation in our on-line Multiple Sclerosis (MS) study survey conducted by WVU School of Pharmacy with a dissertation grant from Biogen Idec. Knowledge gained from this survey would help in improving our understanding of healthrelated quality of life, work productivity, treatment satisfaction, and treatment preferences of individuals living with MS. The results of this survey may also help clinicians and other healthcare professionals provide better treatment and care for individuals with MS.

Please find enclosed herewith a Walmart gift card worth $\$ 25$ as a token of our appreciation for your participation in our survey. You can use this gift card on Walmart.com, SamsClub.com, or any Walmart store or Sam's Club location.

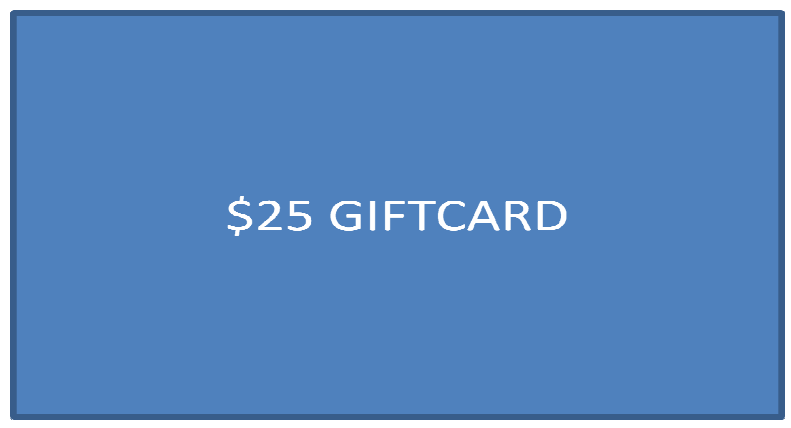

Thank you once again for your time and contribution toward a greater understanding of the health matters of individuals with MS.

Sincerely,

Abhijeet Bhanegaonkar MPH

Ph.D. Candidate

Department of Pharmaceutical Systems and Policy

WVU School of Pharmacy
S. Suresh Madhavan, MBA, Ph.D.

Professor and Chair

Department of Pharmaceutical Systems and Policy WVU School of Pharmacy 


\title{
CURRICULUM VITAE
}

\author{
Abhijeet Bhanegaonkar \\ Address: 112 Ellen Lane Apt\# 3, Morgantown, WV 26505 \\ E-mail: contact.abhijeet@gmail.com \\ Cell: (404) 434-4575
}

\section{EDUCATION}

Doctoral of Philosophy - Pharmaceutical \& Pharmacological Sciences Major Area - Health Economics \& Outcomes Research West Virginia University, Morgantown, WV

Expected Completion: April 2012

Masters in Public Health - Health Services Administration

East Tennessee State University, Johnson City, TN

Bachelor of Pharmacy

University of Pune, Pune, India

Diploma in Pharmacy

Maharashtra State Board of Technical Examination, Pune, India
Aug 05 - May 12

Aug $03-$ Jul 05

Jun 98 - May 01

Jun 96 - May 98

\section{PUBLICATIONS (PEER REVIEWED)}

Bhanegaonkar AJ, Madhavan SS, Khanna R, Remick S. Declining mammography screening in a Medicaid Fee-For-Service program: 1999-2008. Accepted in J Womens Health.

Jones DL, Bhanegaonkar AJ, Billings AA, Kriska AM, Irrgang JJ, Crossett LS, Kwoh CK. Differences between actual and expected leisure activities after total knee arthroplasty for osteoarthritis. Accepted in The Journal of Arthroplasty.

Khanna R, Madhavan SS, Bhanegaonkar AJ, Remick S. Prevalence, healthcare utilization and costs of breast cancer in a state Medicaid Fee-For-Service program. J Womens Health (Larchmt). 2011 May; 20(5):739-47. PMID: 21417935

Canafax D, Bhanegaonkar AJ, Bharmal M, Calloway M. Validation of the post-sleep questionnaire (PSQ) for assessment of sleep in subjects with restless legs syndrome (RLS). BMC Neurol. 2011 Apr 28; 11:48. PMID: 21527006

Khanna R, Bhanegaonkar AJ, Colsher P, Madhavan SS, Halverson J. Breast cancer screening, incidence, and mortality in West Virginia. West Virginia Medical Journal. 2009 Oct; 105 Spec No: 24-32. PMID: 19999262

Wu T, Bhanegaonkar AJ, Flowers JW. Blood concentrations of selected volatile organic compounds and neurobehavioral performance in a population based sample. Archives of Environmental and Occupational Health. 2006 Jan/Feb; 61(1):17-25. PMID: 17503617 


\section{ABSTRACTS}

Bhanegaonkar AJ, Madhavan S, Pawar G, Rajagopalan K, Langlois J. Understanding health related quality of life changes and issues related to disease modifying drugs among multiple sclerosis patients: A qualitative study. Value in Health. May 2011; 14(3):A211.

Bhanegaonkar AJ, Khanna R, Madhavan SS. Patterns of mammography screening among female recipients in a Fee-For-Service state Medicaid program. Poster presented at the American Public Health Association (APHA) 137th Annual Meeting and Exposition, November 711, 2009, Philadelphia, PA.

Khanna R, Madhavan SS, Smith MJ, Bhanegaonkar AJ. Pap smear testing in a Fee-For-Service state Medicaid program. Poster presented at the American Public Health Association (APHA) 137th Annual Meeting and Exposition, November 7-11, 2009, Philadelphia, PA.

Khanna R, Madhavan SS, Bhanegaonkar A. Changes in prevalence and healthcare use and costs of breast cancer among 21-to 64-year old female recipients in a Fee-for-Service state Medicaid program: 2000-2005. Pharmacoepidemiology and Drug Safety. Aug 2009;18:S51-52 Suppl. 1.

Bhanegaonkar AJ, Khanna R, Madhavan SS. Screening mammography trends among women in a Fee-For-Service state Medicaid population. Value in Health. May 2009; 12(3):A55-A56.

Khanna R, Madhavan SS, Bhanegaonkar AJ. Breast cancer prevalence and health care utilization and cost trends among fee-for-service female recipients in a state Medicaid program. Value in Health. May 2009;12(3):A56-A57

Canafax D, Bhanegaonkar A, Bharmal M, Calloway M. Validation of the post-sleep questionnaire (PSQ) for assessment of sleep in subjects with restless legs syndrome (RLS). Sleep. 2009; 32: A303-A304 Suppl. S. Meeting Abstract \#931.

Canafax D, Bhanegaonkar A, Bharmal M, Calloway M. Validation of the Post-Sleep Questionnaire (PSQ) for Assessment of Sleep in Subjects with Restless Legs Syndrome (RLS). Neurolog. Mar 2009;11,A340-A341. Suppl.3.

Bhanegaonkar A, Khanna R, Madhavan SS, Colsher P. Patterns of mammography screening among women in a fee-for-service state Medicaid program. Presented at the E. J. Van Liere Memorial Convocation and Research Day, West Virginia University, April 28-29, 2009, Morgantown, WV.

Bhanegaonkar AJ, Moffett ML. Trends in community based adverse drug events in the United States: 1996-2005. Value in Health. May-Jun 2008;11(3), A45-A45.

Jones DL, Bhanegaonkar AJ, Billings AA, Kriska AM, Irrgang JJ, Crossett LS, Kwoh CK. A comparison of physical activity expectations between two cohorts with knee osteoarthritis. Annals of the Rheumatic Diseases. Jul 2007;66: 279-279. Suppl.2.

Jones DL, Bhanegaonkar AJ, Kriska AM, Irrgang JJ, Crossett LS, Kwoh CK. Physical activity expectations within two cohorts with knee osteoarthritis. Medicine \& Science in Sports \& Exercise. 2007;39(5) (suppl):S230.

Abildso C, Bloomer CL, Blosnich JR, Bhanegaonkar AJ, Biddle EA, Gordon PM. Making the case for public health spending: The cost-effectiveness of community rail-trails in Morgantown, West 
Virginia. Presented at $4^{\text {th }}$ Annual Active Living Research Conference, Coronado, CA. February 22-24, 2007.

Coffindaffer J, Kavookjian J, Scott V, Bhanegaonkar AJ. Assessment of student conflict management style: Impact on patient counseling and communication course grades. Am J Pharm Educ. 2006 June 15; 70(3): 65: 59.

Bhanegaonkar AJ, Flowers JW, Hogan MB, Wu T. Exposure to volatile organic compounds and neurobehavioral effect. American Journal of Epidemiology. Jun 2005, 161(11),S46-S46. Suppl.S.

\section{PRESENTATION}

Bhanegaonkar AJ. Developing attributes and levels for discrete choice experiments using qualitative method: Determining preference for disease modifying drugs among patients with multiple sclerosis. Presented at the Public Health Economics Seminar - 2011 at Johns Hopkins University, May 13, 2011, Baltimore, MD. (Invited Presentation)

\section{INDUSTRY EXPERIENCE}

Biogen Idec Research Fellow

School of Pharmacy, West Virginia University, Morgantown, WV

July 09 - Present

- Prepared grant proposal to secure funding from Biogen Idec Inc. for my dissertation project which is aimed at studying preferences for risks and benefits associated with disease modified drugs among patients with multiple sclerosis (MS)

- Led patient recruitment activities, organized and conducted focus group interviews with MS patients to understand changes in the health related quality of life pre and post MS diagnosis and their experiences, satisfaction, and expectations from the disease modifying drug treatment.

- Designed an online stated preference survey questionnaire to determine patients' risk and benefit preferences related to disease modifying drugs

- Led patient recruitment activities, organized and conducted pre-testing of online survey

- Conducted national online survey using a representative sample of MS patients in the United States

- Analysis of focus group, pretesting of the survey, and patient preference survey (Roles: Co-Pl, grant writing, formulating research plan, budgetary management, preparing IRB application for the 3 phases of the study, survey design, developing online survey; data collection, data management, and data analysis for the 3 phases of the study; and dissemination of study findings in form of posters and manuscripts)

US Health Outcomes Intern, June 08 - Aug 08 GlaxoSmithKline, Research Triangle Park, NC.

- Provided management and liaison skills for validation of "Post Sleep Questionnaire" among restless leg syndrome patients and coordinated project tasks between GSK and Quintiles to ensure the timely completion of project

- Formulating, writing, and submission of manuscript for PSQ validation project detailing the findings in a peer reviewed journal 
- Developed questionnaire, study protocol, and IRB approval of a large survey study investigating why migraineurs do not treat early and the impact of chronobiology of migraines on work productivity

- Involved in matrix team meetings and aid in development, planning, and execution of health outcomes strategies for GSK's migraine franchise

Territory Officer

Mar 02 - July 02

Fulford India Ltd. Mumbai, India (An affiliate of Schering Plough, USA)

- Coordinated launch and promotion of intravenous antiplatelet agent (Integrilin) to interventional cardiologists in 6 counties in the state of Maharashtra, India

- Involved in managing sales activities, marketing plans, situation analysis, competitor evaluation, and sales planning. Established effective distribution network for Integrilin

Territory Officer July 01 - Aug 01

Pharmacia India Pvt. Ltd., Gurgaon, India

- Delivered sales presentations to physicians

Summer Intern

June 00 - July 00

NuLife Pharmaceuticals, Pune, India

- Received training in tablet, capsule, ointment, and ear drop formulation and quality control departments

\section{ACADEMIC EXPERIENCE}

Graduate Instructor

Jan 10 - May 10

School of Pharmacy, West Virginia University, Morgantown, WV

- Outcomes Assessment and Quality Improvement: ( $3^{\text {rd }}$ year Pharm.D. Course) Responsibilities included lecturing, creating and managing course materials

Graduate Research Assistant June 07 - June 09

West Virginia Collaborative Health Outcomes Research of Therapies and Services (WV CoHORTS) Center, School of Pharmacy, West Virginia University, Morgantown, WV

- Worked as a research assistant for Building Research Infrastructure and Capacity (BRIC) grant (1 P20 HS 01593-02) - funded by the Agency for Healthcare Research and Quality (AHRQ)

- Worked on various projects related to breast cancer and cervical cancer disparities in WV and Appalachian region

(Roles: Co-PI on breast cancer screening disparities project, grant writing, research design, data management, data analysis, managed large healthcare datasets, e.g. Medicaid, HCUP, NHANES, BRFSS, etc., and dissemination of study findings in form of posters and manuscripts)

Research Assistant to the Director of Clinical Research June 06 - Dec 06 \& May 07 - Aug 07 Department of Orthopedics, School of Medicine West Virginia University, Morgantown, WV

- Worked on a project evaluating physical activity expectations in osteoarthritis patients (Roles: Study design, data management, data analysis, dissemination of results in the form of poster and manuscript) 
- Assisted in grading, managed online/ in-class course materials, proctored exams, and facilitated student projects in professional and graduate pharmacy courses

- Facilitated skill exercises, evaluating students verbal and nonverbal patient communication skills in lab sessions

Graduate Assistant Jan 04 - May 04 \& Aug 04 - May 05 Office of International Programs, East Tennessee State University, Johnson City, TN

- Provided advice on visa related matters and maintained records of international students

- Organized informative sessions and social events for international students

Research Technician June 04 - Aug 04

Department of Family Medicine, Quillen College of Medicine, East Tennessee State University, Johnson City, TN

- Performing scientific literature review for faculty using Pubmed, CINHAL, and Ovid database

Teaching Assistant Aug 03 - Dec 03 Department of Geology and Geography, East Tennessee State University, Johnson City, TN

- Assisted in grading for undergraduate courses, managed of course materials, and conducted class exercises, and proctored exams

\section{COMPUTER PROFICIENCY}

Statistical Software

Decision Analysis Software

Database Packages

Datasets

\author{
SAS, SPSS \\ TreeAge Pro \\ FoxPro, MS Access, MS Excel \\ Medicaid, BRFSS, HCUP, NHANES
}

\section{GRANTSMANSHIP}

1. Title of the research proposal: Patient Preferences for Benefits and Risks Associated with Disease Modifying Drug Treatments in Multiple Sclerosis

Agency: Biogen Idec Inc.

Principal Investigators: Bhanegaonkar AJ (100\%), Madhavan SS (5\%)

Amount Recieved: $\$ 118,657$

Starting/Ending Dates: July 2009 to December 2011

Funding Status: Funded (Dissertation Grant)

2. Title of the research proposal: Mammography Screening Rates, Persistence, and Costs in the State Medicaid Program

Agency: Susan G. Komen for the Cure: West Virginia Affiliate

Principle Investigator: Madhavan SS

Co-Primary Investigator: Bhanegaonkar AJ

Amount Received: $\$ 32,000$

Starting/Ending Dates: August 2008 to July 2009

Funding Status: Funded 
MANUSCRIPT REVIEWER

- Journal of the American Pharmacists Association (JAPhA)

- Journal of Rural Health (JRH)

- Archives of Environmental and Occupational Health (AEOH)

\section{AWARDS}

- 2011, 2009, 2008 - Graduate Student Travel Award - The Office of Research and Graduate Education, WVU

- 2010 - Recipient of the WVU School of Pharmacy Graduate Student Research Award

- 2009 - Recipient of Doctoral Dissertation Grant $(\mathbf{\$ 1 1 8 , 6 5 7 )}$ awarded by Biogen Idec Inc.

- 2008 - Distinguished Service Award, $13^{\text {th }}$ ISPOR International Meeting

- 2008 - Runners up in the $13^{\text {th }}$ ISPOR Research Competition (Led the WVU team)

- 2003 - Recipient of Tuition Scholarship, College of Public Health, ETSU

\section{AFFILIATIONS}

- 2009 - Toastmasters International

- 2008 - Member of Meeting Planning Committee for $13^{\text {th }}$ Annual ISPOR International Conference

- 2007 - 2008: President of WVU ISPOR Student Chapter

- 2006 - Present: Member of Rho Chi Pharmacy Honor Society

- 2006 - 2007: Vice President of WVU ISPOR Student Chapter

- 2005 - Present: Member of ISPOR

- 2003 - 2005: Treasurer of International Student Organization at ETSU

\section{RELEVANT COURSES}

$\begin{array}{ll}\text { Economics } & \text { Pharmacoeconomics, Microeconomics, Introductory Econometrics, } \\ \text { Epidemiology } & \begin{array}{l}\text { Health Economics, Health Care Finance } \\ \text { Management }\end{array} \\ & \begin{array}{l}\text { Strategic Planning in Healthcare, Human Resource Management in } \\ \text { Healthcare Organization, Health Services Administration }\end{array} \\ \text { Research } & \text { Patient Reported Outcomes, Research Design and Data Analysis, Survey } \\ \text { Methods } & \text { Research Methods, Claims Database Analysis, Social \& Behavioral } \\ \text { Statistics } & \text { Foundations of Public Health, Decision Analysis in Healthcare } \\ & \text { Biostatistics, Applied Biostatistics, Multivariate Methods, Statistical } \\ & \text { Analysis Systems (SAS) }\end{array}$

\section{PROFESSIONAL DEVELOPMENT}

- Graduate Certificate in Health Care Management, College of Public and Allied Health, East Tennessee State University, Johnson City, TN. January 2004 - May 2005

REFERENCES: Available upon request 